\title{
MORAL JUSTIFICATIONS FOR NEGATIVE SCREEN TOURIST BEHAVIOUR
}

\author{
By \\ Taran Irene Helle Jørgensen
}

A thesis submitted to the Victoria University of Wellington in partial fulfilment of the requirements for the degree of Master of Tourism Management

Victoria University of Wellington 


\section{Abstract}

Screen tourism has become increasingly more popular over the last two decades, and while it has positive benefits for stakeholders and destinations, screen tourists engaging in negative tourist behaviour has become a problem at popular screen tourism destinations. However, little is known about how screen tourists justify engaging in this negative behaviour. Bandura's Moral Disengagement theory has been used in various non-tourism and tourism contexts to examine and explain how individuals justify negative behaviours. This thesis applies Moral Disengagement theory to negative tourist behaviour in a screen tourism context, aiming to examine screen tourists' use of moral disengagement mechanisms to justify negative on-site tourist behaviour. It further draws on previous research and literature on fandom and level of leisure involvement to provide a better understanding of how these factors might influence screen tourists' moral justification of negative behaviour. Data was collected using a self-administered online survey, distributed to individuals who self-identified as members of either the Breaking Bad or Game of Thrones fandoms, and received 243 eligible responses. The survey measured level of fandom involvement, participants' use of moral disengagement mechanisms in three hypothetical scenarios presenting negative screen tourism related behaviours, and responses to Bandura's Moral Disengagement scale.

Findings from this research suggest that some screen tourists morally justify engaging in negative behaviour in some contexts. This aligns with findings from previous research on moral disengagement and tourism. Furthermore, this research finds that mechanisms that are centred on disregarding/distorting the perceived harm on the victim were most frequently used. Lastly, groups were found to differ in their use of moral justification mechanisms, indicating that fandom identification, the moral alignment of the fandom object, and level of involvement influence individuals' use of moral justification. It is also argued that (screen) tourism and fandom communities both have characteristics that facilitate moral disengagement. This knowledge can support screen tourism stakeholders in screen tourism development, and in mitigation of negative behaviours. 


\section{ACKNOWLEDGMENTS}

I would first like to extend my deepest gratitude to my supervisor Dr. Ina Reichenberger. This has been a rollercoaster of a journey, and I am forever grateful for your guidance, support, and help throughout it. You have been a great mentor and role model, and I have learned so much from you. Thank you for believing in me when I doubted I could do this, for being there with tissues, biscuits and advice when needed, and for keeping me on track and going in the right direction. Thank you for all the opportunities you have given me, and for being the best supervisor.

Next, and most importantly, I have thank my grandparents and parents. This whole journey would not have been possible without you. Dear Farmor og Farfar, thank you for giving me the opportunity to make this dream become reality, for your love, support and encouragement. Dear mom and dad, thank you for being ok with me moving halfway across the world, and for making this dream come true. Thank you for taking care of my cat, sending care packages, phone calls, listening to endless research talk, proof reading, various help, and just being the best parents anyone could ask for. I could not have done this without your endless support and love. Thank you for believing in me.

I would also like to thank AProf Christian Schott, AProf Mondher Sahli, AProf Ian Yeoman, and Prof Karen Smith for being part of my Victoria University journey, their support, encouragement, and for sharing their passion for tourism management and knowledge throughout my undergrad and postgrad journey. Megan and Rebecca, thank you so much for all administrative help and support. I would also like to thank all my lecturers, tutors and admin staff that have been part of my time at VUW.

Dr. Lisa Woods, you deserve a medal. Thank you so much for your help and statistical support. I will forever be grateful for your patience and advice.

Ashley, thank you so much for your support, advice and encouragement.

Geno and Grace. This has been a journey, but we made it to the end, and I am so proud of us! Thank you for the laughs, tears, hugs, snacks, advice, and support.

Shu and Ryan. Thank you for being such an important part of my New Zealand adventure. Diana, thank you for being a friend, for sharing your knowledge and experiences, and all the tips and tricks on how to make the most out of my studies.

Dearest Stine. Thank you for always being there with support and encouragement.

I would also like to thank the rest of my family and friends in Norway and the US. Thank you for your support and encouragement, and for not forgetting about me.

And lastly, I have to thank everyone who participated in my research. This would not have been possible without you. 


\section{Table of Contents}

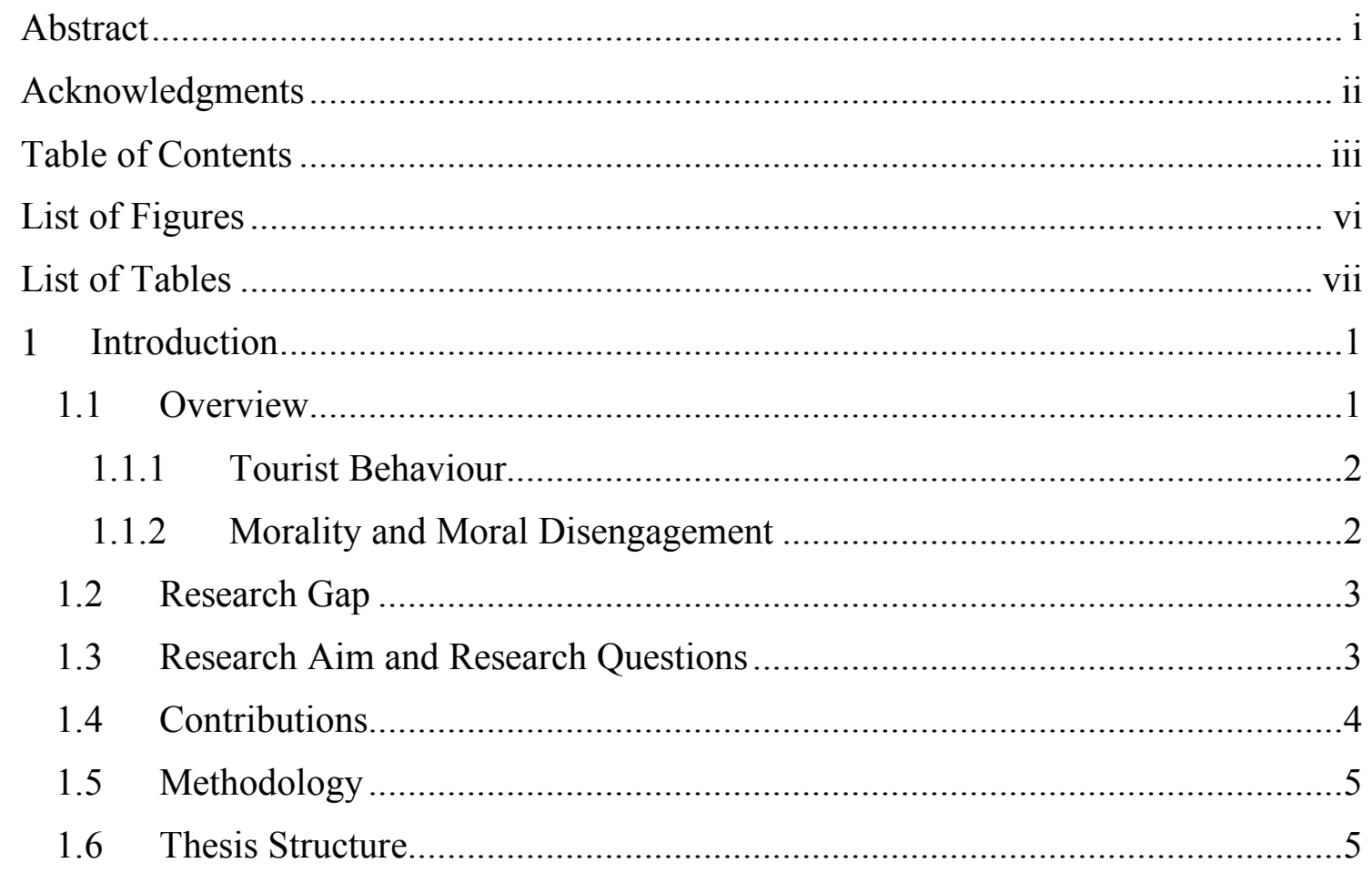

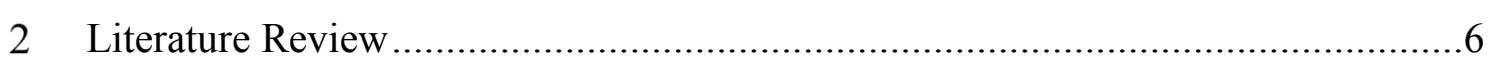

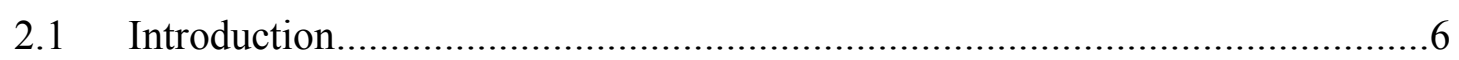

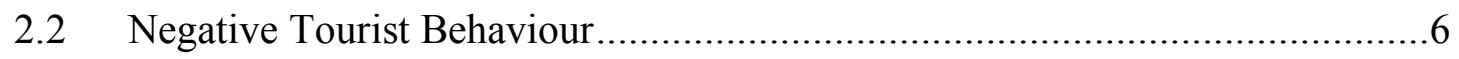

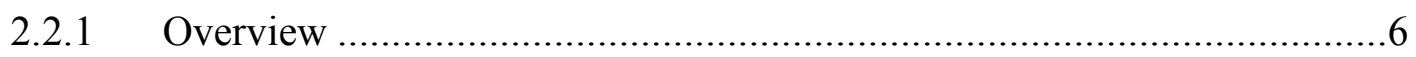

2.2.2 Why Tourists Engage in Negative Behaviour .......................................

2.2.3 Conclusion and Summary ............................................................

2.3 Morality and Moral Disengagement Theory ............................................... 10

2.3.1 Morality, Moral Agency and Morality in Tourism ................................ 10

2.3.2 Moral Disengagement Theory ........................................................... 12

2.3.3 Beyond Moral Disengagement Theory ................................................ 17

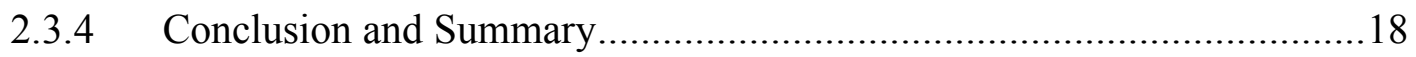

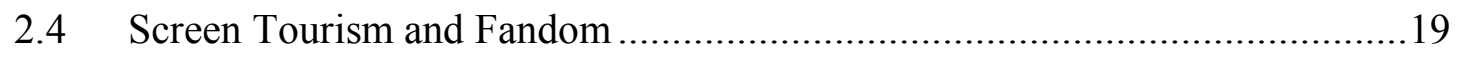

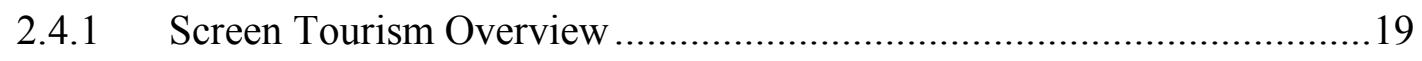

2.4.2 Fandom and Fans as Tourists........................................................20

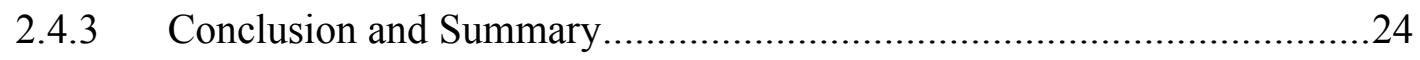

2.5 Summary and Conceptual Framework …..................................................25

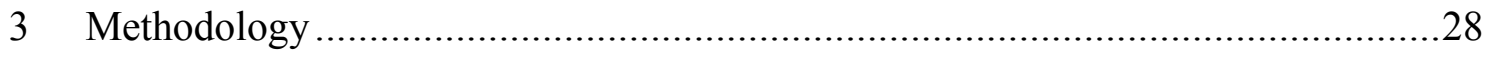

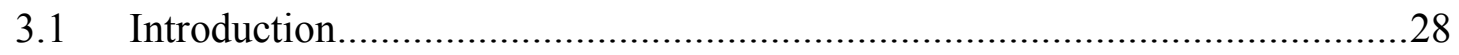




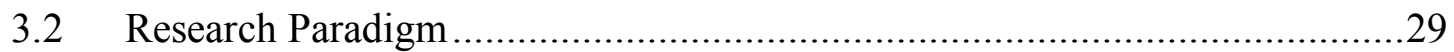

3.3 Quantitative Research Methods ................................................................. 31

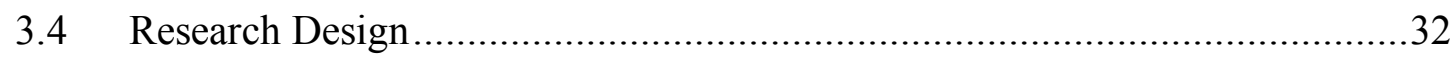

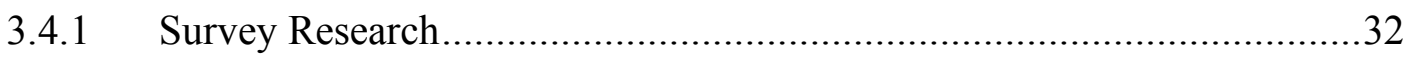

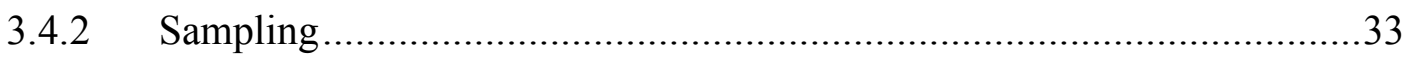

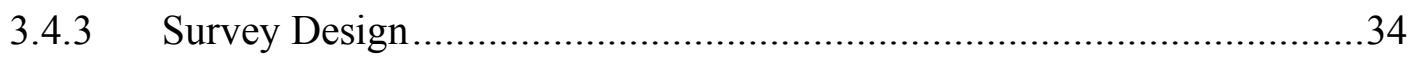

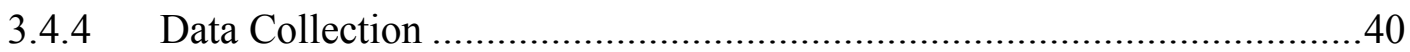

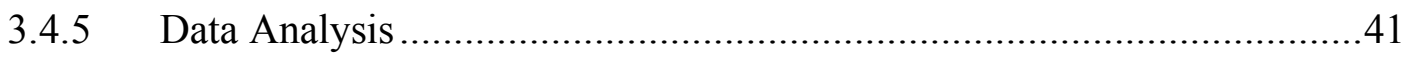

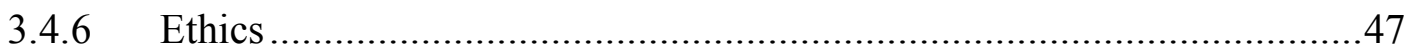

3.5 Methodological Strengths and Limitations................................................48

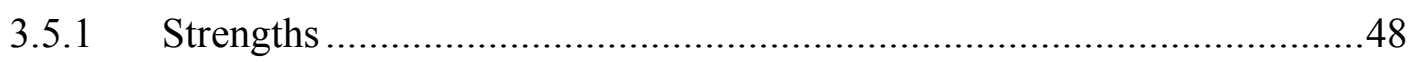

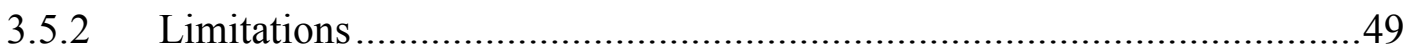

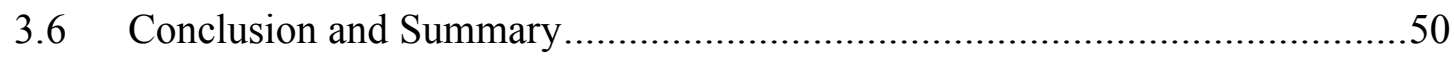

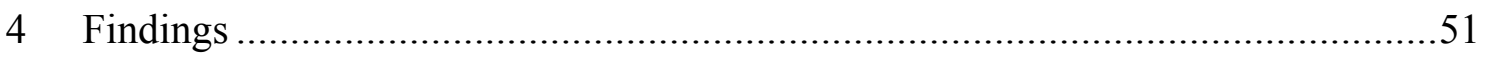

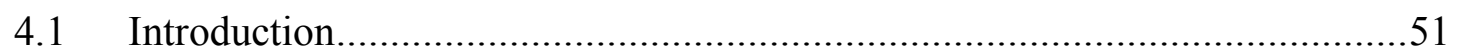

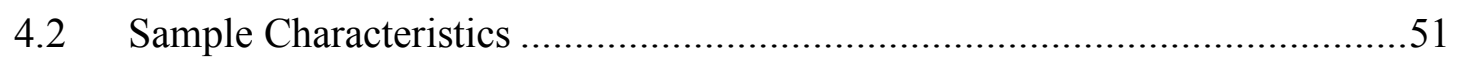

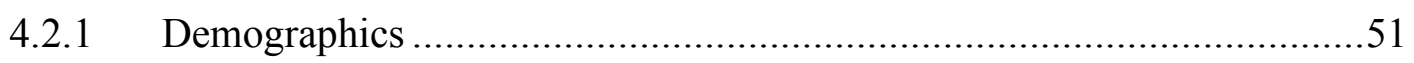

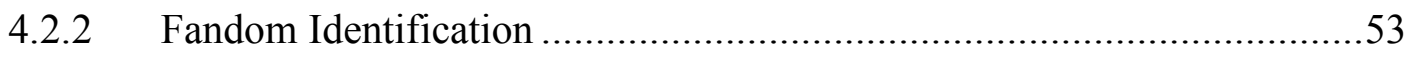

4.3 RQ1 "Do screen tourists use moral disengagement mechanisms to justify their

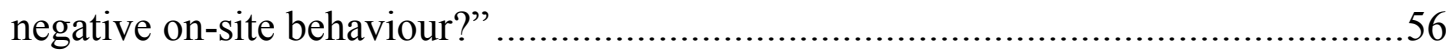

4.4 RQ 2 "Which moral disengagement mechanisms are most frequently used by screen tourists to justify their negative behaviour?" ...................................................58

4.4.1 Moral Disengagement in Scenarios .....................................................58

4.4.2 Moral Disengagement Scale ..........................................................62

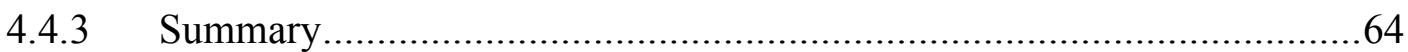

4.5 RQ3 "Do different groups of screen tourists differ in their use of moral

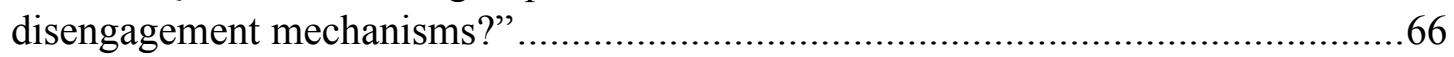

4.5.1 Moral Disengagement Mechanisms x Level of Fandom Involvement .....66

4.5.2 Moral Disengagement Mechanisms x Fandom Identification.................67

4.5.3 Moral Disengagement, Fandom Identification and Level of Involvement 68

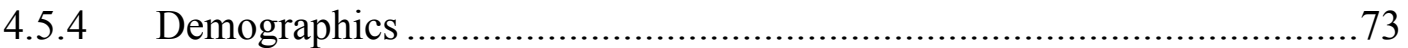

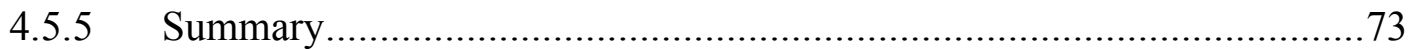

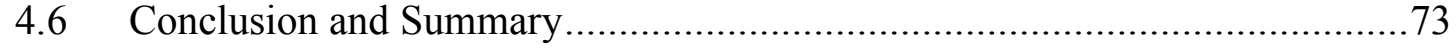

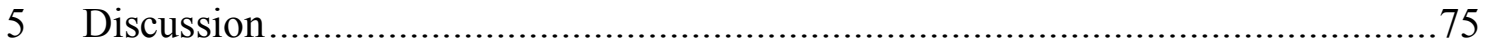

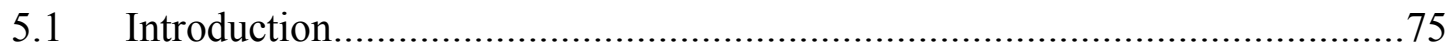


5.2 Screen Tourism and Moral Disengagement …............................................ 75

5.3 Use of Moral Disengagement Mechanisms .................................................... 77

5.3.1 Application of Moral Disengagement Mechanisms................................77

5.3.2 Impact of the Screen Tourism Context on Moral Disengagement.............79

5.3.3 Summary and Answer to Research Question 2 ...................................81

5.4 Fandoms, Involvement and Moral Disengagement …................................82

5.4.1 Fandom and Fandom Involvement.....................................................82

5.4.2 The Impact of Fandom Identification.................................................8 84

5.4.3 Summary and Answer to Research Question 3 ....................................86

5.5 General Discussion, Conclusion and Summary...........................................87

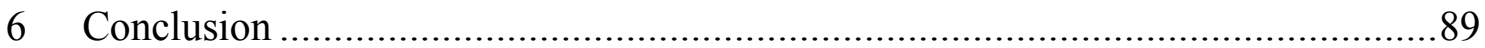

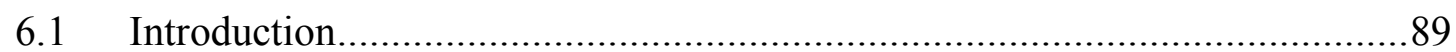

6.2 Concluding the Research Questions and Research Aim ..............................89

6.2.1 Concluding Research Question 1 ......................................................90

6.2.2 Concluding Research Question 2 ....................................................90

6.2.3 Concluding Research Question 3 ................................................. 91

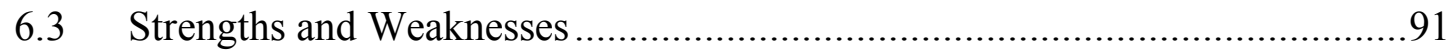

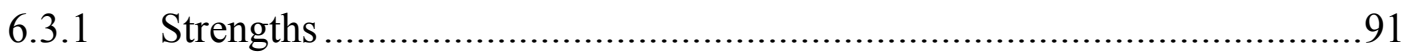

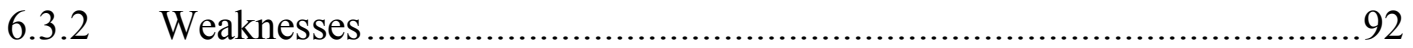

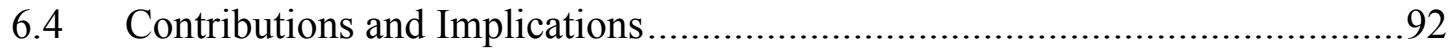

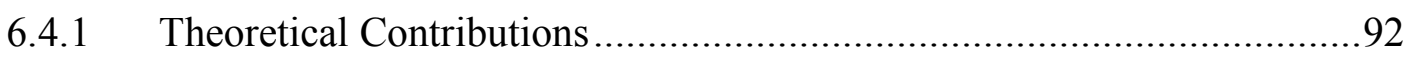

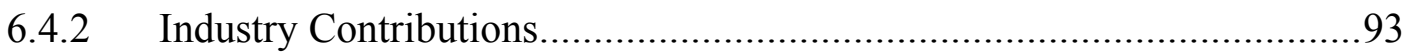

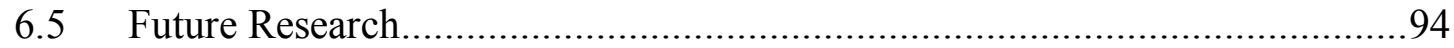

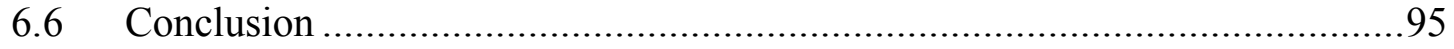

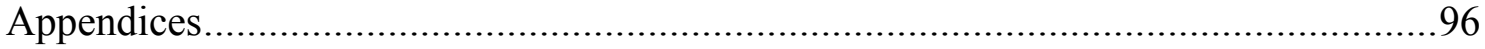

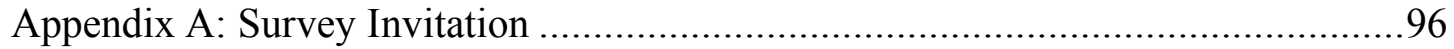

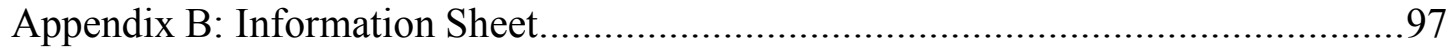

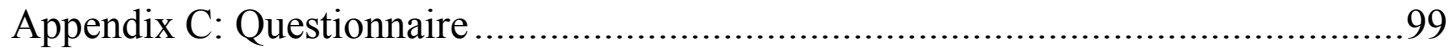

Appendix D: Debrief Sheet and Invitation To Prize Draw ...................................... 113

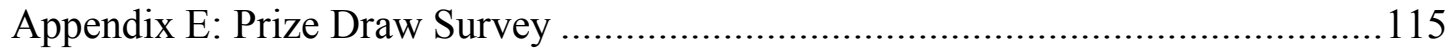

Appendix F: Scenario Statements and Corresponding Mechanisms .......................116

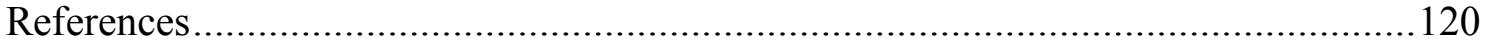




\section{LIST OF FigURES}

Figure 2.3.1 Process of disengaging moral self-censure from reprehensible conduct

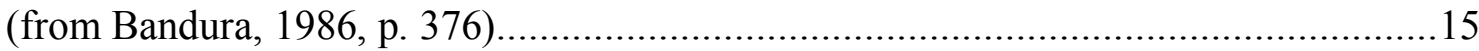

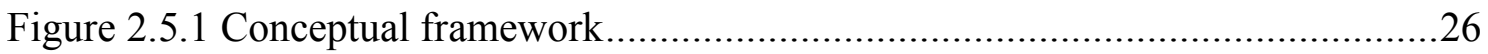

Figure 3.4.2 Example of scenario presented to Breaking Bad fans ............................39

Figure 3.4.6 Standardised estimates for Level of Involvement scale .........................43

Figure 3.4.9 Standardised estimates Moral Disengagement scale .............................46

Figure 4.5.1 Selection of moral disengagement mechanisms in scenarios, per fandom.68 


\section{LIST OF TABLES}

Table 2.3.1 Moral Disengagement Mechanisms ................................................... 14

Table 3.4.1 Items of Fandom Involvement (adapted from Lee, 2007) .........................36

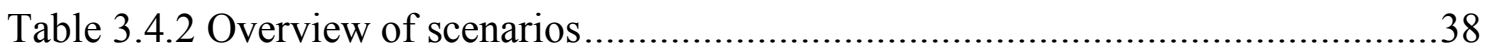

Table 3.4.3 Distribution Channels.......................................................................... 41

Table 3.4.4 Squared Multiple Correlations Level of Involvement scale......................43

Table 3.4.5 Squared Multiple Correlations Moral Disengagement Scale ....................45

Table 4.2.1 Demographic Characteristics of Participants ........................................52

Table 4.2.2 Level of Involvement by Fandom Identification cross-tabulation...............54

Table 4.3.1 Overview comparable behaviours in scenarios .......................................56

Table 4.3.2 Selection of moral disengagement mechanisms in scenarios.....................57

Table 4.4.1 Selection of moral disengagement mechanisms in scenarios, total ............59

Table 4.4.2 Selection of moral disengagement mechanisms - Trespassing ..................60

Table 4.4.3 Selection of moral disengagement mechanisms - "Souveniring" ...............61

Table 4.4.4 Selection of moral disengagement mechanisms - Recreation...................61

Table 4.4.6 Moral Disengagement scale mean scores, categories ..............................63

Table 4.4.7 Point-Biserial correlation results .............................................................64

Table 4.5.1 Moral disengagement mechanisms x fandom identification x level of

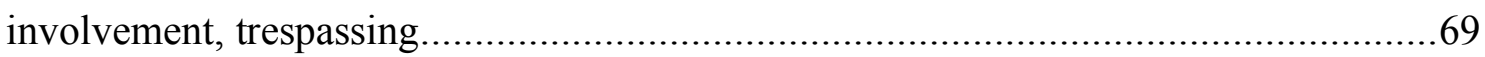

Table 4.5.2 Moral disengagement mechanisms $\mathrm{x}$ fandom identification $\mathrm{x}$ level of

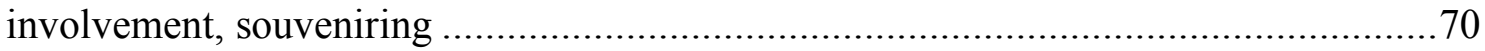

Table 4.5.3 Moral disengagement mechanisms x fandom identification $\mathrm{x}$ level of involvement, scene recreation.

Table 5.3.1 Cognitive facilitation of moral disengagement mechanisms (based on Bandura, 1999; Barriga \& Gibbs, 1996; Sykes \& Matza, 1957) 


\section{INTRODUCTION}

\subsection{OVERVIEW}

Screen tourism is a special interest tourism market, and its popularity and importance have increased over the last two decades (Connell, 2012; Du, Li, Pan, \& Zhang, 2020). Du et al. (2019) define screen tourism as “... the activities of tourists who go to places related to a film or TV series" (p.3), and include activities such as visiting film festivals, attending premieres, and visiting film/TV-series related locations (Du et al., 2019). The increased popularity of screen tourism has positive impacts on destinations, contributing to increased visitor numbers, visitor dispersal, economic benefits, and positive destination image (Connell, 2012; Li, Li, Song, Lundberg, \& Shen, 2017). However, some screen tourists exhibit negative on-site behaviour, such as overcrowding, theft, trespassing private property, and disrespectful behaviour, resulting in negative impacts on stakeholders (BBC, 2020; Brady, 2019; Miller, 2020; Patel, 2020; Taylor, 2018). One of the main activities of screen tourists is visiting filming locations (Du et al., 2019), and there are multiple examples of where this has had negative impacts. In London, the council asked tourists to stop visiting a house famous from the movie Love, Actually (Patel, 2020). Tourists would disregard the privacy of residents to get the perfect picture, or even enter the home if unlocked (Patel, 2020). Similar behaviour has been observed in other locations as well (Brady, 2019; Taylor, 2018), such as taking items as souvenirs (BBC, 2020), and tossing pizzas on the roof of a house famous from the TV-series Breaking Bad (Brady, 2019). Thus, it is clear that some screen tourists engage in negative tourist behaviour on-site when visiting screen related destinations. The question is how some screen tourists engage in negative on-site tourist behaviour, and in turn, what stakeholders can do about it to reduce the negative behaviour and mitigate negative impacts. This thesis will explore this under the umbrella of morality and moral disengagement.

The next sections will give an overview of tourist behaviour, morality and moral disengagement, then present the research gap, research aim, research questions, and contributions. This will be followed by an overview of the research methodology and overall thesis structure. 


\subsubsection{Tourist Behaviour}

While most tourists behave well, some tourists behave both illegally and immorally (Pearce, 2019). Negative on-site tourist behaviour can be both intrusive and destructive, having negative impacts on stakeholders (Pearce, 2019). Pearce (2019) suggest that intentionality is important to consider when examining negative tourist behaviour; i.e. did the tourist mean to do what they did, were they aware of the consequences of their behaviour, "[...] were the effects simply unintended outcomes of the earnest pursuit of their personal fulfilment? Or perhaps more worryingly, was the behaviour the deliberate exploitation of people and contexts for selfish ends?" (Pearce, 2019, p. 283). Pearce (2019) further suggests that the "tourists' personal moral compass" (p. 283) influences their behaviour, stating this "comes into play when they move across space and cultures" (Pearce, 2019, p. 283). Thus, morality is one approach that can be used to understand why some tourists engage in negative behaviour.

\subsubsection{Morality and Moral Disengagement}

While morality is not a new area of interest in tourism research, it has received more attention in recent years. Caton (2012) proposes the need for a moral turn in tourism, suggesting that tourism has a role in moral development (Caton, 2015). Morality can be defined as "a socially constructed set of values that are agreed upon by individuals and societies" (Sharma, 2020, p. 274, based on Pennycook, 1994). Furthermore, what is seen as moral (or not) can differ across cultures and nationalities (Sharma, 2020, p. 274). Caton (2015) further states that tourism "is perhaps the world's only practice though which people with such varied cultural backgrounds viscerally collide in such magnitude, and under the liminal spell of play and self-exploration that is largely particular to leisure contexts" (p. 5). In the context of tourist behaviour, Sharma (2020) states that the process of moral disengagement offers an explanation "[...] when it comes to understanding how individuals engage in cognitive strategies to change meanings in a particular situation or use psychosocial manoeuvres to disengage from immoral behaviour" (p. 277). Moral disengagement is a cognitive process enabling an individual to engage in an unethical behaviour they would otherwise not engage in, through activation of one or more moral disengagement mechanisms (Bandura, 1999). The eight moral disengagement mechanisms are: Moral Justification, Advantageous Comparison, Diffusion of Responsibility, Displacement of Responsibility, Euphemistic Labelling, Dehumanization of Victim, Attribution of Blame, and Distortion of Consequences (Bandura, 1999). When 
cognitive self-regulatory processes are deactivated, the individual uses one or more of the mechanisms proposed by Bandura (1999) to justify their behaviour. This reduces the individual's feeling of guilt or self-censure, and in turn results in immoral behaviour (He $\&$ Harris, 2014). In a tourism context, moral disengagement has been used to examine negative tourist behaviour in dark tourism (Sharma, 2020), environmentally sustainable behaviour (Wu, Font, \& Liu, 2020), and in a hospitality context (He \& Harris, 2014). Sharma (2020) suggests that moral disengagement mechanisms can explain why some dark tourists engage in morally transgressive behaviour in liminal spaces, while $\mathrm{Wu}$ et al. (2020) found that moral disengagement has a negative impact on tourists' proenvironmentally sustainable behaviour.

\subsection{RESEARCH GAP}

There has been little research conducted on screen tourists' negative tourist behaviour, despite screen tourism becoming increasingly popular with both destinations and tourists (Beeton, 2016). While it is clear that some screen tourists exhibit negative and transgressive on-site behaviour (BBC, 2020; Patel, 2020; Taylor, 2018), little to no research has been conducted to understand how screen tourists justify their negative or transgressive on-site behaviour. There is a lack of research addressing the negative behavioural components of screen tourism, and furthermore limited insights into the moral perspective in understanding tourism behaviour. Moral disengagement theory has been successfully applied to examine justification of transgressive tourist behaviour in other tourism contexts, such as in dark tourism (Sharma, 2020), pro-environmental behaviour (Wu et al., 2020) and in an accommodation context (He \& Harris, 2014). This thesis sets out to examine if and how moral disengagement mechanisms are used to justify negative behaviour in a screen tourism context.

\subsection{ReSEARCH AIM AND RESEARCH QUESTIONS}

The research gap identified that there is little knowledge around how screen tourists justify their negative behaviour. Previous research has successfully applied Moral Disengagement theory (Bandura, 2016) to negative behaviour, which will be the main theoretical approach in this thesis. The aim of this research project is to examine whether tourists use moral disengagement mechanisms to justify their negative on-site tourist behaviour, in the context of screen tourism. 
Based on the research gap, the first research question is:

"Do screen tourists use moral disengagement mechanisms to justify their negative onsite behaviour?" From this and what has been identified in the literature, two other research questions arise:

"Which moral disengagement mechanisms are most frequently used by screen tourists to justify their negative behaviour?" and

"Do different groups of screen tourists differ in their use of moral disengagement mechanisms?"

\subsection{Contributions}

In addition to gain knowledge about if and how screen tourists justify their negative onsite tourist behaviour, this research will also improve understanding of the factors that influence screen tourists' justification of negative on-site tourist behaviour. This has both academic and practical contributions. This thesis will contribute to fill a research gap on negative screen tourist behaviour, and provide insight into tourists' justification of engaging in negative on-site behaviour. Furthermore, it increases knowledge about screen tourism, negative screen tourist behaviour, and moral disengagement in a screen tourism context, contributing to start filling the research gap identified in Section 1.2, on the limited understanding of the moral components in tourist behaviour. The inclusion of fandom and level of involvement contributes to a better understanding of how these factors factor into moral disengagement and negative screen tourist behaviour.

This thesis furthermore has practical contributions, as findings from this research can be useful in destination management and development in order to reduce or mitigate negative screen tourist behaviour and impacts. Furthermore, greater knowledge about the factors that influence screen tourists' negative behaviour, such as fandom identification and level of involvement, is important in development of services and products, as well as marketing strategies. Understanding how negative and transgressive on-site tourist behaviour is justified by tourists is important for policy making, developing management strategies, for product and destination development, and in destination management (Sharma, 2020). 


\subsection{Methodology}

This thesis is positioned within a post-positivist paradigm, which guided the methodological choices made throughout the research cycle (Jennings, 2010).

In order to answer the research questions, a quantitative research approach was used by conducting a structured, self-administered online survey. This survey adapted two existing scales: the Level of Involvement scale (McIntyre \& Pigram, 1992), and Bandura's Moral Disengagement scale (Bandura, Barbaranelli, Caprara, \& Pastorelli, 1996) to the context of this research. Further, the survey presented participants with three hypothetical scenarios created by the researcher, exploring use of moral disengagement mechanisms in a fandom tourism specific context. The survey was developed, distributed and monitored using the online survey platform Qualtrics (QualtricsXM, 2021). The sample for this research project was drawn by using a non-probability, purposive sampling technique. The population is defined as individuals who self-identify as fans of either the TV-series Breaking Bad or Game of Thrones, are 18 years or older, and are currently residing in The United Kingdom, Ireland, Canada, the United States, New Zealand or Australia. Data was collected between 27 th January 2021 and $12^{\text {th }}$ March 2021, and an invitation to participate was distributed to online fandom communities for Breaking Bad and Game of Thrones fans. The collected data was statistically analysed in SPSS v26/v27, and SPSS AMOS.

\subsection{Thesis STRUCTURE}

Chapter 2 will provide a comprehensive literature review covering negative tourist behaviour, morality and moral disengagement, screen tourism and fandom.

A conceptual framework illustrates the relationships and connections between screen tourists' negative tourist behaviour and their use of moral disengagement mechanisms. Next, Chapter 3 outlines the methodological choices and processes that have guided the research in this thesis. Findings from the data analysis will be presented in Chapter 4. Chapter 5 presents a discussion of the findings. The thesis concludes in Chapter 6 with the conclusion and implications. 


\section{LITERATURE REVIEW}

\subsection{INTRODUCTION}

This literature review will first, in Section 2.2, provide an overview of negative tourist behaviour, focusing mainly on disruptive and intrusive behaviours, as these behaviours are the main focus of this research. Next, in Section 2.3, the theoretical approach will be discussed by first providing an overview of morality, moral agency, and morality and tourism, before defining and discussing Bandura's Moral disengagement theory. It includes an overview of how moral disengagement theory has been used in tourism research, other approaches to examine moral justification of negative behaviour, and finally, how moral disengagement theory will be used in this thesis. In Section 2.4, the literature review will provide an overview of screen and fandom tourism, as well as fan involvement, to provide a better understanding of the context this research is situated in. The literature finishes with the conceptual framework, which will be discussed in Section 2.5 .

\subsection{Negative Tourist BehaViour}

As discussed in the introduction, not all tourists behave well. Tourists intentionally or unintentionally engage in behaviours that are disruptive, destructive, disrespectful, unsafe and/or harmful. This thesis will focus on screen tourists' negative on-site behaviour, however, it is necessary to understand what negative tourist behaviour is, and the approaches that have been used to understand and explain why tourists engage in negative behaviour.

\subsubsection{Overview}

In the tourism and leisure literature, non-normative tourist behaviour can be referred to as transgressive tourist behaviour, deviant tourist behaviour, negative tourist behaviour, immoral tourist behaviour, destructive tourist behaviour, or disturbing tourist behaviour. All have in common that tourists engage in behaviour that has a negative impact on the tourists themselves, other tourists, the destination, and/or other stakeholders (Pearce, 2019). According to Uriely, Ram, and Malach-Pines (2011, p. 1051), "the phenomenon of deviant tourist behavior involves practices undertaken in a tourism-related context that operate at the fuzzy edge of social legitimacy or legality" (see also Ryan \& Kinder, 1996). 
In the literature review "Behaving Badly", Pearce (2019) introduces four organising categories of negative behaviour: the destructive, the unsafe, the intrusive, and the unsustainable. Destructive behaviours result in damage to or loss of property, such as graffiti, scratching and carving, littering, misuse, theft and "souveniring" (taking objects for "souvenir" purposes) (Pearce, 2019). Unsafe behaviours put tourists or other stakeholders at risk, often related to car and transport injuries, animal interactions, sports, and alcohol and substance abuse (Pearce, 2019). Intrusive behaviours affect negatively other stakeholders, and include behaviours such as being loud in public spaces, queue hopping, not giving way or space to others, not respecting cultural or religious customs, norms, beliefs, needs, taking photos without permission, (Pearce, 2019). Environmentally unsustainable behaviours are related to transport (binge flying), consumption of certain food items, engaging in activities that require high water usage in locations with water shortages, and engaging in activities such as hunting and interactions with animals and wildlife (Pearce, 2019).

\subsubsection{Why Tourists Engage in Negative Behaviour}

Research on negative tourist behaviour is broad and has attempted to better understand the drivers and factors that contribute to tourists' negative behaviour and why they engage in negative behaviour, how and why tourists differ in their negative behaviour, and how the different stakeholders can manage and reduce the negative behaviour.

According to Tsaur, Cheng, and Hong (2019), there are two theoretical approaches that are often used to understand consumer misbehaviour and deviant behaviour: strain theory and label theory. Strain theory proposes that the individual might engage in misconduct when they are unable to or hindered in legally achieving their goal (Tsaur et al., 2019). According to Label theory, social group reactions to an action, and whether it is identified as right or wrong, impact the individual's deviant behaviour, suggesting that they engage in more deviant behaviour if their behaviour is labelled as deviant by the social group (Becker, 1964 in Tsaur et al., 2019, p. 35; Lemert, 1951, in Tsaur et al., 2019, p. 35)

Uriely et al. (2011) note that deviant or negative tourist behaviour is often addressed from a sociological perspective, where the tourism context provides a "[...] permissive domain of social life that enables a temporary suspension of customary rules and moral conduct" (p. 1051). In a dark tourism context, "which deploys taboo subjects and commercially 
exploits the macabre" (Sharma, 2020, p. 273), associated negative behaviour has been explained by the tourist being a "thrill seeker" or as an effect of "digital narcissism" (see Sharma, 2020). Research onto negative tourist behaviour in an environment and sustainability context suggest that intrinsic reasons related to personal preferences, habits and convenience can explain why tourists engage irresponsibly (Budeanu, 2007, p. 505). Another study, examining marine angling tourists' non-compliance with regulations, found that tourists prioritise their own tourist experience over sustainability and resource protection (Solstrand \& Gressnes, 2014). Tourists can also experience tension when there is misalignment between their unsustainable behaviour and their pro-environmental beliefs, as suggested by Juvan, Ring, Leisch, and Dolnicar (2016). Juvan and Dolnicar (2014) suggest there is an attitude-behaviour gap in sustainable tourism, stating that "[p]articipants did not report changing their behaviour; instead, they offered a wide range of explanations justifying their tourist activities" (Juvan \& Dolnicar, 2014, p. 76). Some tourists then engage in negative tourist behaviours simply because it is exciting, to escape everyday constraints, and with the purpose of creating memorable experiences (Briggs \& Turner, 2012; Tutenges, 2012).

\subsubsection{Conclusion and Summary}

While most tourists behave well, some tourists engage in negative behaviour, either unintentionally or intentionally, which can have negative impacts on the tourists themselves, other tourists, the destination, and other stakeholders. To better understand negative behaviours, Pearce (2019) categorised negative tourist behaviour into four categories: destructive behaviour, unsafe behaviour, intrusive behaviour, and unsustainable behaviour. Research has attempted to better understand why tourists engage in negative behaviour, and a number of approaches, factors and drivers have been identified. Different theoretical approaches suggest that individuals engage in negative behaviour when they are hindered in legally achieving their goal (Strain theory), or are influenced by their social group (Label theory). Furthermore, factors such as intentionality, skills, knowledge of consequences, thrill seeking, misalignment between beliefs and behaviour, a desire to escape daily routines, and morality can contribute to tourists' negative behaviour, and can help us better understand why tourists sometimes behave badly. 
From a screen tourist perspective, most of screen tourists' negative behaviour falls into the destructive and intrusive categories. The introduction provides multiple practical examples from news, media and previous research. This thesis will refer to these behaviours as negative tourist behaviour, and the main focus will be on destructive and intrusive behaviour (such as trespassing, theft and "souveniring", and crowding) as these have been found to be those most engaged in by screen tourists. Furthermore, while tourists can engage in negative behaviour pre-trip, on-site and post-trip, the main focus in this thesis will be on tourists' negative on-site behaviour that has a negative impact, mainly on other stakeholders.

The following sections will discuss morality, with a particular focus on Moral Disengagement theory (Bandura, 1999). 


\subsection{Morality AND Moral Disengagement Theory}

As discussed in the previous section, negative tourist behaviour has been examined from a morality perspective, and moral disengagement theory is one of the approaches that has been found to explain how tourists engage in negative behaviour in some settings (Sharma, 2020). This chapter will give an overview of morality, moral agency, Bandura's (1986, 1990, 1991, 1999, 2001, 2002, 2004, 2016) social cognitive theory and more specifically Moral Disengagement theory. Moral Disengagement theory will be used as a theoretical approach to examine how screen tourists might justify their negative on-site tourist behaviour.

\subsubsection{Morality, Moral Agency and Morality in Tourism}

In order to understand moral disengagement, it is necessary to understand morality and moral agency (Lovelock, 2014; Sharma, 2020). The following sections will provide an overview of morality, moral agency, and morality in tourism and research advances.

Morality is a complex, controversial and broad concept (Dimitriou, 2017). (Grimwood \& Caton, 2017) note that morality is "[...] biological and cultural; cognitive, emotional, and embodied; personal and shared; dynamic; situational" (p. 6). According to Krebs (2011), morality is difficult to define, as it is "a concept or an idea — or more exactly a set of ideas - that people harbor in their heads" (p. 15), and will thus to a degree be subjective and dependent on factors such as culture, religion, and context (Krebs, 2011; Sharma, 2020). However, Krebs (2011) states that "the moral domain consists of values, norms, rules, and evaluative judgments pertaining to forms of conduct that people consider right and wrong and character traits that people consider good and bad" (p. 16). This thesis will combine the definition by Krebs (2011) above, with a definition used by Sharma (2020), that defines morality as "a socially constructed set of values that are agreed upon by individuals and societies" (Sharma, 2020, p. 274, based on Pennycook, 1994).

Dimitriou (2017) notes that morality in a tourism context becomes more complicated due to the tourism industry being vast, diverse and constantly changing. Grimwood and Caton (2017) suggest that human relationships are inherently moral, and continue to note tourism's relational nature, stating that " $[\ldots]$ innate to the activity are visceral collisions between self and other, self and environment, self and self" (p. 6). Tucker (2014) notes that "[t]ourism encounters are moral encounters, and highly complex, not only in an ethical sense, but also in an ontological sense" (p. 199). This necessitates a paradigm shift 
so that it focuses on "fluidity and mobility of positions and relations between so-called 'tourists' and 'toured"” (Tucker, 2014, p. 199), thus raising awareness of how tourism encounters are willed with contradictions and ambiguities (Tucker, 2014). Some of the recent research advances into morality and tourism have focused on moral identity, and sense of responsibility in the context of Airbnb hosts' behaviour (Farmaki, Stergiou, \& Kaniadakis, 2019); the individual's moral development in and through tourism (Caton, 2015), and in tourism education (Stevens, Grimwood, \& Caton, 2019); the moral economy of tourism ( $\mathrm{Su}$, Wang, \& Wen, 2013); tourism moralities and mobilities (Grimwood \& Caton, 2017); practical approaches to morality in the tourism industry (Dimitriou, 2017); and animal ethics in tourism and "social media as spaces of collective moral reflexivity" (Mkono \& Holder, 2019, p. 1).

When considering morality, it is important to also understand the role of moral agency (Bandura, 1999; Sharma, 2020). Lovelock (2014) states that "agency is the conscious and deliberate ability to act and implicitly no person (at least those considering travelling) is without 'agency"' (p. 145). Agency requires and allows individuals to take responsibility of and ownership of their behaviour and actions (Lovelock, 2014), and is a part of the development of a moral self (Bandura, 2016). According to Bandura (2016), during this self-regulatory process, the individual develops and adopts standards that guide right and wrong behaviour, and that act as deterrents for conduct. Bandura (2016) argues that the individual will not engage in behaviour that will violate their moral standards, to avoid self-condemnation. Thus, we have self-sanctions that keep our behaviour in accordance with our moral standards (Lovelock, 2014). Further, moral agency can be exercised in an inhibitive form or a proactive form, where the individual either refrain from behaving inhumanely (inhibitive form), or behave humanely and do good (proactive form) (Bandura, 2016). In a tourism context, moral agency means tourists have the capacity "to process social information across different cultural milieus, engage in the construction of their own social context and experiences and devise different ways of justifying their actions, when confronted with moral dilemmas" (Sharma, 2020, p. 279).

However, individuals can disengage their moral standards and self-sanctions to engage in activities that would violate their moral standards, especially when faced with situations where the behaviour has desired or perceived positive benefits (Bandura, 2016). Bandura (1999, p. 194) states that "[s]elective activation and disengagement of personal control 
permit different types of conduct by persons with the same moral standards under different circumstances". Thus, moral disengagement allows an individual to selectively engage in and justify behaviour they or others consider immoral.

\subsubsection{Moral Disengagement Theory}

As discussed in the previous section, moral disengagement allows individuals (tourists) to engage in negative behaviours by activating one or more of the moral disengagement mechanisms. The following sections will discuss moral disengagement theory, the eight moral disengagement mechanisms proposed by Bandura (1999), provide an overview of how moral disengagement theory has been used in previous tourism literature and research to examine and better understand negative tourist behaviour in different contexts, and discuss how moral disengagement will be used in this thesis.

\subsubsection{Background and Overview}

Moral disengagement theory is grounded in Bandura's social cognitive theory, and he has written extensively about the topic (Bandura, 1986, 1990, 1999, 2001a, 2001b, 2002, 2004, 2016; Bandura et al., 1996; Moore, Detert, Treviño, Baker, \& Mayer, 2012). Bandura et al. (1996) argue that moral conduct regulation involve more than just moral reasoning, and propose in their social cognitive theory that "moral reasoning is translated into actions through self-regulatory mechanisms through which moral agency is exercised" (Bandura et al., 1996, p. 364). Further, in social cognitive theory, moral agency is grounded in a self-regulatory system that operates through self-monitoring functions, judgmental functions and self-reactive sub functions (Bandura et al., 1996). Moral standards are constructed though socialisation, from information taught by others, "evaluative social reactions" to the individual's conduct, and by being exposed to "selfevaluative standards modelled by others" (Bandura et al., 1996, p. 364). Once these moral standards are formed, they act as deterrents or guides for behaviour and action, and the individual's actions are regulated by applying consequences to themselves (Bandura et al., 1996). Individuals are likely to do things that give them a sense of self-worth and satisfaction, but refrain from exhibiting behaviour that would violate their moral standards (Detert, Treviño, Sweitzer, 2008), as engaging in this behaviour would bring self-censure (Moore et al., 2012). However, the individual can selectively engage or disengage the self-regulatory processes regulating their behaviour and enable immoral 
behaviour through disengagement of self-sanctions (Boardley \& Kavussanu, 2007). This selective activation and disengagement of internal control, according to Bandura et al. (1996), permits "different types of conduct with the same moral standards" (p. 364).

\subsubsection{Moral Disengagement Mechanisms}

Bandura (1999) proposes eight cognitive moral disengagement mechanisms that facilitate immoral behaviour through either cognitively restructuring the behaviour to make it appear less immoral or unethical (Moral Justification, Advantageous Comparison and Euphemistic Labelling); by obscuring the moral agency of the actor(s) (Diffusion/Displacement of Responsibility); and through reducing or removing the harm the behaviour is perceived to cause the victim(s) (Dehumanization of Victim, Attribution of Blame, and Distortion of Consequences) (Bandura, 1999). These eight mechanisms are Moral Justification, Advantageous Comparison, Diffusion of Responsibility, Displacement of Responsibility, Euphemistic Labelling/Language, Dehumanization of Victim, Attribution of Blame, and Distortion of Consequences (see Table 2.3.1 for a description of each mechanism) (Bandura, 1999). 
Table 2.3.1 Moral Disengagement Mechanisms

\begin{tabular}{|c|c|}
\hline Mechanism & Description \\
\hline Moral justification & $\begin{array}{l}\text { The individual uses Moral Justification to reframe the behaviour as } \\
\text { something that is serving the public good, thus the behaviour is made } \\
\text { socially and personally acceptable (Moore et al., 2012) }\end{array}$ \\
\hline Advantageous comparison & $\begin{array}{l}\text { Advantageous Comparison allows the individual to compare their own } \\
\text { behaviour against other, more reprehensible behaviour (Detert et al., } \\
\text { 2008), as how we perceive behaviour is coloured by the behaviour it is } \\
\text { compared against, and that "[...] By exploiting the contrast principle, } \\
\text { reprehensible acts can be made righteous" (Bandura, 1999, p. 196). }\end{array}$ \\
\hline Diffusion of responsibility & $\begin{array}{l}\text { Diffusion of Responsibility mechanism can be activated when a group of } \\
\text { people are perceived to be responsible for the behaviour, and } \\
\text { responsibility is diffused among the group members (Wu et al., 2020). }\end{array}$ \\
\hline $\begin{array}{l}\text { Displacement of } \\
\text { responsibility }\end{array}$ & $\begin{array}{l}\text { Displacement of Responsibility minimises the individual's connection } \\
\text { and responsibility for the action/behaviour, by displacing the } \\
\text { responsibility onto others, e.g. authorities, or others due to social } \\
\text { pressures or dictates (Bandura, 2004). }\end{array}$ \\
\hline Euphemistic labelling & $\begin{array}{l}\text { Euphemistic labelling involves utilising a morally neutral language, thus } \\
\text { allowing the individual to "sanitise their actions" (Wu et al., 2020), and } \\
\text { reduces personal responsibility (Bandura, 2001). According to Bandura } \\
\text { (1999) it can also "make harmful conduct respectable" (p. 195). }\end{array}$ \\
\hline $\begin{array}{l}\text { Dehumanization of } \\
\operatorname{victim(s)}\end{array}$ & $\begin{array}{l}\text { According to } \mathrm{Wu} \text { et al. }(2020, \mathrm{p} .3) \text {, "dehumanization describes the } \\
\text { mechanism whereby individuals' internal moral standards are less likely } \\
\text { to be activated if the target behaviour has been defined as unworthy of } \\
\text { moral regard". }\end{array}$ \\
\hline Attribution of blame & $\begin{array}{l}\text { Attribution of blame involves shifting the blame onto the victim itself, } \\
\text { other people and/or the context (Wu et al., 2020). }\end{array}$ \\
\hline Distortion of consequences & $\begin{array}{l}\text { Distortion of consequences happens when the individual minimises or } \\
\text { distorts the seriousness of consequences of their behaviour (Moore et al., } \\
\text { 2012). }\end{array}$ \\
\hline
\end{tabular}

Figure 2.3.1 illustrates the process of disengaging moral self-censure from reprehensible conduct, and illustrates the different mechanisms an individual may centre the disengagement on, and where disengagement can occur (Bandura, 2004, p. 39). 


\section{Selective Exercise of Moral Agency}

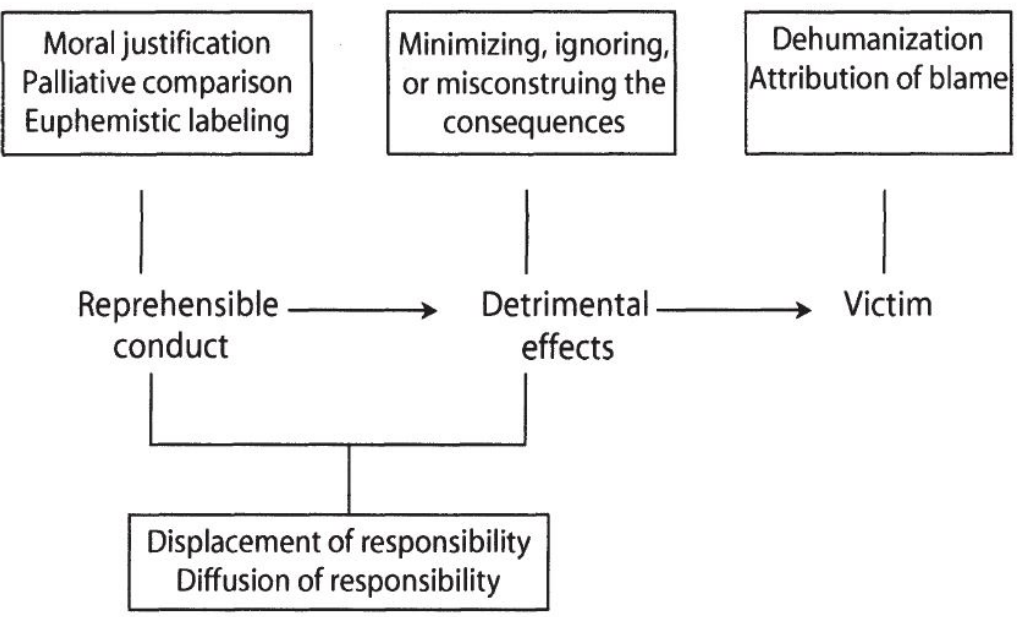

Figure 2.3.1 Process of disengaging moral self-censure from reprehensible conduct (from Bandura, 1986, p. 376).

As illustrated in Figure 2.3.1, the first mechanisms to be activated are centred on the reprehensible conduct and making it morally acceptable. Moral Justification is first activated, as people tend to engage in reprehensible conduct only after justifying to themselves that the behaviour is morally honourable. Advantageous Comparison and Euphemistic Labelling are also activated early in the process (Bandura, 1986). Next, Bandura (1986) suggests that mechanisms that involve Displacement and Diffusion of Responsibility are activated. These centre on both the reprehensible conduct itself, i.e. legitimatising them by either displacing responsibility (often to someone with authority), or diffusing responsibility through e.g. group decision making, and on the detrimental effects of the conduct (Bandura, 1986). Mechanisms that involve minimising, disregarding or misconstruing consequences can also be activated at this stage in the process, and are centred on the detrimental effects of the behaviour. Distorting, minimising and misconstruing the negative consequences of the conduct weakens selfdeterring reactions (Bandura, 1986). The last group focuses on the victim(s) and the consequences they face. According to Bandura (1986), "[...] the strength of selfevaluative reactions partly depends on how the perpetrators view the people toward whom the behavior is directed" (p. 382). 


\subsubsection{Moral Disengagement in Tourism}

Moral Disengagement theory has been used in multiple fields and disciplines to examine transgressive behaviour, including child and adolescent behaviour (Cardwell et al., 2015), military psychology (de Graaff, Giebels, \& Verweij, 2020), criminology and sports psychology (Matosic, Ntoumanis, Boardley, \& Sedikides, 2020; Moore, 2015; Tsai, Wang, \& Lo, 2014); and to understand behaviours such as bullying (Obermann, 2011), criminal behaviour, violence and aggressive behaviour (Blanco, Davies-Rubio, De la Corte, \& Mirón, 2020), and unethical behaviour and workplace conduct (Moore, 2015). In tourism, moral disengagement has been used in a tourism context to examine negative behaviour exhibited by tourists (He \& Harris, 2014; Sharma, 2020; Wu et al., 2020). Sharma (2020) examined moral disengagement in the context of negative tourist behaviour in dark tourism. Findings suggest that moral disengagement explains why some dark tourists engage in transgressive behaviour in liminal spaces. According to Sharma (2020), human agency is fragmented when moral disengagement mechanisms are activated, thus "enabling" tourists to not take ownership of their actions and resulting consequences. Furthermore, the study found that certain mechanisms were more used than others: Euphemistic labelling, Moral Justification, Dehumanization, and Misrepresenting Consequences. The two most used mechanisms centre around the reprehensible conduct itself. The tourists then engage in mechanisms activated later in the moral disengagement process (Sharma, 2020). These results align somewhat with the process proposed by Bandura (1986) in Figure 2.3.1. Mechanisms were used by multiple stakeholders (Sharma, 2020). Sharma (2020) further notes that tourists would place agency on the cremation grounds themselves, thus justifying taking pictures without guilt in a setting where this behaviour was clearly prohibited.

Moral disengagement has also been applied to a sustainable tourism context, where researchers examined tourists' formation of pro-environmentally sustainable behaviour in the context of moral obligations and moral disengagement (Wu et al., 2020). Wu et al. (2020) found that moral disengagement had a significant negative impact on tourists' proenvironmental behaviour and intent. In a hospitality context, He and Harris (2014) examined moral disengagement of hotel guests' negative word of mouth. Their findings suggest that moral emotions are an important factor in the moral disengagement of vindictive negative word of mouth (He \& Harris, 2014, p. 146). Moral disengagement has also been examined in a hunting tourism context (Tickle \& von Essen, 2020), suggesting 
that hunting tourism induces moral disengagement in hunting tourists. Tickle and von Essen (2020) further suggest that due to their liminal character, tourist settings and contexts create a space where tourists are less bound to the norms and conventions that are held at home, or " $[\ldots]$ that touristic settings bring forth deviant norms for conduct" (p. 1).

\subsubsection{Beyond Moral Disengagement Theory}

Moral Disengagement theory is not, however, the only theoretical approach that has been used to examine or explain how individuals justify their negative behaviour. Neutralisation Techniques theory (Sykes \& Matza, 1957) and Self-Serving Cognitive Distortions Theory (Barriga \& Gibbs, 1996) are two theories that examine the cognitive processes that, similar to Bandura's moral disengagement techniques, individuals use to justify to themselves engaging in behaviour that would otherwise be in conflict with their self-concept and moral beliefs (Ribeaud \& Eisner, 2010, p. 299). While these two theories align well with Bandura's theory and there are overlaps between the three theories, some elements are not found in Bandura's Moral Disengagement theory. These elements can be argued to be relevant in a tourism context, and this thesis will combine Moral Disengagement theory with elements from Neutralisation Techniques theory and Selfserving Cognitive Distortions theory. This thesis will use mainly Moral Disengagement theory, but incorporate two elements from Neutralisation Techniques theory and SelfServing Cognitive Distortions theory. These two mechanisms can be argued to be relevant to the context of negative behaviour exhibited by screen tourists. One of the neutralisation techniques presented by Sykes and Matza (1957) is "Appeal to higher loyalties". This mechanism involves neutralisation of internal and external social controls "by sacrificing the demands of the larger society for the demands of the smaller social groups to which the [individual] belongs" (Sykes \& Matza, 1957, p. 669). Thus, the tourism experience creates a setting where the individual can justify their behaviour based on the demands from that smaller group while ignoring societal norms and regulations, justifying behaviour that would otherwise violate their moral standards. Further, this thesis will also draw on an element from Self-Serving Cognitive Distortions theory. Self-Serving Cognitive Distortions theory distinguishes between primary and secondary distortions. According to Barriga and Gibbs (1996, p. 334), "Primary cognitive distortions are selfcentred attitudes, thoughts, and beliefs". This involves the individual according status to 
their own desires, expectations and needs "[...] to such a degree that the legitimate views, etc. of others [...] are scarcely considered or are disregarded altogether" (Barriga \& Gibbs, 1996, p. 334). This aligns with some characteristics of tourism, where the tourist's focus is often on their own experience, satisfaction, expectations and needs (Scott \& Gao, 2018), and where these factors can in some circumstances override or the best interest of others. This can for example be seen in tourists engaging in high-risk activities (Mura, 2010). Incorporating the two elements from Neutralisation Techniques theory and SelfServing Cognitive Distortions theory with Moral Disengagement theory aims to give a broader understanding of how screen tourists might morally justify their negative on-site behaviour.

\subsubsection{Conclusion and Summary}

Moral Disengagement theory is one of the theoretical approaches used to examine negative and immoral behaviour, both in tourism and other disciplines. Bandura's Moral Disengagement theory explains how an individual justifies engaging in behaviour they otherwise would consider immoral. By selectively activating moral disengagement mechanisms, the individual can disengage their moral standards and justify immoral behaviour. Previous research conducted on tourism and moral disengagement has found that tourists use moral disengagement mechanisms to justify negative tourist behaviour; however, there is a lack of research examining negative screen tourist behaviour in particular. Other cognitive theories have also been used to explain how individuals justify engaging in negative behaviour. Two of these are Neutralisation Techniques theory and Self-Serving Cognitive Distortions theory. While it is clear that the mechanisms from each theory overlap, both Neutralisation Techniques theory and Self-Serving Cognitive Distortions theory have elements that are not found in Moral Disengagement theory: Appeal to higher loyalties (Neutralisation Techniques theory) and Primary Self-serving cognitive distortions (Self-Serving Cognitive Distortions theory). Incorporating these two elements with Moral Disengagement theory broadens the understanding of how screen tourists might justify their negative on-site behaviour. Furthermore, to answer the research questions presented in Section 1.3, especially whether groups of screen tourists differ in their use of moral disengagement, it is necessary to understand the characteristics of screen tourism and screen tourists. Screen tourism, and screen tourists will be discussed next, in Section 2.4. 


\subsection{SCREEN TOURISM AND FANDOM}

The previous sections have focused on negative tourist behaviour, and how morality and moral disengagement help us explain and better understand the underlying mechanisms behind tourists' justification of negative behaviour. Further, the previous discussion has provided a brief overview of negative tourist behaviour in a screen tourism context. It is clear from the news articles discussed in Section 1.1 that negative screen tourist behaviour is a problem, however, little attention has been paid to it. Research suggests that screen tourists' behaviour differs from that of other tourists in terms of motivation, involvement, and interests (Macionis, 2004). Further, screen tourists have been found to differ in level of involvement and motivations, in turn influencing their on-site behaviour (Thorne, 2011). As this thesis examines negative tourist behaviour in the context of screen tourism, it is necessary to understand the characteristics of screen tourism and screen tourists. This chapter will provide an overview of screen tourism and fandom to provide a better understanding of the unique characteristics of screen- and fan tourists.

\subsubsection{Screen Tourism Overview}

Screen tourism has become increasingly more popular over the past decade (Connell, 2012). Films and TV-series have been marketing and branding tools for destinations (Cardoso, Estevão, Fernandes, \& Alves, 2017), and are considered to have a positive effect on tourism demand, destination development (Wray \& Croy, 2015), and destination image (Tkalec, Zilic, \& Recher, 2017). Beeton (2016) proposes a definition of screen tourism, where the term is applied to visitation to locations and destinations where movies and television series have been filmed, including film and TV production studio tours and film-themed theme parks. Du et al. (2019) propose a broader definition and define screen tourism as "the activities of tourists who go to places related to a film or TV series" (p.3). For the purpose of this thesis, screen tourism is thus defined as "visitation to film and/or TV-series related locations", as the focus of this research is on screen tourists' negative behaviour when visiting related locations.

Further, it is necessary to understand the people engaging in these negative behaviours. Research suggests that screen tourists are not one homogenous group, rather, screen tourists differ in their motivation to visit screen related locations (Heitmann, 2010; Macionis, 2004). Macionis (2004) presents three typologies of film tourists: the serendipitous film tourist who is coincidentally in a film destination; the general film tourist who participate in film tourism activities, despite their visitation not being solely 
motivated by interest in the film; and the specific film tourist who is motivated to visit a film destination and participate in film tourism activities because of specific films (Macionis, 2004, p. 87). Macionis (2004) suggests that specific film tourists who identify as fans can be more driven to visit a screen related destination and participate in screen tourism related activities. As this is exploratory research, the focus will be on specific film tourists who are fans to ensure access to rich data. As will be discussed in the upcoming section, the specific film tourists (fan tourists) are often more involved with the fan object (i.e. film/TV-series), and some are more likely to engage in negative behaviour for their own benefit.

\subsubsection{Fandom and Fans as Tourists}

Specific film tourists are often fans of the film or TV-series (fandom object) related to the screen tourism destination (Macionis, 2004). Fans have specific characteristics that influence their behaviour, including their tourist behaviour (Thorne, 2011). Fans create communities (fandoms) with their own norms, values and rules (Duffett, 2013), and more involved fans are often willing to invest more resources in activities related to their interests (Thorne, 2011). Thus, as screen tourists, they are likely to engage in behaviours other tourists might not engage in. Waysdorf (2017) suggests that fandom is often what draws a film tourist to visit a screen tourism location. The following sections will define and discuss fans, fandom, fans as tourists, and fan involvement, and provide a better understanding of those highly involved fans at the core of this research.

\subsubsection{Fandoms and Morality}

A fan has been defined as "a person with a relatively deep, positive emotional conviction about someone or something famous" (Duffett, 2013, p. 18), with an enduring involvement with the fan object (Thorne \& Bruner, 2006, p. 52). Furthermore, fans are "driven to explore and participate in fannish practices. Fans find their identities wrapped up with the pleasures connected to popular culture. They inhabit social roles marked up as fandom" (Duffett, 2013, p. 18). Fandoms, a subculture consisting of likeminded fans who share the same fan object or subject (Thorne \& Bruner, 2006, p. 53), act as a community for fans, and can, according to Fuschillo (2020), create strong interpersonal bonds and family-like structures, and a feeling of closeness (Thorne \& Bruner, 2006, p. 53). Fandoms often have their own norms, values, rituals, rules, expectations and 
demands (Duffett, 2013; Fuschillo, 2020). Duffett (2013) notes that fans often imagine that the fandom shares values with each other and the fan object. Thus, moral disengagement mechanisms, in particular the "Appeal to higher loyalties", become relevant in tourism settings where the individual is faced with two (or more) conflicting sets of morals and values, i.e. where engaging in the behaviour is considered immoral by the overall society, but can be considered justifiable and even desired by the fandom's values.

The moral alignment of the fan object (TV-series) have been found to impact the moral values of the fandom. The two fandoms selected for this thesis are the TV-series Breaking Bad and Game of Thrones. Breaking Bad is a TV-series about Walter White, who has been termed as an "anti-hero" (Echart \& García, 2013). The TV-series begins as Walter White is diagnosed with a terminal illness, which becomes the driving force for his increasingly transgressive behaviour and criminal decline (including manufacturing and distributing methamphetamine, murder, etc.) (Echart \& García, 2013). He justifies these behaviours, in part, as means to a greater good to support his family financially (Black, Helmy, Robson, \& Barnes, 2019). However, throughout the series, as Echart and García (2013) note, White's morality declines while he justifies engaging in repulsive behaviour, and becomes "immune to the moral consequences of his actions" (p. 210). Fans go through a similar process, identifying and emphasising with the main character in the first seasons (Echart \& García, 2013). Individuals have been found to be more accepting of fictional characters' immoral behaviour when there is a positive outcome or intention present (Krakowiak \& Tsay-Vogel, 2013). Thus, fans might justify White's moral decline as it is (initially) justified by helping his family through a difficult situation. Furthermore, people are according to Bandura (2001b) motivated to model their behaviour on fictional characters when the (fictional) outcome is positive even if their behaviour is immoral. If fans' own interpretations of morality is influenced by the fandom object, it may impact their moral justification of negative tourist behaviour.

While Breaking Bad is centred on an "antihero" who uses moral disengagement to justify his criminal behaviour, Game of Thrones (based on the book series A Song of Ice and Fire by George R. R. Martin, Penguin Random House, 2021) is a story about good versus bad. The characters faces dilemmas where they have to make the moral choice if causing harm is morally permissible in order to prevent future suffering (Everett \& Crockett, 
2019). Game of Thrones can be argued to be morally ambiguous (Sawant, 2019), noting that Game of Thrones characters are neither purely good nor purely evil. Furthermore, while moral disengagement is used in Breaking Bad to justify transgressive behaviours benefiting Walter White himself, the morally ambiguous behaviours in Game of Thrones can be argued to benefit multiple characters. It has also been argued that the moral ambiguity of Game of Thrones reflect "the real world" to a greater extent than a narrative where the characters are either completely good or completely evil (Sawant, 2019). This information is important when examining the use of moral disengagement of fans of these two series.

\subsubsection{Fan Involvement and Tourism}

Fans then vary in level of fandom involvement, where highly involved fans will spend more resources on fandom engagement and activities (Thorne \& Bruner, 2006). Thorne (2011) presents four levels of fandom involvement: the dilettante fan, the dedicated fan, the devoted fan, and the dysfunctional fan. The dilettante fan is the most casual fan, exhibiting the least involvement, while the devoted is the most involved fan (Thorne, 2011). The devoted fan (and to a certain degree the dedicated fan) is willing to invest more resources and make changes in their life in order to actively accommodate fandom involvement (Thorne, 2011). Furthermore, Thorne and Bruner (2006) found that a higher level of fan(dom) identification is another factor influencing fans' level of involvement. Thorne and Bruner (2006) further state that " [...] fans have a strong wish to acquire items and information related to their area of interest” (p. 66), suggesting that highly involved fans go to further lengths to acquire fandom related items. Zubernis and Larsen (2018) note that acquiring tangible objects can be important to fan tourists as a way to prove they have visited the place, and to gain social capital. Reported negative screen tourist behaviour, as discussed previously, often involve "souveniring" of objects, or trespassing to take specific photographs.

One increasingly popular way for fans to engage with their fan object and fandom is through tourism. This is done by visiting destinations related to the fan object, attending events, theme parks, gatherings, etc., and engaging in fandom related activities (Gyimóthy, Lundberg, Lindström, Lexhagen, \& Larson, 2015). Visiting these locations, such as filming locations, allows fans to re-enact scenes from the film or TV-series. This 
creates stronger bonds between fans, between the fan and the fandom object, as well as the fan and the location, and enables the fan tourist to be part of the fandom object (Waysdorf, 2017). Fandom tourism creates an arena where fans can socialise, interact and strengthen fandom bonds in person (Gyimóthy et al., 2015), as much fandom interaction is now done online (Zubernis \& Larsen, 2018). Similar to fans' levels of engagement, fan tourists also vary in their level of engagement and tourist behaviour (Gyimóthy et al., 2015; Lee \& Yoo, 2015). It can therefore be assumed that screen tourist behaviour, especially its negative manifestations, differs between level of involvement.

\subsubsection{Measuring Fan Involvement}

The above discussion has illustrated how fan (tourists') behaviour is influenced by level of involvement. It is suggested that higher levels of involvement result in more involved behaviour where the individual is willing to invest more resources in their fandom involvement. Research Question 3 asks whether screen tourists differ in their use of moral disengagement mechanisms. To measure this, level of fandom involvement is used to group participants based on their self-identified involvement in their respective fandoms.

Involvement is a multidimensional construct with three identified dimensions: attraction, centrality, and self-expression (Havitz \& Dimanche, 1997; McIntyre \& Pigram, 1992). These three dimensions are important in a tourism and leisure context (Lee, 2007), and have through empirical research found to be the three dimensions with high reliability and validity (see Kyle, Absher, Norman, Hammitt, \& Jodice, 2007). The dimensions refer to the perceived importance, interest, and pleasure derived from involvement with the object (attraction), the extent the individual's life is centred around or on the involvement with the object, in addition to a strong social component (centrality), and the extent involvement presents an arena or opportunity to express an individual's desired image, as well as a sense of freedom from normal day constraints (self-expression) (Lee, 2007, p. 83). Combined, these three dimensions are regarded as indicators of enduring involvement (McIntyre \& Pigram, 1992). Leisure involvement has been measured using various instruments (Havitz \& Dimanche, 1997; Kyle et al., 2007). Based on the Consumer Involvement Profile scale developed by Laurent and Kapferer (1985), McIntyre and Pigram (1992) proposed a three dimensional leisure involvement scale, which includes the three factors mentioned above, to measure enduring involvement in 
various contexts. This scale has been adapted and used to measure touristic and leisure involvement in various tourism contexts (Chang \& Gibson, 2011; Di-Clemente, Hernández-Mogollón, \& Campón-Cerro, 2020). In a fandom and fan tourist setting, Lee (2007) adapted McIntyre and Pigram's (1992) Involvement scale to measure tourists' leisure involvement with Korean celebrities. This will be used in this research to identify respondents' fan involvement and examine potentially different approaches to justifying negative screen tourist behaviour.

\subsubsection{Conclusion and Summary}

This section on screen tourism has provided an overview of the context this research is situated in. One of the research questions asks whether different groups of screen tourists differ in their use of moral disengagement mechanisms when justifying negative on-site tourist behaviours. It is thus necessary to understand both screen tourism, and screen tourists, how they differ from other tourists, how different groups of screen tourists differ, and what makes them unique. Screen tourism is becoming increasingly popular. However, while this has multiple benefits, it is clear that screen tourism can have negative impacts on stakeholders. Screen tourists have been known to engage in intrusive and destructive behaviours at screen related locations. Furthermore, research suggests that screen tourists have characteristics that sets them apart from other tourists, and which might contribute to their behaviour. Screen tourists vary in their motivation for visiting a film location, where some find themselves there by coincidence, while others are motivated by a specific film or TV-series to visit. These specific film tourists are often fans of the specific film or TV-series, further influencing their behaviours and involvement. Similar to screen tourists, fans have unique characteristics. Fans often seek out other fans with similar interests, and create fandoms (fan communities). These have their own set of rules, expectations, norms, and values. The moral alignment of the fan object has been found to impact the fan(dom)'s acceptance of negative behaviour. Furthermore, highly involved fans are often more willing to spend more resources and go to further lengths to engage with the fan object, the fandom, and participate in fan activities, as well as acquiring objects related to the fan object. It is thus likely that highly involved screen tourists/fans exhibit differences in justifying negative tourist behaviour, leading to the necessity to include a fan involvement scale (based on leisure involvement as a three-dimensional construct) in this research. 


\subsection{SUMMARY AND CONCEPTUAL FRAMEWORK}

This literature review has examined and provided an overview of the three main concepts/components of this thesis: negative tourist behaviour, morality and Moral Disengagement theory, and screen tourism and fandom, as this thesis aims to examine if tourists use moral disengagement to justify their negative on-site tourist behaviour, in the context of screen tourism. This section will summarise the main points discussed in the literature review, and present a conceptual framework that illustrates the proposed interrelationships between these three concepts: screen tourism and fans/fandom, negative on-site tourist behaviour, and moral disengagement. The framework presented in Figure 2.5.1 illustrates the proposed interrelationships between fandom, fans and level of involvement, and negative tourist behaviour and the moral disengagement mechanisms used to justify said negative behaviour, set within a screen tourism context.

First, the framework is set within the context of screen tourism, examining how (screen/fan) tourists might use moral disengagement to justify their negative behaviour in a screen tourism setting. The literature review provided an overview of screen tourism and fans/fandom in a tourism context, and recognises that screen tourists have unique characteristics that sets them apart from other tourists, but also that screen tourists are not a homogenous group (Macinois, 2004). Screen tourists vary in level of involvement, where highly involved screen tourists are often considered to be fans of the particular object (Macinois, 2004). Next, from the top, the framework illustrates how fans are part of a fandom (Duffett, 2013). Fans create communities (fandoms) based on common interest in their fan object (Duffett, 2013). Further, the literature suggests that fans vary in level of involvement with the fandom (Thorne, 2011), and that fans' level of engagement also influence their behaviour and participation in the fandom (Thorne \& Bruner, 2006). This is reflected in the conceptual framework by the arrow illustrating the connection between fandom/fans and the level of involvement box on the right side, indicating a two-way relationship. 


\section{Screen Tourism}

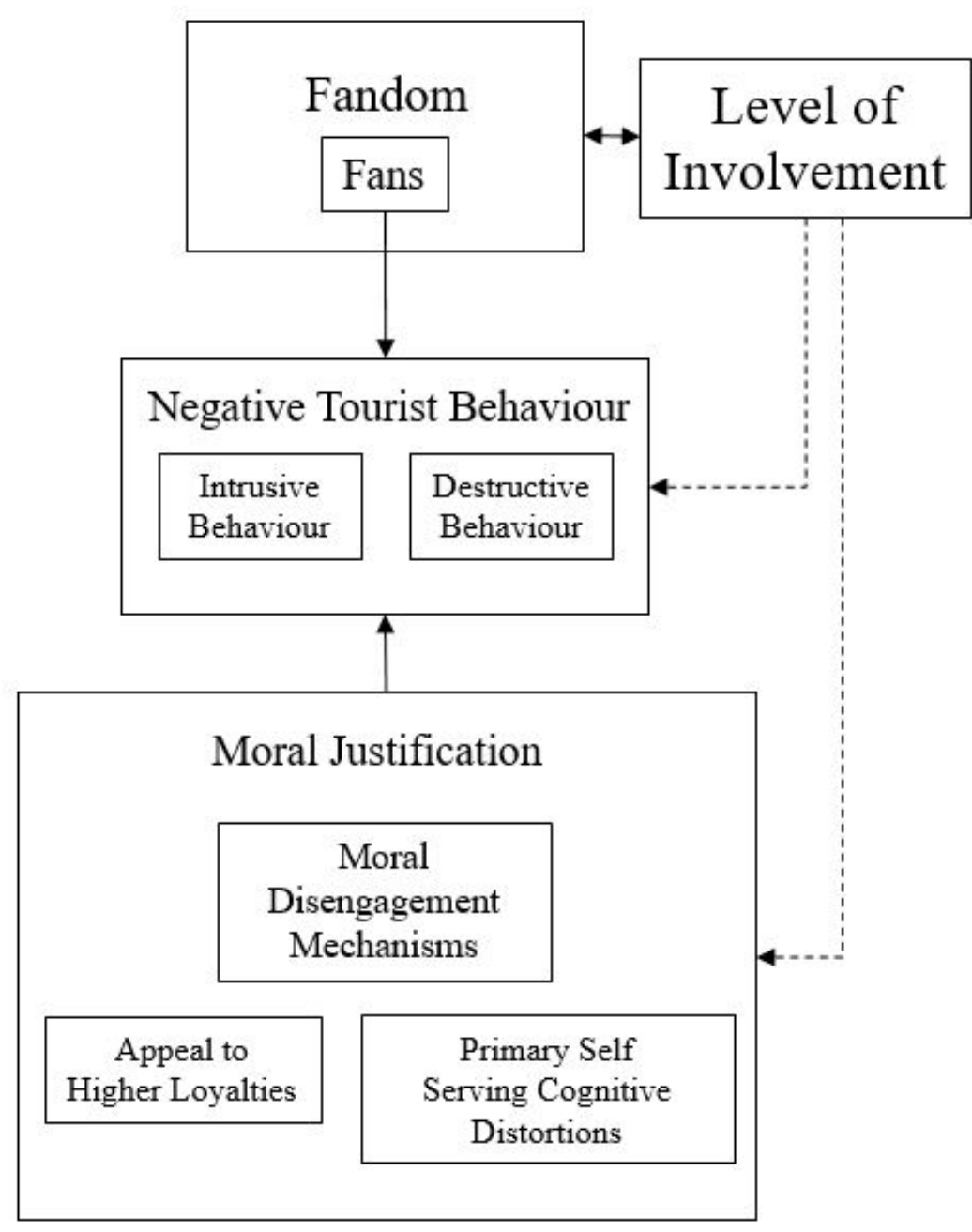

Figure 2.5.1 Conceptual framework

The next process illustrated in the framework is fans engaging in negative tourist behaviour. While Pearce (2019) identified four main categories of negative tourist behaviour, as discussed in Section 2.2.1, the main focus in this thesis is intrusive and destructive behaviours. These behaviours were identified to be the most common negative tourist behaviours in a screen tourism context. As illustrated in the framework's lower half, the next process involves this behaviour being justified using moral disengagement mechanisms. The literature has identified multiple approaches used to explain how 
individuals justify their negative behaviour. This thesis will focus on moral justification of negative behaviour, and in particular Moral Disengagement theory (Bandura, 2016). This theory has been used in different tourism contexts as an approach to explain how tourists justify engaging in behaviours they otherwise would consider immoral ( $\mathrm{He} \&$ Harris, 2014; Sharma, 2020; Wu et al., 2020). However, the literature review also identified two other theories that, similarly to Moral Disengagement Theory, aims to explain how individuals justify negative behaviour: Neutralisation Techniques theory (Sykes \& Matza, 1957) and Self-serving Cognitive Distortions (Barriga \& Gibbs, 1996).

While research has found some overlap between all three theories' mechanisms, two moral disengagement mechanisms are not found in Bandura's Moral Disengagement theory: Appeal to higher loyalties (Neutralisation Techniques theory) and primary selfserving cognitive distortions (Self-Serving Cognitive Distortions). These two mechanisms are combined with the moral disengagement mechanisms, creating the variable moral justification. Furthermore, as fans' behaviour is influenced in part by level of involvement (Thorne \& Bruner, 2006), it can be assumed that level of involvement also influences the tourists' negative behaviour and use of moral disengagement mechanisms. The dotted lines indicate potential relationships between level of involvement and negative tourist behaviour, and between level of involvement and use of moral disengagement. However, these interrelations were not confirmed through the literature review, and are therefore part of what is being examined in this thesis. The conceptual framework thus illustrates the relationships between screen tourism, level of fandom involvement, negative tourist behaviour, and moral disengagement mechanisms. These relationships will be examined and investigated in this thesis by using a quantitative research approach. The next chapter, Chapter 3, will discuss the methodology and methodological choices that have guided this research project. 


\section{Methodology}

\subsection{INTRODUCTION}

This chapter will outline the methodological choices that have guided the research in this thesis, in order to answer the research questions presented in Section 1.3. The literature review suggests that while screen tourism has mostly positive impacts and benefits, some screen tourists engage in negative behaviour (BBC News, 2020; Brady, 2019; Miller, 2020; Patel, 2020; Taylor, 2018). Furthermore, screen tourists, and in particular highly involved screen tourists have characteristics that differ from other tourist segments (Thorne, 2011), influencing their behaviour and choices they make. While there are multiple approaches to explaining why individuals engage in negative behaviour, the literature review identified Moral Disengagement theory (Bandura, 2016), Neutralisation Techniques theory by Sykes and Matza (1957) and Self-Serving Cognitive Distortions by Barriga and Gibbs (1996) as three approaches used to explain how individuals justify negative behaviour in various non-tourism contexts (de Graaff et al., 2020; Matosic et al., 2020; Moore, 2015; Tsai et al., 2014) and tourism contexts (He \& Harris, 2014; Sharma, 2020; Wu et al., 2020).

This thesis takes a quantitative survey approach to investigate moral disengagement of negative tourist behaviour in a screen tourism context, and answer the three research questions proposed in Section 1.3:

- "Do screen tourists use moral disengagement mechanisms to justify their negative on-site behaviour?"

Next, the literature review identified that some moral disengagement mechanisms are frequently used (Sharma, 2020). As this has been found in other tourism contexts, this thesis will examine whether this occurs in a screen tourism context:

- "Which moral disengagement mechanisms are most frequently used by screen tourists to justify their negative behaviour?"

Lastly, the literature review suggests that screen tourists and fandom tourists exhibit different behaviours depending on their level of involvement (Thorne \& Bruner, 2006). The literature further suggests that the fandom object as well as the depiction of morality within the TV-series or movie potentially impact screen tourists' behaviour (Krakowiak \& Tsay-Vogel, 2013). This suggests that level of involvement may have an impact on use of moral disengagement mechanisms, as proposed in the third and last research question: 
- "Do different groups of screen tourists differ in their use of moral disengagement mechanisms?"

To investigate these three research questions, a quantitative research approach is used, through a self-administered online survey questionnaire distributed to individuals who self-identify as part of a fandom.

The following sections will first discuss the research paradigm, then provide a brief overview of quantitative research methods, before discussing the research design. This discussion follows the research cycle, and includes a brief overview of survey research, the sampling process, survey design, data collection, data analysis, and ethical considerations, before concluding with methodological strengths and weaknesses.

\subsection{RESEARCH PARADIGM}

This thesis will take a post-positivist approach. This section will first define paradigm, then discuss post-positivism, and how it is appropriate for this thesis.

Paradigms are defined as "[...] universally recognized scientific achievements that for a time provide model problems and solutions to a community of practitioners" (Kuhn, 1970, p. viii, as cited in Munar \& Jamal, 2016, p. 2). Thus, the research paradigm guides the researcher, the research and the choices made throughout the research project. Postpositivism evolved from the positivist paradigm, and has been argued to be a critique of positivism (Fox, 2008). A positivist worldview proposes that there is one objective reality, and that "truth in positivist inquiry is achieved through the verification and replication of observable findings concerning directly perceivable entities or processes" (Clark, 1998, p. 1243). Critics of positivism emphasise however, that there is no neutral knowledge (Ryan, 2006), and that the researcher cannot be impartial, but is in fact influenced by their own values, beliefs, and prejudices (Mason, 2014). These factors influence participants as well, thus, the data collected is not objective, but is dependent on context (Mason, 2014).

Post-positivism emerged as an "an attempt to transcend and upgrade positivism, not the rejection of all positivist ideas and postulates of the scientific method" (Adam, 2014, p. 5). According to Henderson (2011), post-positivism "[...] suggests that the social sciences are often fragmented, that knowledge is not neutral (and really never has been), and that all knowledge is socially constructed" (p. 342). Thus, post-positivism moves 
away from the idea that there is one universal truth, as well as the strict collection of quantifiable data, instead opening up for collection of more subjective data, using a greater variety of data collection methods, and put greater emphasis on meanings (Mason, 2014). However, post-positivism does not reject quantitative methods completely (Clark, 1998). As opposed to positivists' aim for findings to be generalizable and objective, Clark (1998) notes that " $[\mathrm{t}]$ he contextually bound nature of research findings $[\ldots]$ warrants that knowledge deemed to be 'truthful' under post-positivistic inquiry is not universally generalizable to all cases and all situations" (p. 1246). Furthermore, the researcher and their perceptions are not wholly detached from their research, and personal processes are acknowledged as a characteristic of human inquiry (Clark, 1998, p. 1245). Postpositivism allows for reflexivity, accounts for researcher bias, and acknowledges the researcher's influence on the research project, development and choices, and the interpretation of the data collected and analysed.

While this research project uses a strictly quantitative approach (a self-administered structured questionnaire with closed-ended questions), a post-positivist approach is appropriate as it allows for acknowledgment of the researcher's own bias, in particular in the development of the parts of the research instrument not based on existing research instruments (i.e. the hypothetical scenarios). It further acknowledges that the constructs being measured, level of fandom involvement in particular, are subjective and that participants are influenced by their own context, norms, values, and experiences. Thus, it can be argued that there is no "one universal truth" to be observed. As will be discussed later in greater detail, this research project has used a non-probability sampling technique, which affects the research project's generalizability (Nardi, 2018). 


\subsection{Quantitative Research Methods}

Quantitative research is defined as "explaining phenomena by collecting numerical data that are analysed using mathematically based methods (in particular statistics)" (Aliaga \& Gunderson, 2002, as cited in Muijs, 2011, p.1). Furthermore, quantitative research aims to establish relationships between variables and explain causal relationships between variables (Mertler, 2016; Muijs, 2011). Mertler (2016) notes that one of the main characteristics of quantitative research is the philosophical belief that the "world is relatively stable and uniform, such that we can measure and understand it as well as make broad generalizations about it" (p. 108). Other characteristics of quantitative research are that it has an etic (outsider) perspective, sampling strategies usually involve random or probability sampling methods, and the research design aims to be replicable, highly structured, and systematic (Jennings, 2010; Mertler, 2016).

As mentioned above, a quantitative research approach aligns with a post-positivist worldview (Mackenzie \& Knipe, 2006). Mackenzie and Knipe (2006) note that quantitative research designs are still appropriate with a post-positivist world-view. A quantitative approach is thus used in this research project as it enables the collection of large amounts of data from a larger population. It is further appropriate due to the research aim, and the data this research project aims to collect. The research questions ask whether moral disengagement mechanisms are used, which mechanisms are most frequently used, and whether groups differ in their use of moral disengagement. These questions do not aim to collect in-depth data from a smaller sample to get subjective data in order to gain a deeper understanding of the phenomena, in which case a qualitative approach would be appropriate (Mertler, 2016). The data necessary to answer this research project's research questions is data that can be analysed using a statistical approach. This is done by administering a survey questionnaire research design to the sample.

The following sections will discuss the research design in more detail. 


\subsection{RESEARCh DESIGN}

A self-administered, online survey questionnaire is used to examine if and how tourists use moral disengagement mechanisms to justify their negative on-site tourist behaviour, in the context of screen tourism. This section will first briefly provide an overview of survey research, before discussing the sampling design, followed by the survey design. This will cover a brief overview of online survey design, questionnaire design, including structure, scales, and scenarios, data collection, data analysis, and ethical considerations.

\subsubsection{Survey Research}

Survey research is a common research tool in quantitative research, as it is a flexible and cost and time effective method (Nardi, 2018). It is effective when the aim is to collect data from large populations using a standardised instrument (questionnaire) which is distributed to a large sample drawn from a population (Muijs, 2011). Due to the postpositivist, quantitative nature of this research project, survey research is used to collect data (Mackenzie \& Knipe, 2006). This approach aligns with prior research conducted on both level of involvement (Chang \& Gibson, 2011; Di-Clemente et al., 2020; Lee, 2007; Lee, 2011; Lee, 2012) and moral disengagement (Bandura, 1996; He \& Harris, 2014; Sharma, 2020; Wu et al., 2020). It further aligns with the research aim and research questions, as it allows for collection of large amounts of data using a standardised questionnaire distributed to samples from two populations (fandoms), enabling comparisons amongst different groups.

Self-administered surveys have further been suggested to be appropriate when participants are asked to self-report on sensitive topics. According to Fowler, (1995, p. 29) '[q]uestions tend to be categorized as 'sensitive' if a 'yes' answer is likely to be judged by society as undesirable behaviour", and if the behaviour deviate from social norms (Krumpal, 2013). As this survey examines individuals' attitudes towards and justifications of negative behaviour, in particular in the Moral Disengagement scale, it can be argued that this survey is examining a sensitive topic where a quantitative selfadministered approach is likely to reduce social desirability bias. 


\subsubsection{Sampling}

This thesis examines screen tourists' moral justification of negative on-site tourist behaviour, and it is necessary to select participants who can provide insight relevant to the research questions (Muijs, 2011). This section will provide an overview of sampling process and sample design used in this research project.

Sampling can be defined as "a set of procedures for selecting study elements from, or about, which data are collected" (Daniel, 2015, p. 511), and determines whether and how much can be generalized from the elements included in the study to a wider population (Daniel, 2015). The first step in the sampling design process is to define the population (Alreck \& Settle, 2004), the "total collection of units or elements you want to analyse" (Nardi, 2018, p. 116).

This thesis examines screen tourists use of moral disengagement and justification, and the relevant population is fans, as noted in the literature review, highly involved fans are more likely to travel as screen tourists. Furthermore, due to the COVID-19 pandemic, a hypothetical approach was most feasible. The literature review identified level of involvement as an important factor that influence screen tourists and fans' behaviour, in addition to the importance of fandom communities. As discussed in Section 2.4.2.1, the Internet, especially social media platforms, plays a vital role in facilitating, creating and maintaining a fandom community (Zubernis \& Larsen, 2018). It is likely that individuals who are part of an online fandom community identify as part of the fandom (Zubernis \& Larsen, 2018). To answer the research questions, the population for this thesis is defined as individuals who self-identify as fans of either Breaking Bad or Game of Thrones. These two were selected as fandoms as they both have relatively large online presences, and there are existing literature and media coverage identifying negative tourist behaviour associated with screen tourists visiting locations related to the two TV-series (see discussion in Introduction and Chapter 2).

Participants also have to be 18 years or older, and currently residing in The United Kingdom, Ireland, Canada, the United States, New Zealand or Australia. Participation was restricted to these countries due to the ethical concerns raised by the Ethics Committee, discussed in more detail below, in Section 3.4.6. The next step in the sampling process is to determine the sample size (Alreck \& Settle, 2004). To determine sample size, statistics are often used to determine if the sample size and degree of confidence that the findings are representative and reflect the whole population. For this 
research, an online calculator was used to calculate the sample size needed at a $95 \%$ confidence level with a $5 \%$ margin of error. However, as the population size for the population is unknown and a sample frame does not exist, this is rough estimate. The ideal sample size is assumed to be between 300-500 participants.

After determining the sample size, the sample design is decided (Alreck \& Settle, 2004). This research project uses a non-probability, purposive sampling technique. This technique is used as there is no sample frame of the population using these social media platforms, thus, probability sampling is not suitable. Furthermore, a purposive technique ensures that the participants fit the sample characteristics this research project aims to study (Jennings, 2010). A Snowball sampling approach was used in combination with the purposive sampling approach midway through the data collection period. Snowball sampling uses participants' networks or connections to reach participants who might be hard to reach (Jennings, 2010). Survey invitation messages contained a request that participants could share the invitation post if they knew others who fit the sample criteria and might be interested in participating (see Appendix A). Lastly, the sample for the main survey is drawn (Alreck \& Settle, 2004). As mentioned above, the sample is drawn from a population of individuals who self-identify as part of either the Game of Thrones fandom or the Breaking Bad fandom, and fit within the population parameters (age, current country of residence). A prize draw was used as an incentive to increase participation (Singer \& Bossarte, 2006), and participants could enter to win one of three \$100 NZD Amazon gift vouchers.

\subsubsection{Survey Design}

\subsubsection{Online Survey Design Overview}

Web-based surveys are becoming more popular, in particular for developing and distributing self-administered questionnaires (Nardi, 2018). Various online allow researchers to create, distribute and monitor surveys. Further, using existing providers requires limited computer skills, and can be a cost and time effective alternative to face to face administration and interviews (Jennings, 2010). Online surveys are furthermore appropriate when the sample population is difficult to reach, e.g. without a sample frame, as an invitation can be posted using distribution channels online (e.g. forums, social media, discussion boards, websites, etc.) (Nardi, 2018). Using an online survey as the 
data collection tool in this research project has multiple benefits. First, as briefly discussed above and in the literature review, fandom communities are predominantly online, thus an online survey is easily distributed to a population that is already online and is likely to have the skills and infrastructure necessary to participate. Furthermore, as there is no existing sample frame, the sample population is hard to reach using a paper-based survey. A face to face administered survey would be difficult to conduct due to the current global COVID-19 situation, in addition to time and financial related costs. Additionally, an online-based survey can be distributed to a broader sample population.

The following sections will outline the survey design for the questionnaire used in this research project.

\subsubsection{Survey Questionnaire Design}

The survey was developed using the Qualtrics Survey platform (QualtricsXM, 2021). Qualtrics was chosen as it is available through Victoria University of Wellington.

The survey is divided into six parts: information section, demographic questions, Level of Involvement scale, scenarios, Moral Disengagement scale, and debrief section. First, the information section (Appendix B) provides information about the research project. The questionnaire (Appendix C) first prompts the participant to explicitly select whether they consent to participate; participation is automatically terminated for participants selecting no. The demographic section contains questions about age group, current place of residence, gender identification, and highest level of completed education. Age and place of residence are filter questions, filtering out participants younger than 18 years old, and participants who do not meet sample criteria. Because these questions are filter questions, the survey begins with the demographic section. Next, participants are asked about their fandom identification (Breaking Bad or Game of Thrones). Participation is terminated if "none of the above" is selected, ensuring that participants meet the sample characteristic criteria, and that correct fandom specific questions (for Level of Involvement scale and scenarios) are presented. Using the piped text function in Qualtrics, participants are automatically presented with the correct fandom based on their response to this question. Next, participants are presented with the Level of Involvement scale, followed by the hypothetical scenarios. After completing these sections, participants are given the choice to skip the Moral Disengagement scale, as the Human Ethics Committee raised a concern some statements in the scale might be emotionally 
distressing. Participants who opt to skip the Moral Disengagement scale are automatically directed to the debrief section, otherwise participants are presented with the Moral Disengagement scale. The questionnaire ends with the debrief section (Appendix D) and the option to enter the prize draw and registering interest in receiving a summary report by clicking a link to a separate survey (Appendix E). As discussed briefly above, the questionnaire uses two scales adapted from existing scales to fit the context of this research, in addition to three fandom specific scenarios mirroring common negative screen tourist behaviour, developed by the researcher. The scales and scenarios will now be discussed in greater detail in the upcoming section.

\subsection{Level of Involvement scale}

The Level of Involvement scale was adapted from Lee (2007, who adapted it from McIntyre \& Pigram, 1992), and is adapted to the Breaking Bad or Game of Thrones context by specifying the respective fandom in questions (Appendix C). The scale measures the constructs attraction, centrality, and self-expression, with four items measuring each construct (see Table 3.4.1, adapted from Lee, 2007).

Table 3.4.1 Items of Fandom Involvement (adapted from Lee, 2007)

\begin{tabular}{ll} 
Type of involvement & \multicolumn{1}{c}{ Items } \\
\hline & Breaking Bad/Game of Thrones is very important to me \\
Activities that involve Breaking Bad/Game of Thrones offer me & relaxation when pressures build up \\
& Participating in activities that involve Breaking Bad/Game of Thrones is \\
one of the most satisfying things I do \\
I really enjoy participating in activities which involve Breaking \\
Bad/Game of Thrones \\
\hline I find a lot of my life is organized around activities that involve Breaking \\
Bad/Game of Thrones \\
Activities that involve Breaking Bad/Game of Thrones have a central \\
role in my life \\
I enjoy discussing Breaking Bad/Game of Thrones with my friends \\
Most of friends are in some ways connected in activities related to \\
Breaking Bad/Game of Thrones \\
Participating in activities that involve Breaking Bad/Game of Thrones \\
says a lot about who I am \\
You can tell a lot about people by seeing them participating in activities \\
that involve Breaking Bad/Game of Thrones \\
When I participate in activities that involve Breaking Bad/Game of \\
Thrones I can really be myself \\
When I participate in activities that involve Breaking Bad/Game of \\
Thrones others see me the way I want them to see me \\
\hline \multirow{3}{*}{ Self-expression } \\
\end{tabular}

The items are presented in a matrix format, and measured on a seven-point Likert scale from "strongly agree" (1) to "neither agree nor disagree" (4) to "strongly disagree" (7). 
The Level of Involvement scale further include five items measuring frequency of fandom participation (adapted from Lee, 2007), measured on a seven point scale from "daily or nearly every day" (1) to "never" (7). A question about annual income was removed as it was regarded as irrelevant to the research aims, and due to the demographic characteristics of the sample (participants from multiple countries). Nardi (2018) suggests that participants should not be required to calculate from one currency to another. Lastly, participants are asked one question about future participation in the fandom, measured on a seven-point scale from "extremely likely" (1) to "neither likely nor unlikely" (4) to "extremely unlikely" (7). The second scale is the Moral disengagement scale adapted from Bandura et al. (1996).

\subsection{Moral Disengagement scale}

The Moral Disengagement scale (Appendix C) was adapted from Bandura et al. (1996) to the context of adults in a general/tourism setting, as it was originally developed to measure moral disengagement in children and adolescents (Bandura et al., 1996). It measures participants' attitude towards and proneness to moral disengagement mechanisms in general, whereas the scenarios measure attitudes towards moral disengagement mechanisms as justification for negative behaviour in a screen tourism and fandom specific context. As such, the Moral Disengagement scale is also included as a control measurement, examining whether participants' moral justification of negative behaviour differ between the two contexts. The scale consists of 32 statements (four items measuring each moral disengagement mechanism), presented in a matrix format, and measured on a seven point Likert scale from "strongly agree" (1) to "neither agree nor disagree" (4) to "strongly disagree" (7). Based on concerns raised by the Ethics Committee, some words were changed to appear less violent, e.g. "punch" to "fight".

A seven-point Likert scale was chosen for both scales as seven-point Likert scales have been found to score higher on reliability and validity, as well as allowing for more nuanced responses, compared to Likert scales with fewer categories (Preston \& Colman, 2000). Furthermore, the odd number of categories in a seven-point scale includes a neutral option ("neither agree nor disagree" (4)) (Wakita, Ueshima, \& Noguchi, 2012). A matrix format is used to present scale items, as Nardi (2018) suggests matrix format to be appropriate for scales with multiple items, as it reduces repetition and number of separate questions. 


\subsection{Scenarios}

Six scenarios (three for each fandom) were developed to measure participants' attitude towards and use of moral disengagement mechanisms to justify hypothetical negative tourist behaviour in fandom tourism specific contexts (see Appendix C). These scenarios are based on the examples of negative tourist behaviour identified in the literature review, and are developed by the researcher. The behaviours identified were trespassing private property in order to take pictures, recreating popular scenes by throwing pizza on the Walter White house roof or blocking access to a busy street, and souveniring (see Table 3.4.2).

Table 3.4.2 Overview of scenarios

\begin{tabular}{lll} 
Behaviour & Breaking Bad & Game of Thrones \\
\hline Trespassing & Scenario 1: & Scenario 2: \\
& Entering through locked & Climbing over fence to take \\
& gate to take a picture & picture \\
\hline Souveniring & Scenario 3: & Scenario 3: \\
& Take object to bring & Take object to bring home as a \\
& home as a souvenir & souvenir \\
\hline Scene Recreation & Scenario 2: & Scenario 1: \\
& Throwing pizza on top of & Blocking access on busy street \\
& roof & \\
\hline
\end{tabular}

Thus, Breaking Bad scenario 1 and Game of Thrones scenario 2, and scenario 3 for both fandoms as well as Breaking Bad scenario 2 (throwing pizza) and Game of Thrones scenario 1 (blocking access) are comparable. However, while the impacts of Breaking Bad scenario 2 and Game of Thrones scenario 1 are different, the behaviour is similar, as they both involve recreation of a famous scene. An example of a Breaking Bad scenario is presented in Figure 3.4.2. 


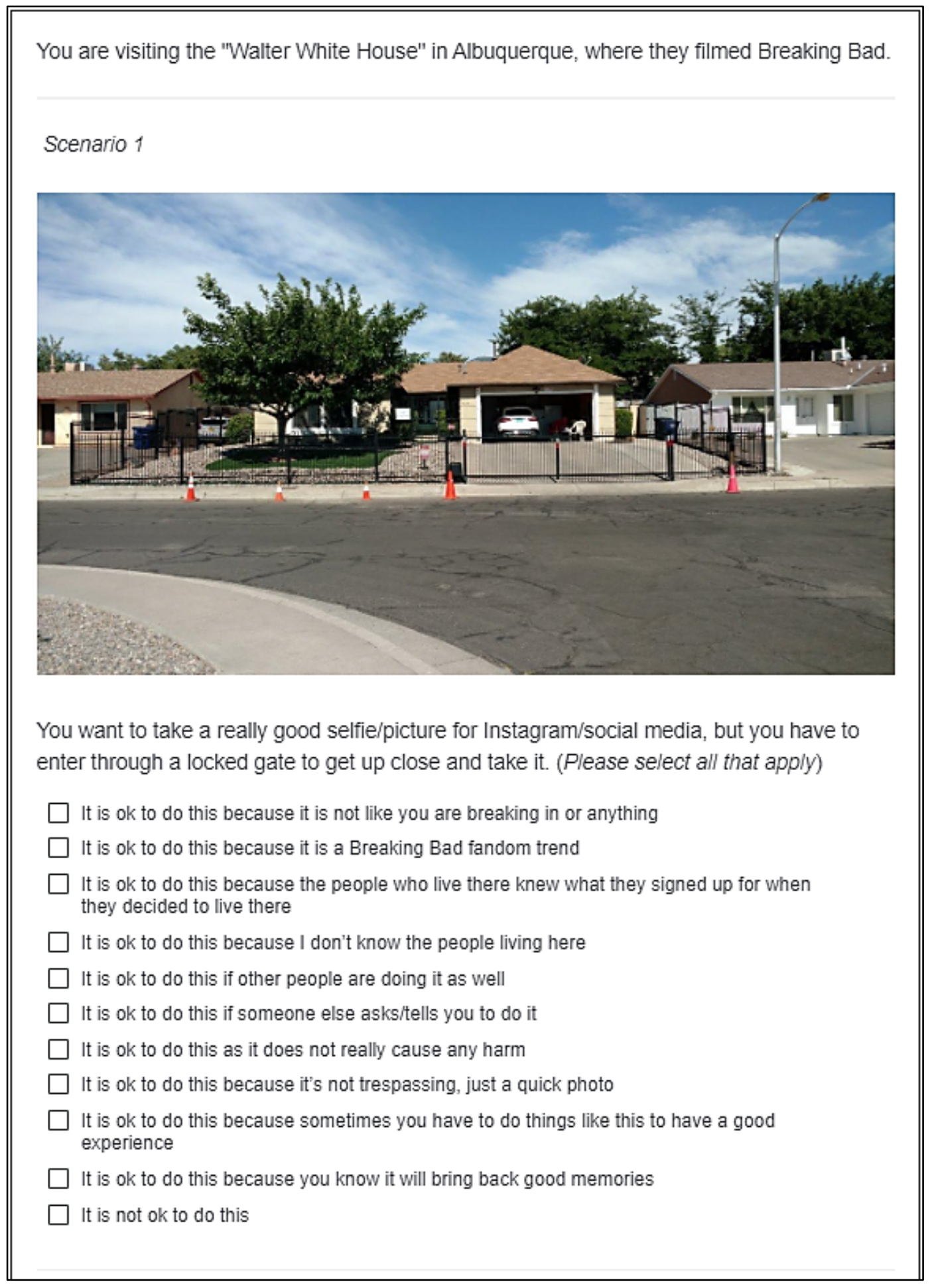

Figure 3.4.1 Example of scenario presented to Breaking Bad fans

Participants are presented with the hypothetical behaviour, and 11 statements justifying participating in the negative behaviour or not. Ten of the statements are based on the moral disengagement mechanisms by Bandura (1986), Sykes and Matza (1957), and Barriga and Gibbs (1996). The last statement is "It is not ok to do this". 
The statements and corresponding moral disengagement mechanisms are presented in Appendix F. The statements are kept as similar across all six scenarios as possible, however, slight variations are made to fit the context of the scenario. Participants are presented with three scenarios related to their fandom based on their response on the fandom identification question earlier in the questionnaire, and are asked to select all the statements they agree with. Four of the scenarios include a picture illustrating the behaviour or the related scene from the TV-series, whereas two scenarios do not include a picture as they were difficult to illustrate or had no related scene in the TV-series.

\subsubsection{Data Collection}

After completing the first questionnaire draft, a pre-test was conducted. According to Nardi (2018), pre-testing is necessary to assess survey flow, clarity, and to check for errors, and response time. The questionnaire was distributed to 15 individuals who matched the sample characteristics (self-identifying as fans of the two TV-series), and received ten complete responses. These participants were asked to provide feedback, and their responses were read over to identify problems obvious from the responses. Feedback were overall positive and only minor changes were suggested, such changing the wording slightly to make the answer alternatives for Q13 more clear. After the pre-test was concluded, the questionnaire was updated and completed, and then distributed for data collection. The participation invitation (Appendix A) was posted in fandom relevant online distribution channels (see Table 3.4 .3 for full list). 
Table 3.4.3 Distribution Channels

\begin{tabular}{|c|c|c|}
\hline Fandom & Distribution channel & Notes \\
\hline \multirow[t]{5}{*}{ Game of Thrones } & https://reddit.com/r/gameofthrones & \\
\hline & https://reddit.com/r/HBOgameofthrones & \\
\hline & https://reddit.com/r/citadel & \\
\hline & https://reddit.com/r/asoiaf & \\
\hline & https://asoiaf.westeros.org/ & \\
\hline \multirow[t]{3}{*}{ Breaking Bad } & https://reddit.com/r/bettercallsaul & \\
\hline & https://www.facebook.com/groups/ & \\
\hline & breakingbadchem & \\
\hline \multirow[t]{11}{*}{ Both } & https://reddit.com/r/samplesize & \\
\hline & https://www.tumblr.com/blog/ & Posted with tags: \\
\hline & fandomtourismresearch & \#breakingbad \\
\hline & & \#breaking bad \\
\hline & & \#walterwhite \#walter \\
\hline & & white \#got \#game of \\
\hline & & thrones \#game of \\
\hline & & thrones HBO max \\
\hline & & $\#$ \# jesse pinkett \#jon \\
\hline & & snow \#el camino \\
\hline & & \#better call saul \\
\hline
\end{tabular}

The invitation post contained brief information about the survey, the researcher, the prize draw and a link to the Qualtrics survey. Moderators were asked for permission before posting invitations (permission was received for all distribution channels except two, where no invitation was posted), and before posting follow-up posts. All invitation posts were deleted after the survey closed. Participants could withdraw from the survey at any stage by exiting the survey, and the survey took 10-15 minutes to complete. The three winners of the prize draw were selected using a random number generator provided by Google.com, and winners were selected and notified via e-mail $17^{\text {th }}$ March 2021. Data collection started $27^{\text {th }}$ January, and ended $12^{\text {th }}$ March.

The next section will discuss the data preparation and data analysis that were conducted in order to meet the research aim and answer the research questions presented in the introduction.

\subsubsection{Data Analysis}

After the data collection was completed, data was statistically analysed using SPSS v26/v27, and SPSS AMOS. 


\subsubsection{Data Preparation}

Before starting data analysis, the dataset was cleaned, and incomplete responses were deleted (Jennings, 2010). First, $n=36$ responses were deleted as they either did not consent to participate, or did not meet sample criteria. A decision was made to only retain and analyse responses that had completed at minimum the Level of Involvement scale. However, responses missing the Moral Disengagement scale were retained. Thus, $n=46$ responses with only completed demographic questions and/or incomplete fandom involvement scale responses were deleted. The complete dataset used for analysis consisted of $n=243$ responses, with $n=207$ complete responses. The 37 incomplete responses had not completed the Moral Disengagement scale.

\subsubsection{Confirmatory Factor Analysis}

As discussed in Section 3.4.3.2.1, twelve items in the questionnaire related to the Level of involvement with the fandom are believed to measure the three constructs (Attraction, Centrality and Self-expression), as found by McIntyre and Pigram (1992). A Confirmatory Factor Analysis (CFA) was used to "identify factors that account for the variation and covariation among a set of indicators" (Brown, 2015, p. 35) for both the Level of Involvement scale and the Moral Disengagement scale. Brown (2015) notes that a strong conceptual and empirical foundation is needed for the specification and evaluation of the CFA (p. 35). Brown (2015) further states that " $[t]$ he acceptability of the specified model is evaluated by goodness of fit and by the interpretability and strength of the resulting parameter estimates" (p. 42).

\section{Level of Involvement scale}

The squared multiple correlations between the twelve Level of Involvement items are given in Table 3.4.4. For each item, these indicate the percentage of variance explained by the latent factor where larger percentages mean the better the item is at measuring the factor. 
Table 3.4.4 Squared Multiple Correlations Level of Involvement scale

\begin{tabular}{cc} 
Item & Estimate \\
\hline Q11_8 & .487 \\
Q11_7 & .008 \\
Q11_6 & .861 \\
Q11_5 & .853 \\
Q11_12 & .603 \\
Q11_11 & .583 \\
Q11_10 & .660 \\
Q11_9 & .802 \\
Q11_4 & .496 \\
Q11_3 & .684 \\
Q11_2 & .484 \\
Q11_1 & .276 \\
\hline
\end{tabular}

Based on the work of McIntyre and Pigram (1992) and Lee (2007), it is expected that these items measure three latent constructs: Attraction (Q11_1-Q11_4), Self-expression (Q11_9-Q11_12) and Centrality (Q11_5-Q11_8) It is noted that Q11_7, "I enjoy discussing [fandom] with my friends" has a very small value, indicating that the predictors of Q11_7 (the Centrality construct) explains just $0.8 \%$ of its variance, so this item has been removed from the CFA. The resulting standardized estimated are given in Figure 3.4.6.

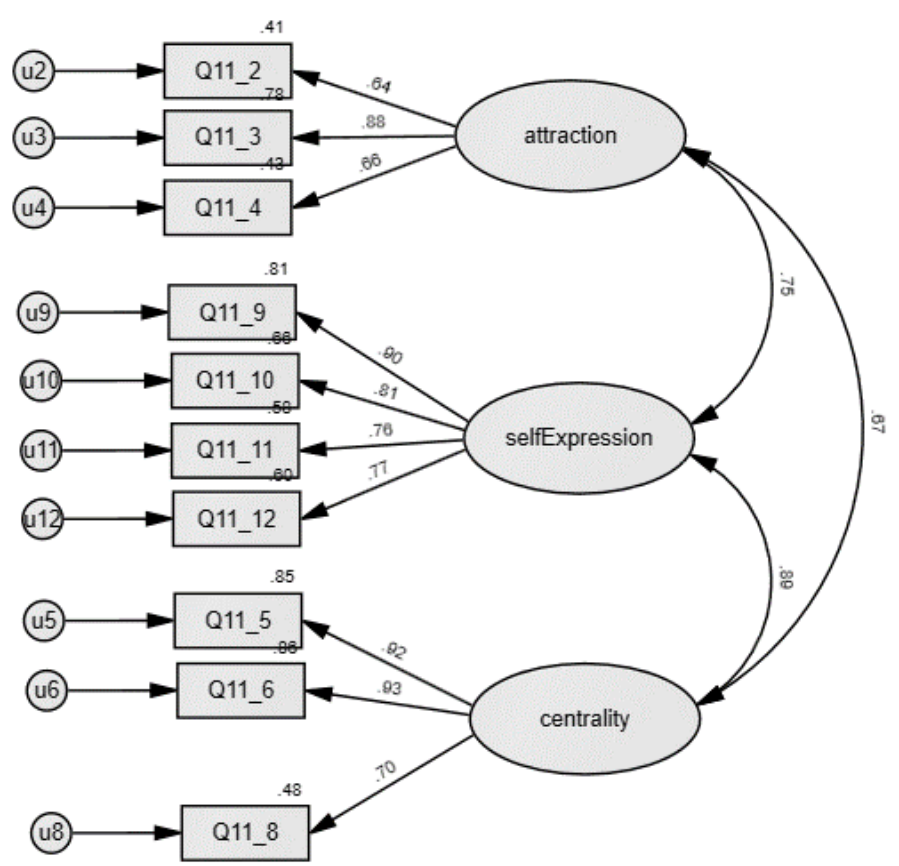

Figure 3.4.2 Standardised estimates for Level of Involvement scale 
The Goodness of fit indices for the three-factor model generally suggest a good fit. The CMIN/DF is $4.197(p<.0005)$, and values between two and five are regarded as indicators of good fit (Marsh \& Hocevar, 1985). The CFI is .927 and the TLI is .902, both are above 0.9 which indicates an adequate fit (Moss, 2016). The Chi-squared is $\chi^{2}(41)=$ $172.087, p<.0005$ which would typically indicate poor fit, however, Moss (2016) states that while the model is most often regarded as unacceptable if the Chi-square is significant, "[...] many researchers disregard this index if both the sample size exceeds 200 or so and other indices indicate the model is acceptable". The sample size for this sample is 243 , thus the sample size might explain the significant chi-squared result. The RMSEA is 0.114 , and according to Lai and Green, (2016) cut-offs for RMSEA yield the following interpretations: values less than .06 suggest a "good" fit, while values between .05 and .10 suggest an "acceptable" fit, and values larger than .10 suggest a "bad" fit (see Lai and Green, 2016, p. 220). Overall, the three-factor model provides an adequate fit and component-based scores were created for the Attraction, Self-expression and Centrality constructs. The scores are moderately correlated (Pearson correlation coefficients from 0.494 to 0.787 ), so they were then combined to create an overall scale for Level of involvement (this will be further discussed in Section 4.2.2 in the upcoming chapter).

\section{Moral Disengagement scale}

Similar to the Level of Involvement scale, the 32 items in the Moral Disengagement scale measure eight constructs identified by Bandura (1986): Moral Justification, Euphemistic Language, Advantageous Comparison, Diffusion of Responsibility, Displacement of Responsibility, Distortion of Consequences, Dehumanization of Victim, and Attribution of Blame. The squared multiple correlation for the 32 Moral Disengagement items are given in Table 3.4.5, below. 
Table 3.4.5 Squared Multiple Correlations Moral Disengagement Scale

\begin{tabular}{lc} 
Item & Estimate \\
\hline Q26_32 & .433 \\
Q26_24 & .761 \\
Q26_16 & .349 \\
Q26_8 & .678 \\
Q26_4 & .336 \\
Q26_12 & .436 \\
Q26_20 & .435 \\
Q26_28 & .651 \\
Q26_31 & .794 \\
Q26_23 & .770 \\
Q26_15 & .747 \\
Q26_7 & .660 \\
Q26_3 & .728 \\
Q26_11 & .531 \\
Q26_19 & .514 \\
Q26_27 & .369 \\
Q26_30 & .822 \\
Q26_22 & .772 \\
Q26_14 & .623 \\
Q26_6 & .351 \\
Q26_2 & .525 \\
Q26_10 & .736 \\
Q26_18 & .687 \\
Q26_26 & .045 \\
Q26_29 & .666 \\
Q26_21 & .591 \\
Q26_13 & .564 \\
Q26_5 & .491 \\
Q26_1 & .076 \\
Q26_9 & .587 \\
Q26_17 & .803 \\
Q26_25 & .379 \\
\hline &
\end{tabular}

Based on the work of Bandura (1986), it is expected that these items measure eight latent constructs: Moral Justification (Q26_1, Q26_9, Q26_17 and Q26_25), Euphemistic Language (Q26_2, Q26_10, Q26_18, And Q26_26), Advantageous Comparison (Q26_3, Q26_11, Q26_19 And Q26_27), Diffusion of Responsibility (Q26_4, Q26_12, Q26_20 And Q26_28), Displacement of Responsibility (Q26_29, Q26_21, Q26_13 And Q26_5), Q26_30, Distortion of Consequences (Q26_22, Q26_14 And Q26_6), Dehumanisation of Victim(Q26_31, Q26_23, Q26_15 And Q26_7) and Attribution of Blame (Q26_32, Q26_24, Q26_16 And Q26_8). It is noted that the Moral Justification construct explains just 7.6\% of the variance in Q26_1, "It is alright to fight to protect your friends", and the Euphemistic Language construct explains just 4.5\% of the variability in Q26_26, "It is 
not a bad thing to 'get high' once in a while" is not highly correlated with Q26_2, Q26_10 and Q26_18. These two items were therefore removed from the CFA. The resulting standardized estimates are given in Figure 3.4.9.

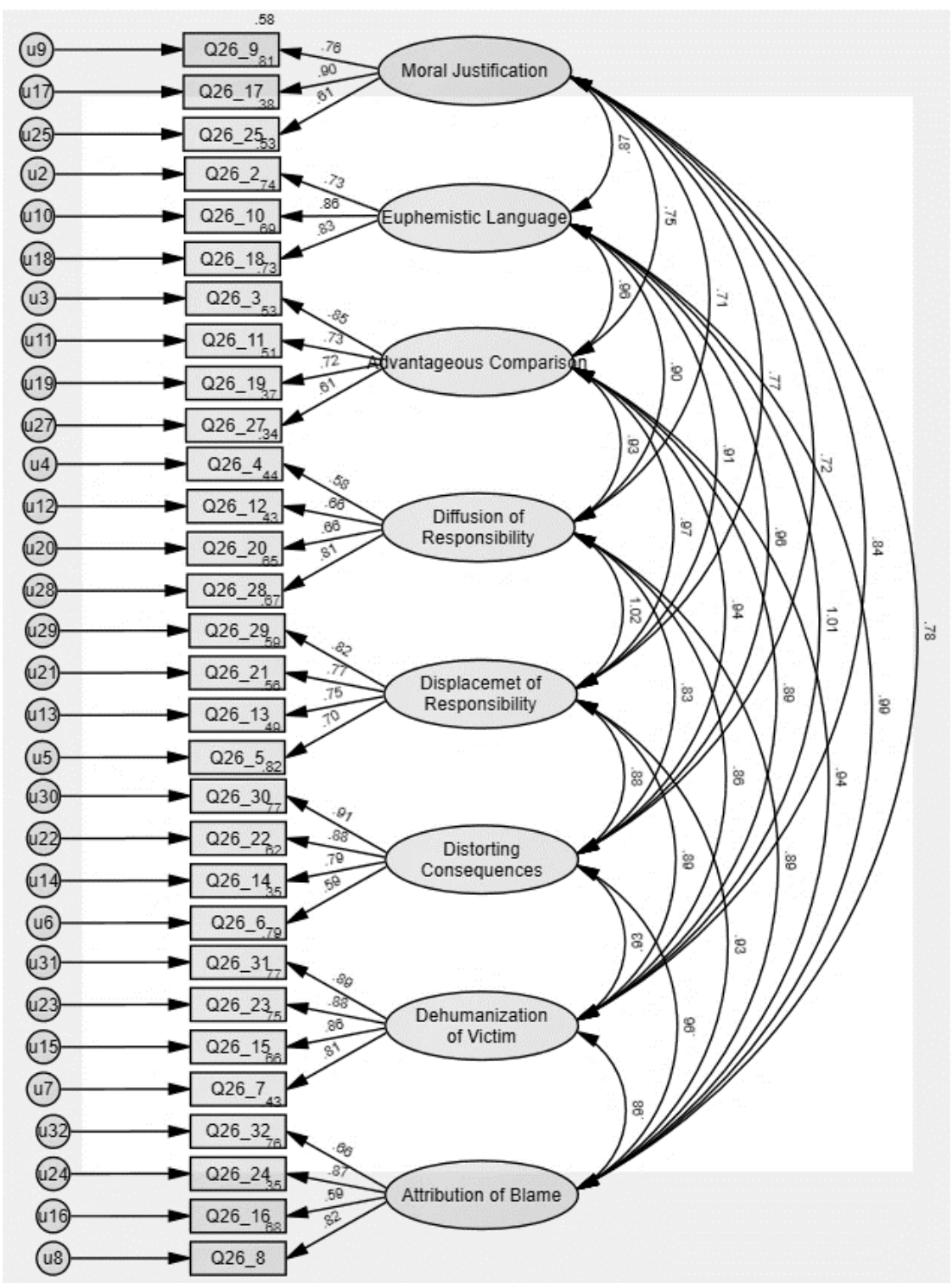

Figure 3.4.3 Standardised estimates Moral Disengagement scale

The Goodness of fit indices for the eight-factor model suggest that the model was an adequate fit, except for the Chi-square and TLI. The CMIN/DF is $2.207(p<.0005)$. The CFI is .910 and the TLI is .889. The Chi-squared is $\chi^{2}(377)=832.199, p<.0005$, and the RMSEA is .070. Overall, the model provides an adequate fit, and component-based scores were created for the eight constructs. The scores are moderately correlated (Pearson correlation coefficients from 0.579 to 0.725 ), so they were then combined to generate an overall scale for moral disengagement. 


\subsubsection{Statistical Tests}

CFA was used to create both the Level of Involvement and Moral Disengagement scales. Level of involvement data and Moral Disengagement scale data are approximately normally distributed; however, equal variances could not be assumed. Thus, Welch's unequal variances t-test and ANOVA have been used consistently in all tests, with Games-Howell post-hoc tests for ANOVA results (Field, 2018). Welch's unequal variances t-test was used to compare Moral Disengagement scale scores between the two fandom groups. Welch's ANOVA was used to compare the Moral Disengagement scale score between the involvement groups, both overall and for each fandom separately. ChiSquared tests were used to determine if there was an association between level of fandom involvement and fandom identification, and a Point-Biserial correlation was used to measure the strength and direction of the association between Moral Disengagement scale (a continuous variable) and selection of moral disengagement mechanisms in scenarios (a dichotomous variable) (Lund Research Ltd., 2018).

\subsubsection{Ethics}

It is important that researchers follow ethical guidelines when conducting research in order to protect the rights of participants and individuals (Jennings, 2010).

This research project received ethics approval by the Victoria University of Wellington Pipitea Human Ethics Committee (\#0000028770) before starting data collection. The guidelines set out by the Human Ethics Committee require informed consent, voluntary participation, acknowledgement of the Treaty of Waitangi, and minimisation of harm, and guidance related to collection and storage of data, anonymity and privacy (Human Ethics Committee, 2018). This research project conforms to these requirements as the survey is anonymous, and there is no connection between participants' survey responses and personal data collected for the prize draw. Participation is voluntary, and all participants are required to be 18 years or older and have to consent to participate, although consent could be withdrawn up until submitting the survey. The data is only accessible by the researcher, supervisor, and is securely stored.

One of the main concerns raised by the Ethics Committee was the potential emotional stress caused by the Moral Disengagement scale due to the violent nature of some statements. It was strongly suggested that participants should be provided with more information about the purpose of the research project, the Moral Disengagement scale, 
and question examples, as well as inclusion of a debrief section. Extra information was provided in the information section, as well as throughout the questionnaire itself. Furthermore, the Ethics Committee required information about free 24/7 mental health support services to be provided. Due to this, participation eligibility was limited to current residents in the United Kingdom, Ireland, The United States, Canada, Australia, and New Zealand, and a link to a website (https://checkpointorg.com/global/) containing information about free 24/7 mental health support services were provided throughout the questionnaire. Participants were encouraged to end the survey and contact support services if experiencing any type of emotional distress. Participants were given the option to skip the Moral Disengagement scale section. Lastly, some words in the Moral Disengagement scale statements were changed to make them appear less violent, e.g. words such as punch, slapping, and shoving were changed to words such as fight and being physical.

\subsection{Methodological Strengths ANd Limitations}

\subsubsection{Strengths}

While this research project takes a fully quantitative approach, the post-positive paradigm is a strength, as it accounts for subjectivity. This is a particular strength in this thesis as it guides the development of the research instrument, the data analysis and the discussion. As the topic (human behaviour) is not easily quantifiable and is likely to be subjective, it is necessary to consider this when interpreting the findings and in the discussion. At the same time, a Post-positivist approach aligns well with a quantitative, structured research instrument, appropriate for collection of larger amounts of data that can be statistically analysed, in order to meet the research aim and answer the research questions. Another strength of this research project is the use of two well-established, existing scales that have been repeatedly tested for reliability and validity in different contexts and settings (Bandura et al, 1996; McIntyre \& Pigram, 1992). These two scales have solid theoretical foundations, in particular the Moral Disengagement theory by Bandura. Combining this theory with two elements from two additional moral justification theories expands the moral justification variable. Furthermore, by including the original Moral Disengagement scale by Bandura et al (1996) as a control variable, the research project is able to explore whether participants' use of moral disengagement mechanisms is context specific or transferable between general and specific contexts and behaviours. In addition to account for fandom as an influencing factor, including the Level of Involvement scale allows for 
creating groups of level of involvement, providing insight into whether level of involvement impact tourists' negative behaviour and use of moral disengagement. The scenarios are based on real life tourist behaviour issues identified in the news media and literature, and while they are specific to the two fandoms that make up the sample population for this research project, the negative tourist behaviours have been found in other contexts. Thus, the findings from this research project can be valuable outside the context of this thesis.

\subsubsection{Limitations}

Two of the main methodological limitations are the time-constraints and limitations of scope that come with postgraduate research, specifically an 8 month timeframe. This influenced methodological choices, in particular those related to sampling and choice of data collection methods (e.g. a quantitative approach instead of qualitative approach, etc.). While a non-probability, purposive sampling technique was deemed appropriate as discussed in Section 3.4.2 about sampling, it does have limitations. First, results are generally not generalizable or representative of the population (Jennings, 2010). Further, participation bias is possible, as individuals are free to decide whether they wish to participate, and the researcher has less control over the sample. As the invitation was distributed via online fandom communities, it is possible that participants opting to participate did not fit the sample criteria, but participated regardless. Related to this is the difference in the two fandoms' willingness to participate. Individuals identifying as Game of Thrones fans were more willing to participate in the research project than those identifying as Breaking Bad fans. Coming in contact with, and getting permission to post invitations in the Breaking Bad related communities proved to be difficult, whereas Game of Thrones communities were more accommodating and eager to participate. This is reflected in the low number of participants identifying as part of the Breaking Bad fandom compared to the Game of Thrones fandom. Next, the questionnaire does not include any open-ended questions, and thus no in-depth data is collected. Open-ended questions or a mixed-method research design would have enriched the research project with more indepth data that could have provided a greater understanding of the topic (Jennings, 2010). 


\subsection{CONCLUSION AND SUMmaRY}

This chapter has outlined the methodological choices guiding the research project. The research project takes a quantitative approach, and is situated within the post-positivist paradigm. A self-administered online survey was distributed to individuals who selfidentify as part of either the Breaking Bad or Game of Thrones fandoms and invitations were posted in different online fandom communities. The survey consisted of two existing scales: Fandom involvement was measured by the Level of Leisure Involvement scale by McIntyre and Pigram (1992), adapted to the context of this research project from an adaptation by Lee (2007), and moral disengagement was measured by the Moral Disengagement scale by Bandura et al. (1996), adapted to adults in a general context. In addition to these two scales, a total of six scenarios were developed based on existing negative tourist behaviours identified in the literature and media. These scenarios explored participants' use of moral disengagement mechanisms in a fandom tourism specific context, whereas the Moral Disengagement scale was included as a control measure to measure use of moral disengagement mechanisms in a more general context. The data was statistically analysed after the data collection ended. The findings from the data analysis will be presented in the next in Chapter 4 . 


\section{FINDINGS}

\subsection{INTRODUCTION}

This upcoming chapter will present findings and results from the data analysis that was conducted on the collected data in order to answer Research Question 1: Do screen tourists use moral disengagement mechanisms to justify negative on-site behaviour?, Research Question 2: Which moral disengagement mechanisms are most frequently used, and Research Question 3: Whether different groups of screen tourists differ in their use of moral disengagement mechanisms. This chapter will first present sample characteristics in Section 4.2, then present findings in Sections 4.3 (research question 1), 4.4 (research question 2) and 4.5 (research question 3 ), and a conclusion and summary in Section 4.6.

\subsection{SAmple Characteristics}

\subsubsection{Demographics}

The demographic characteristics were analysed using descriptive statistics. A full overview of the demographic characteristics is presented in Table 4.2.1.

The majority (72.4\%) of the total 243 participants reported living in the United States of America, and the majority (76.5\%) of participants were between 20 and 34 years old, whereas only $17.3 \%$ were older than 35 . Just over half $(54.7 \%)$ of participants reported identifying as male, $43.6 \%$ identified as female, and $1.6 \%$ reported identifying as another gender. Furthermore, the majority $(68.3 \%)$ of participants completed an undergraduate degree or higher. 
Table 4.2.1 Demographic Characteristics of Participants

\begin{tabular}{|c|c|c|c|}
\hline & & Frequency & $\begin{array}{c}\text { Percent } \\
(\%)\end{array}$ \\
\hline \multicolumn{4}{|c|}{$\begin{array}{l}\text { Current country } \\
\text { of residence } \\
(n=243)\end{array}$} \\
\hline & United States of America & 176 & $72.4 \%$ \\
\hline & United Kingdom & 25 & $10.3 \%$ \\
\hline & Canada & 19 & $7.8 \%$ \\
\hline & Australia & 11 & $4.5 \%$ \\
\hline & New Zealand & 7 & $2.9 \%$ \\
\hline & Ireland & 2 & $0.8 \%$ \\
\hline & Prefer not to say & 3 & $1.2 \%$ \\
\hline \multicolumn{4}{|c|}{$\begin{array}{l}\text { Age Groups } \\
(n=243)\end{array}$} \\
\hline & $18-19$ & 15 & $6.2 \%$ \\
\hline & $20-24$ & 67 & $27.6 \%$ \\
\hline & $25-29$ & 65 & $26.7 \%$ \\
\hline & $30-34$ & 54 & $22.2 \%$ \\
\hline & $35-39$ & 16 & $6.6 \%$ \\
\hline & $40-44$ & 10 & $4.1 \%$ \\
\hline & $45-49$ & 5 & $2.1 \%$ \\
\hline & $50-54$ & 8 & $3.3 \%$ \\
\hline & $60-69$ & 2 & $0.8 \%$ \\
\hline & 70 and older & 1 & $0.4 \%$ \\
\hline \multicolumn{4}{|c|}{$\begin{array}{l}\text { Gender identification } \\
(n=243)\end{array}$} \\
\hline & Male & 133 & $54.7 \%$ \\
\hline & Female & 106 & $43.6 \%$ \\
\hline & Another gender & 4 & $1.6 \%$ \\
\hline \multicolumn{4}{|c|}{$\begin{array}{l}\text { Highest level of } \\
\text { completed education } \\
(n=243)\end{array}$} \\
\hline & No completed education & 4 & $1.6 \%$ \\
\hline & High school graduate & 72 & $29.6 \%$ \\
\hline & Undergraduate degree & 121 & $49.8 \%$ \\
\hline & Postgraduate degree & 36 & $14.8 \%$ \\
\hline & Doctorate & 9 & $3.7 \%$ \\
\hline & Prefer not to say & 1 & $0.4 \%$ \\
\hline Total & & 243 & $100 \%$ \\
\hline
\end{tabular}

Cross tabulation analysis was conducted to better understand the distribution of highest level of education by age group, as almost $80 \%$ of participants reported their highest level of completed education as an undergraduate degree. Findings suggest that the high 
number of participants who reported high school graduate $(29.6 \%)$ or undergraduate degree $(49.8 \%)$ as their highest level of completed education is associated with participants' age group. Over $65 \%$ of the respondents reporting being high school graduates are between 18 and 24 years old, whereas just over $90 \%$ of the participants reporting having completed a postgraduate degree are 25 years or older. Thus, the younger age groups are likely too young to have had the opportunity to complete an undergraduate degree or higher.

\subsubsection{Fandom Identification}

The survey was distributed to both Breaking Bad fan communities and Game of Thrones fan communities. The majority $(66.7 \%, n=162)$ of participants identified as part of the Game of Thrones fandom, whereas the remaining 33.3\% $(n=81)$ identified as part of the Breaking Bad fandom.

In order to answer the research questions, in particular Research Question 3 about whether different groups of screen tourists differ in their use of moral disengagement mechanisms, participants' Level of Involvement scale mean scores were used to create three groups: Highly involved, Moderately involved, and Less involved. Before these groups were created, the CFA results (see Section 3.4.5.2) and Cronbach's Alpha was used to test for internal reliability for both existing scales used in the survey (Tavakol \& Dennick, 2011). Tavakol and Dennick (2011) state that "internal consistency describes the extent to which all the items in a test measure the same concept or construct and hence it is connected to the inter-relatedness of the items within the test" (p. 53). Cronbach's Alpha scores above .75 are considered adequate for research purposes, indicating high levels of correlation between the items (Tavakol \& Dennick, 2011). Cronbach's Alpha for the 12-item Level of Involvement scale was .908, which is considered high for research purposes (Taber, 2018). However, removing item 7 ("I enjoy discussing Breaking Bad/Game of Thrones with my friends") increased Cronbach's Alpha to .916. Furthermore, Cronbach's Alpha for the Centrality subscale/latent factor shows that deleting item 7 will increase Cronbach's Alpha for Centrality from .758 to .880. Item 7 has been found to have low Alpha values in previous research as well (Lee, 2007), and based on the CFA results, Item 7 is thus excluded from the subsequent analysis. 
Individual mean scores were then calculated for the remaining 11 items. Means were first calculated for the three subscales (items for each category (attribution, centrality and selfexpression)), before calculating an overall Level of Involvement scale mean from these three means. De Vaus, (2002, p. 167) recommends trichotomising a variable using a distributional approach as a method of creating groups. This is done by creating a frequency table of the participants' means, then locating the value closest to the cumulative $33 \%$, and assigning the participants in this group to the highly involved group ( $m=1-2.92)$, next step is assigning the means (participants) who falls between the cumulative $33.4 \%$ and $67.2 \%$ to the moderately involved group $(m=2.93-3.89)$, and the remaining mean falling between cumulative $67.3 \%-100 \%$ into the less involved group $(m=3.9-7)$. These three groups roughly corresponds with the scale values.

Table 4.2.2 depicts a cross-tabulation of level of involvement by Fandom identification, presenting the percent of participants within each level of involvement group in each fandom.

Table 4.2.2 Level of Involvement by Fandom Identification cross-tabulation

Level of Involvement * Fandom Identification

\begin{tabular}{llccr}
\hline & & \multicolumn{2}{c}{ Fandom identification } & \\
\cline { 3 - 5 } & & Breaking Bad & Game of Thrones & Total \\
$(n=81)$ & $(n=162)$ & $(n=243)$ \\
\hline \multirow{2}{*}{$\begin{array}{l}\text { Level of } \\
\text { Involvement }\end{array}$} & Highly involved & $46.9 \%$ & $25.9 \%$ & $32.9 \%$ \\
\cline { 2 - 5 } & Moderately involved & $35.8 \%$ & $34.6 \%$ & $35 \%$ \\
\cline { 2 - 5 } & Less involved & $17.3 \%$ & $39.5 \%$ & $32.1 \%$ \\
\hline \multirow{2}{*}{ Total } & & $100.0 \%$ & $100.0 \%$ & $100.0 \%$ \\
\hline
\end{tabular}

While the distribution of participants in total is evenly distributed between the three Level of involvement groups, Table 4.2.2 illustrates the difference between the two fandoms. Almost half of the participants who identify as Breaking Bad fans are highly involved, whereas almost $40 \%$ of the Game of Thrones fans fall in the less involved group. The majority of Breaking Bad fans falls within the moderately to highly involved groups, whereas the majority of the Game of Thrones fans fall within the moderately to less involved groups. A Chi-square test was conducted to determine if there was an association between level of involvement and fandom identification. The relationship between these variables were significant, $\chi^{2}(2, N=243)=15.56, p<.005$. This confirms that 
participants identifying as Breaking Bad fans were significantly more likely to be highly involved than participants who identify as Game of Thrones fans.

In addition to the Level of Involvement items adapted from Lee (2007) and McIntyre and Pigram (1992), the questionnaire included six items measuring the frequency of engaging in fandom activities (see Appendix C). Level of involvement responses were crosstabulated with each of these six items. The overall trend showed that the highly involved participants generally engaged in fandom activities more frequently than moderately and less involved participants.

The following sections will present the findings of the data analysis conducted to answer each of the three research questions presented in Chapter 1, structured by research question. Different statistical tests were used to analyse the collected data, including Welch's unequal variances t-test and ANOVA, and Point-Biserial correlation. 


\subsection{RQ1 "DO SCREEN TOURISTS USE MORAL DISENGAGEMENT MECHANISMS TO JUSTIFY THEIR NEGATIVE ON-SITE BEHAVIOUR?"}

The scenarios were used to investigate whether participants used moral disengagement mechanisms to justify the negative on-site behaviour they were presented with in the questionnaire. Participants were presented with three scenarios specific to their fandom and were asked to select any of the 11 statements they agreed with. As discussed in Chapter 3, the behaviours were comparable between the two fandoms (see Table 4.3.1 below): Breaking Bad scenario 1 and Game of Thrones scenario 2 presented a hypothetical situation where the negative behaviour was trespassing to take a picture for social media, both scenario 3 where the negative behaviour was "souveniring" an object, while Breaking Bad scenario 2 and Game of Thrones scenario 1 involved recreating a scene. Thus, Breaking Bad scenario 1 and Game of Thrones scenario 2, Breaking Bad Scenario 3 and Game of Thrones scenario 3, and finally Breaking Bad scenario 2 and Game of Thrones scenario 1 will be compared and presented together throughout the coming sections.

Table 4.3.1 Overview comparable behaviours in scenarios

\begin{tabular}{lll} 
& Breaking Bad & Game of Thrones \\
\hline Comparable behaviours & $\begin{array}{l}\text { Scenario 1: } \\
\text { Trespassing - Entering through } \\
\text { locked gate to take a picture }\end{array}$ & $\begin{array}{l}\text { Scenario 2: } \\
\text { Trespassing - Climbing over fence } \\
\text { to take a picture }\end{array}$ \\
\hline Comparable behaviours & $\begin{array}{l}\text { Scenario 3: } \\
\text { Souveniring - Take object to bring } \\
\text { home as a souvenir }\end{array}$ & $\begin{array}{l}\text { Scenario 3: } \\
\text { Souveniring - Take object to bring } \\
\text { home as a souvenir }\end{array}$ \\
\hline Comparable behaviours & $\begin{array}{l}\text { Scenario } 2: \\
\text { Recreate scene by throwing pizza } \\
\text { on top of roof }\end{array}$ & $\begin{array}{l}\text { Scenario } 1: \\
\text { Recreate scene by blocking access } \\
\text { on busy street }\end{array}$ \\
\hline
\end{tabular}

Table 4.3.2 below depicts the selection of moral disengagement mechanisms for each scenario per fandom group, and the selection of the statement "It is not ok to do this". The table illustrates the percentage of the participants in each fandom group who selected at least one mechanism or more for each scenario, and the percentage of participants who selected "It is not ok to do this". 
Table 4.3.2 Selection of moral disengagement mechanisms in scenarios

\begin{tabular}{lcccccc} 
& \multicolumn{2}{c}{ Breaking Bad $(\boldsymbol{n}=\mathbf{8 1})$} & \multicolumn{2}{c}{ Game of Thrones $(\boldsymbol{n}=\mathbf{1 6 2})$} \\
\hline & Scenario 1 & Scenario 2 & Scenario 3 & Scenario 1 & Scenario 2 & Scenario 3 \\
\hline $\begin{array}{l}\text { Selected one } \\
\begin{array}{l}\text { mechanism or } \\
\text { more }\end{array}\end{array}$ & $54.32 \%$ & $55.56 \%$ & $66.67 \%$ & $42.60 \%$ & $27.78 \%$ & $46.30 \%$ \\
\hline $\begin{array}{l}\text { Selection of "It is } \\
\text { not ok to do this" }\end{array}$ & $45.68 \%$ & $44.44 \%$ & $33.33 \%$ & $57.41 \%$ & $72.22 \%$ & $53.70 \%$ \\
\hline
\end{tabular}

The results in Table 4.3.2 suggest that mechanisms are used to justify engaging in negative on-site tourist behaviour by both fandoms, to a certain degree. However, the findings suggest that the Breaking Bad group was more likely to select at least one mechanism to justify engaging in negative behaviour for all three scenarios, whereas the Game of Thrones group was less willing to morally justify engaging in negative behaviour, in particular for scenario 2 (trespassing), where the majority selected "It is not ok to do this". Participants from both fandoms were more willing to justify engaging in the souveniring (scenario 3 ).

This section has found that screen tourists do use moral disengagement mechanisms to justify engaging in negative on-site behaviour. The findings further indicate that there are differences in use of mechanisms between the two fandom groups, and also that use of moral disengagement mechanisms might be context specific. However, this section has not looked at the use of the individual mechanisms. Whether some moral disengagement mechanisms are more frequently used than others will be discussed next in Section 4.4. 


\subsection{RQ 2 "WHICH MORAL DISENGAGEMENT MECHANISMS ARE MOST FREQUENTLY USED BY SCREEN TOURISTS TO JUSTIFY THEIR NEGATIVE BEHAVIOUR?"}

The previous section examined whether screen tourists used moral disengagement mechanisms to justify negative on-site behaviour, and the findings suggest that screen tourists do morally justify engaging in negative on-site tourist behaviour. This section will present the findings related to Research Question 2, and examine which moral disengagement mechanisms are most frequently used to justify negative behaviour. First, use of moral disengagement mechanisms in scenarios will be presented, followed by agreement with moral disengagement mechanism statements in the Moral Disengagement scale.

\subsubsection{Moral Disengagement in Scenarios}

This section will first present the total selection of each moral disengagement mechanism for all six scenarios, before presenting comparisons for the two scenarios where participants were presented with the behaviour trespassing, followed by the scenarios involving souveniring, before presenting the findings for scene recreation. Table 4.4.1 presents the total selection of each moral disengagement mechanism, for all six scenarios combined. Each participant was shown three scenarios, and could therefore have selected each mechanism at least three times. Thus, the findings present the percent of participants who selected the given mechanism at least once. The results are presented in percent, and sorted from most to least selected. These findings suggest that some moral disengagement mechanisms were more frequently used than others to justify engaging in negative onsite behaviour. The three most selected mechanisms are Distortion of consequences, Attribution of Blame and Euphemistic Language, selected in at least once scenario by $36.2 \%, 30 \%$, and $26.3 \%$, respectively. The least selected mechanism, Advantageous Comparison, was selected by about half as many respondents as Distortion of consequences. 
Table 4.4.1 Selection of moral disengagement mechanisms in scenarios, total

\begin{tabular}{lr} 
Moral Justification Mechanism & Total \% \\
\hline Distortion of consequences & $36.2 \%$ \\
\hline Attribution of blame & $30.0 \%$ \\
\hline Euphemistic language & $26.3 \%$ \\
\hline Dehumanisation of victim & $22.2 \%$ \\
\hline Displacement of responsibility & $21.8 \%$ \\
\hline Moral justification & $21.0 \%$ \\
\hline Diffusion of responsibility & $19.8 \%$ \\
\hline Appeal to higher loyalties & $18.9 \%$ \\
\hline Primary Self-serving cognitive distortions & $18.5 \%$ \\
\hline Advantageous comparison & $16.0 \%$ \\
\hline
\end{tabular}

Note: Sorted from most to least selected mechanism

The following sections will look at the use of justification mechanisms per behaviour; first trespassing across fandoms, then souveniring across fandoms, followed by recreation of scenes.

\section{Negative behaviour: Trespassing}

The findings presented in Table 4.4.2 present the selection of mechanisms for trespassing. The findings suggest that Breaking Bad fans are more likely to justify trespassing in order to take a picture for social media compared to Game of Thrones fans, where almost $80 \%$ of the participants in the Game of Thrones group selected "It is not ok to do this" compared to just under half of the Breaking Bad group. Attribution of Blame is the most used mechanism to justify trespassing for both groups, followed by Displacement of Responsibility and Euphemistic Language in the Breaking Bad group, and Advantageous Comparison and Dehumanisation of Victim in the Game of Thrones group. Primary selfserving cognitive distortions is the least selected mechanism by both groups. The overall total selection of mechanisms for this behaviour follow the same pattern as for the Breaking Bad group, with over $60 \%$ selecting "It is not ok to do this", and Attribution of Blame the most selected, followed by Euphemistic Language. 
Table 4.4.2 Selection of moral disengagement mechanisms - Trespassing

Breaking Bad Scenario 1/ Game of Thrones Scenario 2

Fandom

Total

\begin{tabular}{lrrr} 
Moral Justification Mechanism & $\begin{array}{r}\mathrm{BB} \\
(n=81)\end{array}$ & $\begin{array}{r}\text { GoT } \\
(n=162)\end{array}$ & $(n=243)$ \\
\hline Advantageous comparison & $12.35 \%$ & $8.02 \%$ & $9.47 \%$ \\
\hline Appeal to higher loyalties & $13.58 \%$ & $6.79 \%$ & $9.05 \%$ \\
\hline Attribution of blame & $32.10 \%$ & $12.96 \%$ & $19.34 \%$ \\
\hline Dehumanisation of victim & $8.64 \%$ & $8.02 \%$ & $8.23 \%$ \\
\hline Diffusion of responsibility & $11.11 \%$ & $2.47 \%$ & $5.35 \%$ \\
\hline Displacement of responsibility & $17.28 \%$ & $4.32 \%$ & $8.64 \%$ \\
\hline Distortion of consequences & $12.35 \%$ & $6.79 \%$ & $8.64 \%$ \\
\hline Euphemistic language & $17.28 \%$ & $6.17 \%$ & $9.88 \%$ \\
\hline Moral justification & $9.88 \%$ & $6.17 \%$ & $7.41 \%$ \\
\hline Primary Self-serving cognitive distortions & $7.41 \%$ & $2.47 \%$ & $4.12 \%$ \\
\hline It is not ok to do this & $45.68 \%$ & $77.22 \%$ & $63.37 \%$ \\
\hline
\end{tabular}

Note: The three most selected are highlighted in yellow

\section{Negative behaviour: Souveniring}

A similar trend is found for justifying engaging in souveniring, presented in Table 4.4.3. Participants identifying as part of the Breaking Bad fandom are more likely to justify engaging in souveniring than those identifying as Game of Thrones fans. However, both fandom groups seem to be more willing to engage in this behaviour compared to trespassing (Table 4.4.2). The most selected mechanism for both groups is Distortion of consequences, whereas the Breaking Bad group is more likely to use mechanisms such as Displacement and Diffusion of Responsibility and Euphemistic Language to justify this behaviour compared to the Game of Thrones group where these are some of the least selected mechanisms. The second selected mechanism by Game of Thrones fans is Dehumanisation of victim, similar to the previous scenario. However, this group's third most selected mechanism to justify souveniring is Primary self-serving cognitive distortions, which was one of the two least selected mechanisms for trespassing. For this behaviour overall, the majority with almost half of the respondents selected "It is not ok to do this", and the most selected mechanism follows the same pattern as both fandom groups, with Distortion of consequences. 
Table 4.4.3 Selection of moral disengagement mechanisms - "Souveniring"

Breaking Bad Scenario 3/ Game of Thrones Scenario 3
Fandom

\begin{tabular}{lrrr}
\multicolumn{1}{c}{$\begin{array}{c}\text { Breaking Bad Scenario 3/ } \\
\text { Game of Thrones Scenario 3 }\end{array}$} & BB & GoT & Total \\
\cline { 2 - 4 } Moral Justification Mechanism & $(n=81)$ & $(n=162)$ & $(n=243)$ \\
\hline Advantageous comparison & $11.11 \%$ & $8.64 \%$ & $9.47 \%$ \\
\hline Appeal to higher loyalties & $16.05 \%$ & $6.17 \%$ & $9.47 \%$ \\
\hline Attribution of blame & $22.22 \%$ & $11.11 \%$ & $14.81 \%$ \\
\hline Dehumanisation of victim & $13.58 \%$ & $13.58 \%$ & $13.58 \%$ \\
\hline Diffusion of responsibility & $23.46 \%$ & $4.32 \%$ & $10.70 \%$ \\
\hline Displacement of responsibility & $16.05 \%$ & $4.94 \%$ & $8.64 \%$ \\
\hline Distortion of consequences & $33.33 \%$ & $19.14 \%$ & $23.87 \%$ \\
\hline Euphemistic language & $17.28 \%$ & $3.70 \%$ & $8.23 \%$ \\
\hline Moral justification & $9.88 \%$ & $8.02 \%$ & $8.64 \%$ \\
\hline Primary Self-serving cognitive distortions & $18.52 \%$ & $11.73 \%$ & $13.99 \%$ \\
\hline It is not ok to do this & $33.33 \%$ & $53.70 \%$ & $46.91 \%$ \\
\hline
\end{tabular}

Note: The three most selected are highlighted in yellow

\section{Negative behaviour: Scene recreation}

Just over $40 \%$ of the Breaking Bad fans were not willing to engage in the negative behaviour they were presented with in this scenario, compared to almost $60 \%$ of the Game of Thrones fans (see Table 4.4.4 below). Similar to trespassing (Table 4.4.2), the most selected mechanism for this behaviour is Attribution of Blame, followed by Diffusion of responsibility, and Euphemistic Language for the Breaking Bad group, whereas Euphemistic Language and Moral justification are the second and third most selected by the Game of Thrones group. The two least selected justifications are Primary self-serving cognitive distortions and Advantageous Comparison.

Table 4.4.4 Selection of moral disengagement mechanisms - Recreation

Breaking Bad Scenario 2/ Game of Thrones Scenario 1

\begin{tabular}{lrrr} 
Moral Justification Mechanism & $\begin{array}{r}\text { BB } \\
(n=81)\end{array}$ & $\begin{array}{r}\text { GoT } \\
(n=162)\end{array}$ & $(n=243)$ \\
\hline Advantageous comparison & $6.17 \%$ & $4.32 \%$ & $4.94 \%$ \\
\hline Appeal to higher loyalties & $16.5 \%$ & $9.26 \%$ & $11.52 \%$ \\
\hline Attribution of blame & $24.69 \%$ & $19.14 \%$ & $20.99 \%$ \\
\hline Dehumanisation of victim & $13.58 \%$ & $5.56 \%$ & $8.23 \%$ \\
\hline Diffusion of responsibility & $20.99 \%$ & $9.26 \%$ & $13.17 \%$ \\
\hline Displacement of responsibility & $14.81 \%$ & $11.11 \%$ & $12.35 \%$ \\
\hline Distortion of consequences & $12.35 \%$ & $14.2 \%$ & $13.58 \%$ \\
\hline Euphemistic language & $17.28 \%$ & $17.28 \%$ & $17.28 \%$ \\
\hline Moral justification & $16.05 \%$ & $15.43 \%$ & $15.64 \%$ \\
\hline Primary Self-serving cognitive distortions & $8.64 \%$ & $6.17 \%$ & $7 \%$ \\
\hline It is not ok to do this & $44.44 \%$ & $57.41 \%$ & $53.09 \%$ \\
\hline
\end{tabular}




\section{$\underline{\text { Summary }}$}

These findings indicate that the frequency with which the different moral disengagement mechanisms are used differ between scenarios/behaviours, and also differ between the two fandoms. Attribution of Blame, Distortion of consequences, and Euphemistic Language are three of the most used mechanisms. The findings suggest that participants who identify as Breaking Bad fans are generally more willing to engage in the behaviour they were presented with, and use different mechanisms to justify the behaviour they are presented with. The findings also suggest that the least used justification mechanisms vary between the different behaviours. For example, Primary self-serving cognitive distortions is one of the least selected by both fandom groups to justify trespassing, and recreating scenes, but is more frequently used to justify engaging in souveniring. This section has presented findings related to the six scenarios. The upcoming section will present the findings related to which moral disengagement mechanisms were most frequently agreed with in the Moral Disengagement scale.

\subsubsection{Moral Disengagement Scale}

The Moral Disengagement scale was included in the questionnaire as a "control variable" to examine whether participants' use of moral disengagement mechanisms were fandom/screen tourism context specific or not. This section will first briefly outline the Moral Disengagement scale, then present the mean scores for each category, before presenting the results from a Point-Biserial correlation analysis. Participants were presented with 32 statements in the Moral Disengagement scale section of the questionnaire (see Appendix C), and were asked to indicate the degree to which they agreed or disagreed with each statement on a Likert-scale ( 1 - Strongly agree, 4 - Neither agree nor disagree, 7 - Strongly disagree). The 32 items correspond to the eight moral disengagement mechanisms discussed in the literature review (Table 2.3.1). In order to create the Moral Disengagement scale, CFA was used to confirm the latent structure (see Section 3.4.5.2), and Cronbach's Alpha was used to test for internal reliability (Tavakol \& Dennick, 2011). Cronbach's alpha for the 32-item Moral Disengagement scale was .97, which is considered high for research purposes (Taber, 2018). However, Cronbach's Alpha for each subscale/latent factor show that deleting item 1 ("It is alright to fight to protect your friends") will increase Cronbach's Alpha for Moral Justification from .749 to .801. Furthermore, deleting item 26 ("It is not a bad thing to 'get high" once in a while" 
will increase Cronbach's Alpha for Euphemistic Language from .706 to .847. Based on these results and CFA results, items 1 and 26 were excluded from the subsequent analysis.

Mean scores calculated for each of the eight categories, allowing for examining which mechanisms participants agreed with the most. Table 4.4.6 illustrates the mean Moral Disengagement scores for each category of mechanisms. A lower mean indicates that participants are more likely to agree with using this mechanism to justify engaging in negative behaviour. The mean scores presented in the table suggest that there are differences regarding which mechanisms are most agreed with. Moral justification related mechanisms were agreed with most strongly $(M=4.39), .86$ lower than Dehumanisation of Victim, which is the least agreed with mechanism. Moral justification is also one of the more selected mechanisms for scenarios overall (Table 4.3.2), but is less frequently used as disengagement mechanism when looking at use of moral disengagement mechanisms in the scenarios individually. However, it is worth noting that while there are differences in the mean scores, all means range from "Neither agree nor disagree (4)" to just over "Somewhat disagree (5)", thus none are very strongly agreed with.

Table 4.4.5 Moral Disengagement scale mean scores, categories

\begin{tabular}{lcccccc} 
& Total & \multicolumn{3}{c}{ BB } & \multicolumn{2}{c}{ GoT } \\
Moral Disengagement Mechanism & $M$ & Total & $M$ & BB & $M$ & GoT \\
$(n=207)$ & $S D$ & $(n=66)$ & $S D$ & $(n=141)$ & $S D$ \\
\hline Advantageous Comparison & 5.01 & 1.45 & 4.42 & 1.55 & 5.28 & 1.32 \\
\hline Attribution of Blame & 4.88 & 1.34 & 4.36 & 1.55 & 5.12 & 1.31 \\
\hline Dehumanisation of Victim & 5.25 & 1.39 & 4.73 & 1.81 & 5.49 & 1.53 \\
\hline Diffusion of responsibility & 4.55 & 1.46 & 4.20 & 1.46 & 4.72 & 1.25 \\
\hline Displacement of Responsibility & 4.75 & 1.43 & 4.22 & 1.52 & 5.00 & 1.26 \\
\hline Distortion of consequences & 4.88 & 1.45 & 4.41 & 1.56 & 5.10 & 1.36 \\
\hline Euphemistic Language & 5.10 & 1.52 & 4.55 & 1.59 & 5.35 & 1.41 \\
\hline Moral Justification & 4.39 & 1.66 & 3.93 & 1.43 & 4.60 & 1.41 \\
\hline
\end{tabular}

Note: Lowest mean (most agreeable) = green, highest mean (least agreeable) = yellow

Whether participants' use of moral disengagement mechanisms was tourism context specific was tested by using Point-Biserial correlation. Point-Biserial correlation is a version of Pearson's product-moment correlation that measures strength and direction of the association between a continuous and a dichotomous variable (Lund Research Ltd., 2018). The effect size is considered strong if $r= \pm .50$, and the relationship can be either negative (from -1 to 0 ) or positive (from 0 to 1 ) (LeBlanc \& Cox, 2017). Here, it is used 
to compare participants' selection of the "It is not ok to do this" statement in scenarios to their Moral Disengagement scale mean scores, within each fandom group. This examines whether there is a correlation between participants' selection of the statement "It is not ok to do this" in the scenarios and their agreement with Moral Disengagement scale statements. A significant, positive, moderate to strong relationship between selecting "It is not ok to do this" for each scenario and Moral Disengagement scale mean scores was found for all scenarios in both fandom groups (see Table 4.4.7), i.e. participants who selected "It is not ok to do this" had higher Moral Disengagement scale mean scores.

Table 4.4.6 Point-Biserial correlation results

Point-Biserial Correlations

\begin{tabular}{|c|c|c|c|c|c|c|}
\hline $\begin{array}{l}\text { Moral Disengagement Scale Mean } \\
\text { scores }\end{array}$ & $\begin{array}{c}\text { Breaking } \\
\text { Bad } \\
\text { Scenario } 1 \\
\text { "It is not } \\
\text { ok to do } \\
\text { this" } \\
\end{array}$ & $\begin{array}{c}\text { Breaking } \\
\text { Bad } \\
\text { Scenario } 2 \\
\text { "It is not } \\
\text { ok to do } \\
\text { this" } \\
\end{array}$ & $\begin{array}{c}\text { Breaking } \\
\text { Bad } \\
\text { Scenario } 3 \\
\text { "It is not } \\
\text { ok to do } \\
\text { this" } \\
\end{array}$ & $\begin{array}{c}\text { Game of } \\
\text { Thrones } \\
\text { Scenario } 1 \\
\text { "It is not } \\
\text { ok to do } \\
\text { this" }\end{array}$ & $\begin{array}{c}\text { Game of } \\
\text { Thrones } \\
\text { Scenario } 2 \\
\text { "It is not } \\
\text { ok to do } \\
\text { this" } \\
\end{array}$ & $\begin{array}{c}\text { Game of } \\
\text { Thrones } \\
\text { Scenario } 3 \\
\text { "It is not } \\
\text { ok to do } \\
\text { this" }\end{array}$ \\
\hline $\begin{array}{l}\text { Point-Biserial } \\
\text { Correlation }\end{array}$ & .755 & .727 & .619 & .644 & .721 & .572 \\
\hline Sig. (2-tailed) & $<.001 * *$ & $<.001 * *$ & $<.001 * *$ & $<.001 * *$ & $<.001 * *$ & $<.001 * *$ \\
\hline $\mathrm{N}$ & 66 & 66 & 66 & 141 & 141 & 141 \\
\hline
\end{tabular}

**. Correlation is significant at the 0.01 level (2-tailed).

The positive relationship suggests that participants who were less likely to use moral disengagement mechanisms to justify fandom tourism specific behaviour (participants who selected "It is not ok to do this") were also less likely to use moral disengagement mechanisms to justify engaging in negative behaviour in general, as higher Moral Disengagement scale mean scores suggest that the individual is less likely to justify negative behaviour using moral disengagement mechanisms. This suggests that participants' use of moral disengagement mechanisms is not context specific.

\subsubsection{Summary}

The findings in this section suggest that some moral disengagement mechanisms are more frequently used than others. In particular, Attribution of Blame, Distortion of Consequences and Euphemistic Language are three of the most selected mechanisms overall, for justifying negative tourism-specific behaviour, and negative behaviour in general, whereas the least selected mechanisms varied between the different 
behaviours/scenarios. A Point-Biserial correlation analysis found a significant, positive, correlation between participants' use of moral disengagement mechanisms in both fandom tourism contexts and in general, suggesting that use of moral disengagement mechanisms to justify negative behaviour is not context specific. Instead, participants' use of moral disengagement mechanisms translates from a general context to a fandom tourism specific context. Furthermore, the findings presented in this section suggest there is a difference in the two fandoms' use of moral disengagement mechanisms in scenarios. The next section will present the findings examining whether groups of screen tourists differ in their use of moral disengagement mechanisms. 


\subsection{RQ3 “DO DIFFERENT GROUPS OF SCREEN TOURISTS DIFFER IN THEIR USE OF MORAL DISENGAGEMENT MECHANISMS?"}

The findings presented in the two previous sections suggest that screen tourists use moral disengagement mechanisms to justify engaging in negative behaviour, and that some mechanisms are more frequently used than others. The findings in Section 4.4 indicate that the two groups differ in their use of mechanisms, which is the focus of research question 3. This section examines whether different groups of screen tourists differ in their use of moral disengagement mechanisms, and if so, how. These groups include level of fandom involvement, fandom identification, gender identification and age group. Welch's ANOVA tests and independent sample t-tests were used to test for differences in Moral Disengagement scale mean scores between the three level of involvement groups, and for Moral Disengagement scale mean scores difference in involvement groups for each fandom separately. As discussed in Chapter 3, although Level of involvement data and Moral Disengagement scale data are approximately normally distributed, equal variances could not be assumed. Thus, Welch's unequal variances t-test and ANOVA have been used consistently in all tests (Field, 2018), with Games-Howell post-hoc test for further analysis of ANOVA results (Field, 2018).

\subsubsection{Moral Disengagement Mechanisms x Level of Fandom Involvement}

Welch's ANOVA was used to test for differences in the three involvement groups' Moral Disengagement scale mean scores. Analysis of variance showed a statistically significant difference at the $\mathrm{p}<.05$ level in Moral Disengagement scale mean scores for the three involvement groups: $F(2,119.839)=28.96, p<.001$. Post-hoc comparisons using the Games-Howell test indicated that the mean score for the highly involved fan group $(M=$ $3.90, S D=1.49)$ was significantly different from the moderately involved fan group $(M$ $=5.07, S D=1.12)$ and the less involved fan group $(M=5.86, S D=.71)$. No difference was found between the moderately involved fan group and the less involved fan group. Thus, level of fandom involvement has an impact on use of moral disengagement mechanisms, as highly involved fans were more likely to agree with Moral Disengagement scale statements, i.e. were more likely justify negative behaviour using moral disengagement mechanisms, compared to participants who were moderately or less involved in their fandom. 
The upcoming section will present the findings related to differences in the two fandoms' use of moral disengagement mechanism in scenarios compared to Moral Disengagement scale responses.

\subsubsection{Moral Disengagement Mechanisms x Fandom Identification}

Differences in use of moral disengagement mechanisms between the two fandom groups were examined for both the Scenarios and the Moral Disengagement scale mean scores. Frequencies were used to compare the overall selection of each moral disengagement mechanism across the three scenarios per fandom, and a Welch's t-test was used to test for statistical difference between the two fandom groups' Moral Disengagement scale mean scores. A Welch's t-test showed a statistically significant difference between the two fandom groups and their Moral Disengagement scale scores. The 62 Breaking Bad fans $(M=4.35, S D=1.43)$ scored significantly lower on the Moral Disengagement scale compared to the 141 Game of Thrones fans $(M=5.08, S D=1.17), t(107.020)=-3.602$, $p<.001$ (two-tailed). This confirms that Breaking Bad fans $(M=4.35)$ were significantly more likely to justify engaging in negative behaviour using moral disengagement mechanisms compared to Game of Thrones fans $(M=5.08)$, as a lower mean corresponds to being more agreeable to justifying a behaviour with a moral disengagement mechanism.

Figure 4.5.1 below depicts the overall selection of each moral disengagement mechanism across all three scenarios for each fandom. This is calculated by the total respondents in each fandom who selected each mechanism at least once. The findings suggest that the two groups differ in their justification of engaging in the negative on-site behaviour they were presented with in the scenarios. Breaking Bad fans appear more likely to use moral disengagement mechanisms to justify engaging in such behaviour compared to Game of Thrones fans. The most selected mechanism by both groups is Distortion of Consequences followed by Attribution of Blame, which aligns with previous findings. However, the two fandom groups differ in their use of some of the mechanisms, such as Appeal to higher loyalties and Diffusion and Displacement of responsibilities, where the Breaking Bad group has selected these mechanisms around twice as much as the Game of Thrones group. 


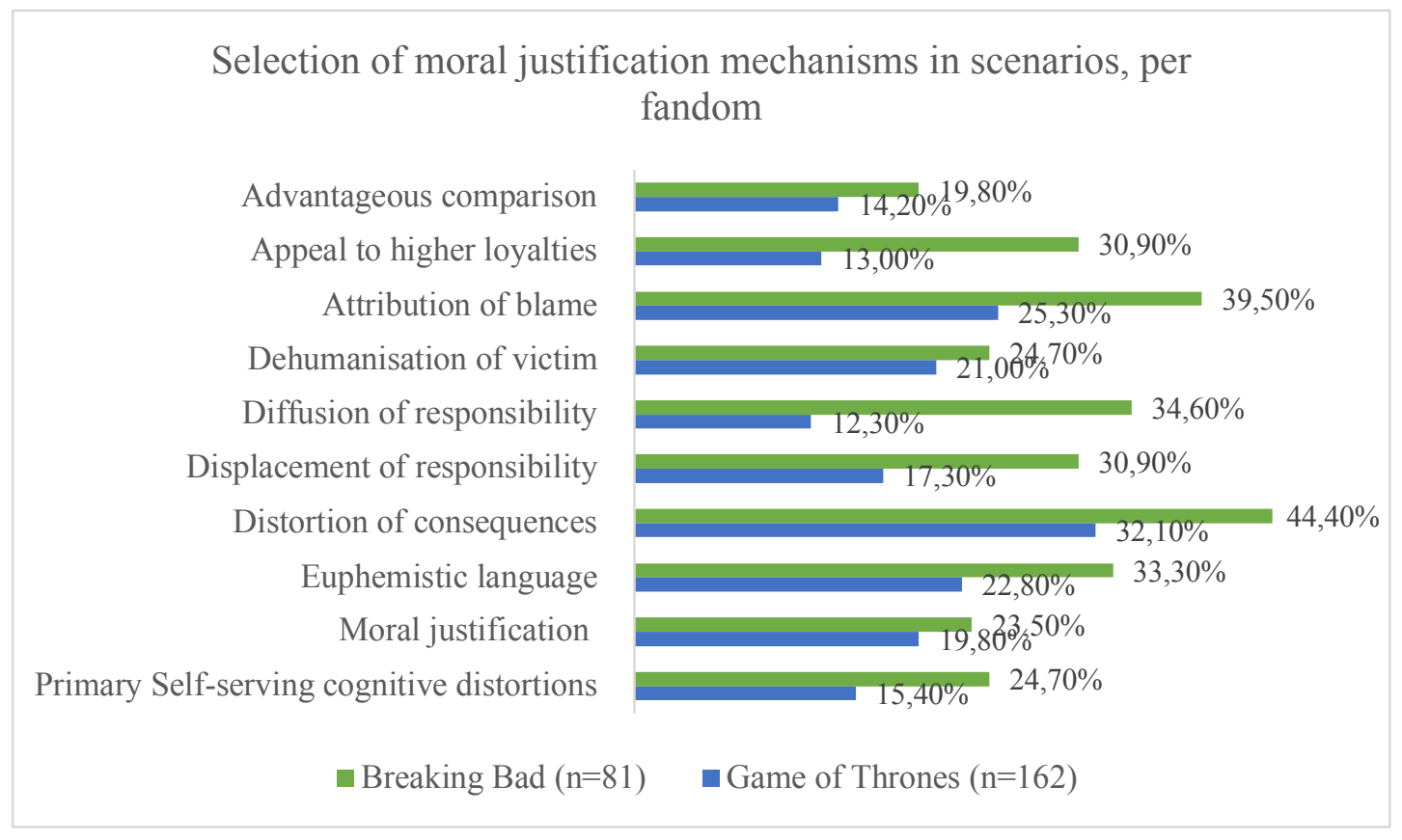

Figure 4.5.1 Selection of moral disengagement mechanisms in scenarios, per fandom

These findings suggest that participants were more likely to use moral disengagement mechanisms to justify negative behaviour in the tourism specific context compared to the general context they were presented with in the Moral Disengagement scale. However, overall, the patterns are similar, as Breaking Bad fans are more likely to use moral disengagement mechanisms in both contexts (both in scenarios and in the Moral Disengagement scale)

\subsubsection{Moral Disengagement, Fandom Identification and Level of Involvement} Use of moral disengagement mechanisms within each level of involvement group in scenarios were examined for each fandom, by using frequencies. As discussed previously, Breaking Bad scenario 1 is compared with Game of Thrones scenario 2, Breaking Bad scenario 3 and Game of Thrones scenario 3 are also compared, and Breaking Bad scenario 2 and Game of Thrones scenario 1 are compared (Section 4.5.3.1). An Analysis of variance was used to analyse differences in use of moral disengagement mechanisms between the involvement groups, in the two fandom groups separately (Section 4.5.3.2), and for the two demographic variables (Section 4.5.4). 


\subsubsection{Impact of Level of Involvement and Fandom Identification on Scenarios}

This section will first present the findings related to the impact of level of involvement and fandom identification on the behaviour trespassing, followed by the behaviour souveniring, followed by scene recreation.

\section{Negative behaviour: Trespassing}

Table 4.5.1 below presents the selection of moral disengagement mechanisms by each involvement group by both fandom groups for the behaviour trespassing. Both highly involved groups are more likely to justify engaging in trespassing, compared to the moderately and less involved groups. However, the highly involved Breaking Bad group seems to be more willing to engage in trespassing private property. While around $20 \%$ and $40 \%$ of the highly involved participants from both fandoms were not willing to engage in this behaviour, over $90 \%$ of both the less involved Breaking Bad and Game of Thrones fans selected "It is not ok to do this". Similar to previous findings, Attribution of Blame is one of the most selected mechanisms for all groups except the less involved Game of Thrones group. While the level of involvement groups differ from each other, the two fandom groups within the same level of involvement also differ. In the highly involved group, Breaking Bad fans selected mechanisms such as Diffusion and Displacement of responsibility, two of the least selected mechanisms by the highly involved Game of Thrones group.

Table 4.5.1 Moral disengagement mechanisms $x$ fandom identification $x$ level of involvement, trespassing

\begin{tabular}{lcccccc}
\hline $\begin{array}{l}\text { Breaking Bad S1/ } \\
\text { Game of Thrones S2 } \\
\text { Trespassing }\end{array}$ & \multicolumn{2}{c}{ Level of Involvement } \\
\cline { 2 - 7 } & Highly Involved & Moderately Involved & Less Involved \\
\hline Moral Justification Mechanism & $\begin{array}{c}\text { BB } \\
(\boldsymbol{n}=\mathbf{3 8})\end{array}$ & $\begin{array}{c}\text { GoT } \\
(\boldsymbol{n}=\mathbf{4 2})\end{array}$ & $\begin{array}{c}\text { BB } \\
(\boldsymbol{n}=\mathbf{2 9})\end{array}$ & $\begin{array}{c}\text { GoT } \\
(\boldsymbol{n}=\mathbf{5 6})\end{array}$ & $\begin{array}{c}\text { BB } \\
(\boldsymbol{n}=\mathbf{1 4})\end{array}$ & $\begin{array}{c}\text { GoT } \\
(\boldsymbol{n}=\mathbf{6 4})\end{array}$ \\
\hline Advantageous comparison & $18.42 \%$ & $16.67 \%$ & $10.34 \%$ & $8.93 \%$ & $0 \%$ & $1.56 \%$ \\
\hline Appeal to higher loyalties & $21.05 \%$ & $19.05 \%$ & $10.34 \%$ & $5.36 \%$ & $0 \%$ & $0 \%$ \\
\hline Attribution of blame & $50 \%$ & $30.95 \%$ & $20.69 \%$ & $12.50 \%$ & $7.14 \%$ & $1.56 \%$ \\
\hline Dehumanisation of victim & $7.89 \%$ & $23.81 \%$ & $13.79 \%$ & $5.36 \%$ & $0 \%$ & $0 \%$ \\
\hline Diffusion of responsibility & $18.24 \%$ & $7.14 \%$ & $6.90 \%$ & $0 \%$ & $0 \%$ & $1.56 \%$ \\
\hline Displacement of responsibility & $23.68 \%$ & $7.14 \%$ & $17.24 \%$ & $7.14 \%$ & $0 \%$ & $0 \%$ \\
\hline Distortion of consequences & $21.05 \%$ & $16.67 \%$ & $6.90 \%$ & $7.14 \%$ & $0 \%$ & $0 \%$ \\
\hline Euphemistic language & $26.31 \%$ & $14.29 \%$ & $13.79 \%$ & $7.14 \%$ & $0 \%$ & $0 \%$ \\
\hline Moral justification & $13.16 \%$ & $14.29 \%$ & $6.90 \%$ & $3.57 \%$ & $7.14 \%$ & $3.13 \%$ \\
\hline $\begin{array}{l}\text { Primary Self-serving cognitive } \\
\text { distortions }\end{array}$ & $10.53 \%$ & $2.38 \%$ & $6.90 \%$ & $3.57 \%$ & $0 \%$ & $1.56 \%$ \\
\hline It is not ok to do this & $21.05 \%$ & $42.86 \%$ & $55.17 \%$ & $66.07 \%$ & $92.86 \%$ & $96.88 \%$ \\
\hline
\end{tabular}

Note: The three most selected mechanisms are highlighted in yellow 


\section{Negative behaviour: Souveniring}

The highly involved groups in both fandoms are also more likely to use moral disengagement mechanisms to justify souveniring, compared to the two other level of involvement groups (see Table 4.5.2, below). However, compared to the previous behaviour, the moderately and less involved groups seem to be more willing to take an object to bring home, i.e. fewer participants selected "It is not ok to do this" compared to selection of this statement for trespassing. While Breaking Bad fans were more willing to justify engaging in this behaviour in both the highly and the moderately involved groups, the two less involved groups did not differ much. However, the selected mechanisms by the two less involved fandom groups did differ, as Game of Thrones fans used a wider range of mechanisms to justify engaging in this behaviour. The most selected mechanism for all groups is Distortion of consequences. The second most selected mechanism, Attribution of Blame, is the same for both highly involved fan groups. Dehumanisation of Victimis then the second most selected mechanism by the moderately involved groups. The second most selected mechanism by the less involved groups is Primary self-serving cognitive distortions.

Table 4.5.2 Moral disengagement mechanisms $x$ fandom identification $x$ level of involvement, souveniring

\begin{tabular}{lcccccc}
\hline $\begin{array}{l}\text { Breaking Bad S3/ } \\
\text { Game of Thrones S3 } \\
\text { "Souveniring" }\end{array}$ & \multicolumn{2}{c}{ Level of Involvement } \\
\cline { 2 - 7 } \multicolumn{1}{c}{ Mighly Involved } & Moderately Involved & Less Involved \\
\hline Advantageous comparison & $\begin{array}{c}\text { BB } \\
(\boldsymbol{n}=\mathbf{3 8})\end{array}$ & $\begin{array}{c}\text { GoT } \\
(\boldsymbol{n}=\mathbf{4 2})\end{array}$ & $\begin{array}{c}\text { BB } \\
(\boldsymbol{n}=\mathbf{2 9})\end{array}$ & $\begin{array}{c}\text { GoT } \\
(\boldsymbol{n}=\mathbf{5 6})\end{array}$ & $\begin{array}{c}\text { BB } \\
(\boldsymbol{n}=\mathbf{1 4})\end{array}$ & $\begin{array}{c}\text { GoT } \\
(\boldsymbol{n}=\mathbf{6 4})\end{array}$ \\
\hline Appeal to higher loyalties & $13.16 \%$ & $11.90 \%$ & $6.90 \%$ & $10.71 \%$ & $14.29 \%$ & $4.69 \%$ \\
\hline Attribution of blame & $21.05 \%$ & $14.29 \%$ & $13.79 \%$ & $7.14 \%$ & $7.14 \%$ & $0 \%$ \\
\hline Dehumanisation of victim & $35.21 \%$ & $30.95 \%$ & $17.24 \%$ & $7.14 \%$ & $0 \%$ & $1.56 \%$ \\
\hline Diffusion of responsibility & $13.16 \%$ & $26.19 \%$ & $20.69 \%$ & $16.07 \%$ & $0 \%$ & $3.13 \%$ \\
\hline Displacement of responsibility & $31.58 \%$ & $9.52 \%$ & $24.14 \%$ & $5.36 \%$ & $0 \%$ & $0 \%$ \\
\hline Distortion of consequences & $28.95 \%$ & $7.14 \%$ & $6.90 \%$ & $7.14 \%$ & $0 \%$ & $1.56 \%$ \\
\hline Euphemistic language & $39.47 \%$ & $19.05 \%$ & $24.14 \%$ & $21.43 \%$ & $35.71 \%$ & $17.19 \%$ \\
\hline Moral justification & $21.05 \%$ & $14.29 \%$ & $20.69 \%$ & $0 \%$ & $0 \%$ & $0 \%$ \\
\hline $\begin{array}{l}\text { Primary Self-serving cognitive } \\
\text { distortions }\end{array}$ & $13.16 \%$ & $11.90 \%$ & $6.90 \%$ & $5.36 \%$ & $7.14 \%$ & $7.81 \%$ \\
\hline It is not ok to do this & $21.05 \%$ & $11.90 \%$ & $17.24 \%$ & $10.71 \%$ & $14.29 \%$ & $12.5 \%$ \\
\hline
\end{tabular}

Note: The three most selected mechanisms are highlighted in yellow

\section{Negative Behaviour: Scene recreation}

The findings for the scene recreation scenarios are presented in Table 4.5.3 below. The highly involved group of Breaking Bad fans used more mechanisms to justify throwing 
pizzas on the roof of the Walter White house than the moderately and less involved groups, which reflects the patterns found for the other scenarios as well as the Moral Disengagement scale scores. The majority of the less involved group were not ok with engaging in this behaviour, with $80 \%$ of the participants selecting this statement. This is a large difference from the highly involved group where only $21.05 \%$ selected "It is not ok to do this". Attribution of Blame is the most selected mechanism for both the highly involved and moderately involved group, however, it is not selected at all by the less involved group. Advantageous Comparison was the least selected mechanism by the highly involved group, whereas Distortion of Consequences was the least selected mechanism by the moderately involved group, but one of the more selected mechanisms by the highly involved group.

Table 4.5.3 Moral disengagement mechanisms x fandom identification $x$ level of involvement, scene recreation

\begin{tabular}{lcccccc}
\hline $\begin{array}{l}\text { Breaking Bad S2/ } \\
\text { Game of Thrones S1 } \\
\text { Scene Recreation }\end{array}$ & \multicolumn{2}{c}{ Lighly Involved } & Moderately Involved & Less Involved \\
\cline { 2 - 7 } \multicolumn{1}{c}{ Moral Justification Mechanism } & $\begin{array}{c}\text { BB } \\
(\boldsymbol{n}=\mathbf{3 8})\end{array}$ & $\begin{array}{c}\text { GoT } \\
(\boldsymbol{n}=\mathbf{4 2})\end{array}$ & $\begin{array}{c}\text { BB } \\
(\boldsymbol{n}=\mathbf{2 9})\end{array}$ & $\begin{array}{c}\text { GoT } \\
(\boldsymbol{n}=\mathbf{5 6})\end{array}$ & $\begin{array}{c}\text { BB } \\
(\boldsymbol{n}=\mathbf{1 4})\end{array}$ & $\begin{array}{c}\text { GoT } \\
(\boldsymbol{n}=\mathbf{6 4})\end{array}$ \\
\hline Advantageous comparison & $7.89 \%$ & $11.90 \%$ & $6.90 \%$ & $1.79 \%$ & $0 \%$ & $1.56 \%$ \\
\hline Appeal to higher loyalties & $21.05 \%$ & $26.19 \%$ & $13.79 \%$ & $7.14 \%$ & $7.14 \%$ & $0 \%$ \\
\hline Attribution of blame & $36.84 \%$ & $42.86 \%$ & $20.69 \%$ & $17.86 \%$ & $0 \%$ & $4.69 \%$ \\
\hline Dehumanisation of victim & $18.42 \%$ & $9.52 \%$ & $13.79 \%$ & $8.93 \%$ & $0 \%$ & $0 \%$ \\
\hline Diffusion of responsibility & $28.95 \%$ & $14.29 \%$ & $17.24 \%$ & $14.29 \%$ & $7.14 \%$ & $1.56 \%$ \\
\hline Displacement of responsibility & $15.79 \%$ & $14.29 \%$ & $17.24 \%$ & $19.64 \%$ & $7.14 \%$ & $1.56 \%$ \\
\hline Distortion of consequences & $21.05 \%$ & $26.19 \%$ & $3.45 \%$ & $10.71 \%$ & $7.14 \%$ & $9.38 \%$ \\
\hline Euphemistic language & $28.95 \%$ & $16.67 \%$ & $6.90 \%$ & $23.21 \%$ & $7.14 \%$ & $12.5 \%$ \\
\hline Moral justification & $26.31 \%$ & $26.19 \%$ & $10.34 \%$ & $17.86 \%$ & $0 \%$ & $6.25 \%$ \\
\hline $\begin{array}{l}\text { Primary Self-serving cognitive } \\
\text { distortions }\end{array}$ & $13.16 \%$ & $2.38 \%$ & $3.45 \%$ & $10.71 \%$ & $7.14 \%$ & $4.69 \%$ \\
\hline It is not ok to do this & $21.05 \%$ & $30.95 \%$ & $55.17 \%$ & $48.21 \%$ & $85.71 \%$ & $82.81 \%$ \\
\hline
\end{tabular}

Note: The three most selected mechanisms are highlighted in yellow

Similar to findings from the other scenarios, highly involved Game of Thrones fans use more mechanisms to justify engaging in negative behaviour (see Table 4.5.4 above). Only $30 \%$ of the highly involved Game of Thrones fans agreed that it is not ok to block access to take a picture, compared to $80 \%$ of the less involved group, similar to the less involved Breaking Bad group above. The most selected mechanism by the highly involved group was Attribution of Blame, however, it was less selected by both the moderately and the less involved groups, whose second most select mechanism was Euphemistic Language. 


\subsubsection{Impact of Level of Involvement and Fandom Identification on Moral Disengagement Scale Scores}

Welch's tests were used to test whether the level of involvement groups differed in their Moral Disengagement scale mean scores, for each fandom group.

Analysing Moral Disengagement scale mean scores for level of involvement groups further contributed to confirming whether the findings in Section 4.5.3.1 were context specific or not. Findings for the Breaking Bad group will first be presented, followed by the Game of Thrones group.

Analysis of variance of the Breaking Bad group's responses to the Moral Disengagement scale showed a statistically difference at the $p<.05$ level in Moral Disengagement scale scores for the three involvement groups: $F(2,39.69)=12.32, p<.001$. Post-hoc comparisons using the Games-Howell test found that the mean score for the highly involved group $(M=3.58, S D=1.41)$ was significantly different from the moderately involved group $(M=4.81, S D=1.28)$ and the less involved group $(M=5.25, S D=.75)$. No difference was found between the moderately involved group and the less involved group. Highly involved Breaking Bad fans agreed more with justifying negative behaviour using moral disengagement mechanisms compared to the moderately and less involved groups. For the Game of Thrones group, an analysis of variance showed a statistically difference at the $p<.05$ level in Moral Disengagement scale scores for the three involvement groups: $F(2,67.77)=11.99, p=.001$. Post-hoc comparisons using the Games-Howell test found that the mean score for the highly involved group $(M=4.18$, $S D=1.51)$ was significantly different from the moderately involved group $(M=5.20$, $S D=1.04)$ and the less involved group $(M=5.50, S D=.70)$.

No difference was found between the moderately involved group and the less involved group. Highly involved Game of Thrones fans agreed more with justifying negative behaviour using moral disengagement mechanisms compared to the moderately and less involved groups. These findings align with the previous findings, and the findings from the scenarios. Both highly involved Breaking Bad fans and highly involved Game of Thrones fans were more likely to use moral disengagement mechanisms to justify engaging in negative behaviour in a general context, compared to moderately and less involved participants in both fandom groups. However, moderately and less involved participants do not differ significantly in their use of moral disengagement mechanisms. 


\subsubsection{Demographics}

Welch's ANOVA tests were also used to test for differences in age groups and gender identification, however, no significant results were found for age groups $(F(7,22.091)=$ $.987, p=.466)$. A significant result was found for gender identification $(F(2,204)=4.166$, $p=.017)$. The male group had a significantly lower Moral Disengagement scale mean ( $M$ $=4.65)$ than the female group $(M=5.12)$, however, the mean difference is very small (.47). Thus, the male group agreed more with the use of moral disengagement mechanisms to justify the behaviours they were presented with in the Moral Disengagement scale, compared to the female group, however, although there is a significant difference, it is minor.

\subsubsection{Summary}

The findings presented in this section suggest that groups differ in their use of moral disengagement mechanisms. Highly involved groups in both fandoms differed significantly from moderately and less involved participants in their Moral Disengagement scale scores, suggesting that highly involved participants were more likely to agree with justifying engaging in negative behaviour with moral disengagement mechanisms, in a general context. When comparing the two fandom groups' response to justifying the negative on-site fandom specific behaviour they were presented in the scenarios, participants in the highly involved groups, and especially the highly involved Breaking Bad fans, were found to be more willing to engage in the negative hypothetical screen tourism behaviour, and applied more moral disengagement mechanisms to justify this behaviour.

\subsection{CONCLUSION AND SUMMARY}

This chapter has presented the findings from the data analysis in order to answer the research questions presented in Chapter 1, and will be the basis for the remaining chapters, in particular Chapter 5, the discussion.

Three level of involvement groups were created based on participants' Level of Involvement scale scores, and Breaking Bad fans were found to be significantly more likely to be higher involved than Game of Thrones fans. These groups were also used in further data analysis. The findings suggest that screen tourists do use moral disengagement mechanisms in order to justify engaging in negative on-site behaviour, answering the first research question. The next research question asked which 
mechanisms are more frequently used. This was examined in both the scenarios and participants' agreements with the Moral Disengagement scale statements. Attribution of Blame, Distortion of Consequences and Euphemistic Language were found to be the most frequently used mechanisms when justifying negative behaviour in scenarios. A significant, positive, strong Point-Biserial correlation found that participants who selected "It is not ok to do this" in scenarios have higher Moral Disengagement scale mean scores, suggesting that participants who were not ok with engaging in the negative behaviour presented in the scenarios were less willing to use moral disengagement mechanisms to justify negative behaviour in general. This suggests that participants' use of moral disengagement mechanisms is not context specific.

Lastly, the third research question asked whether different groups differed in use of their moral disengagement mechanisms. Fandom identification was found to have an impact on participants' use of moral disengagement mechanisms. Breaking Bad fans were significantly different from Game of Thrones fans in their Moral Disengagement scale scores, as Breaking Bad fans were more likely to agree with use of Moral Disengagement mechanisms in a general context. The findings also suggest that Breaking Bad fans were more likely to use moral disengagement mechanisms to justify engaging in the negative behaviour they were presented with in scenarios. Furthermore, highly involved participants significantly differed from moderately and less involved participants, overall and within the two fandom groups, in their agreement with the using moral disengagement mechanisms in the Moral Disengagement scale, as well as in the fandom specific context they were presented with in the scenarios. No significant differences were found for age groups, and while a Welch's ANOVA found a significant difference the male and female groups' Moral Disengagement scale mean scores, where men were more likely to use moral disengagement mechanisms, the mean difference is very small. The findings will be discussed with concepts from the literature in Chapter 5. Chapter 5 will also provide a broader discussion of how these statistical findings answer the research questions. 


\section{Discussion}

\subsection{INTRODUCTION}

The previous chapter presented the findings from the data analysis. This chapter will discuss these findings with key concepts from the literature in order to address the research aim and research questions. Similar to Chapter 4, this chapter is structured around each research question. However, instead of following the exact same structure as the previous chapter, each section will discuss the overall theme of the research question. The chapter begins discussing Screen Tourism and Moral Disengagement (Research Question 1), then Use of Moral Disengagement Mechanisms (Research Question 2), followed by Fandoms, Involvement and Moral Disengagement (Research Question 3), and ends with a general discussion, conclusion and summary in Section 5.5.

\subsection{SCREen TOURISM AND MORAL DisengagemenT}

This section discusses the first research question which asked whether screen tourists use moral disengagement mechanisms to justify their negative on-site behaviour. This was measured by examining participants' selection of moral disengagement mechanisms used to justify the hypothetical negative behaviour in scenarios. The findings presented in Chapter 4 found that some participants used moral disengagement mechanisms to justify engaging in the negative behaviour they were presented with. These findings align with previous research on moral disengagement in other tourism contexts (He \& Harris, 2014; Sharma, 2020, Wu et al., 2020), and indicate that moral disengagement is used in a screen tourism context, in addition to contexts such as dark tourism (Sharma, 2020), tourists' pro-environmental behaviours (Wu et al., 2020), and customer revenge (He \& Harris, 2014). As briefly discussed in the literature review, Sharma (2020) suggests that the liminal nature of tourism facilitates moral disengagement. Liminality, or The Liminal Period, which is the second stage of Van Gennep's (1960) Rites of Passage theory, is defined as "units of space and time in which behavior and symbolism are momentarily enfranchised from the norms and values that govern the public lives of incumbents of structural positions" (Turner, 2017, p. 166). According to Turner (2017), the ambiguity of the liminal period is important as "it implies a possibility and openness on resisting social structure" (Zhang \& Xu, 2019, p. 85, based on Turner, 2017). Ryan and Kinder (1996) state that "tourism can also be observed as a liminal behaviour, in that it is a temperorally [sic] constrained, socially tolerated period of wish fulfilment, a form of 
fantasy enactment that is normally denied to people" (p. 507), where "in a liminal world, people can behave in a way as if they are free from constraints and obligations" (Zhang \& Xu, 2019, p. 84). Thus, (screen) tourism becomes a space facilitating moral disengagement, and enables the tourist to engage in behaviours that in the "normal" social structure would be considered immoral. These behaviours may also be outside what tourists would engage in at home. This can be further influenced by the characteristics of fandoms. The literature review identified that fandoms create their own social structures that might contrast with the wider society's social structures and norms (Duffett, 2013; Fuschillo, 2018). Thus, the screen (fan) tourist may not only experience openness to resisting the wider society's moral norms, they can also be influenced by the specific moral norms of their fandom. By applying Ryan and Kinder's (1996) definition of tourism as a liminal behaviour, screen tourism enables wish fulfilment and fantasy enactment, two potential motivations of fandom participation (see Chapter 2, Section 2.4.2.2). Thus, it can be assumed that this combination facilitates moral disengagement for some screen tourists in some contexts, enabling them to disengage the self-regulatory mechanisms that normally would stop them from engaging in the negative behaviour.

Bandura (1986) argues that a cognitive conflict arises in the individual when they are "socially or materially rewarded for behaviour they themselves devalue" (p. 374). The reward of engaging in negative on-site behaviour might override the self-reproach engaging in the behaviour would normally cause, in particular for screen tourists who are part of a fandom. Thus, the combination of tourism as a liminal space and fandom involvement facilitates a space where moral disengagement can be activated more readily, compared to a space where only one of the factors is available. Furthermore, the individual can experience (perceived) positive impacts by engaging in the negative behaviour, e.g. a feeling of wish fulfilment or becoming part of the fandom object (Waysdorf, 2017). This section has discussed the findings that answer Research Question 1, and found support that the participants sometimes used moral disengagement mechanisms to justify engaging in the negative on-site behaviour. These findings confirm prior research that has found moral disengagement used in other tourism contexts, acknowledging the facilitating role of the liminal nature of tourism and characteristics of fandom. The upcoming section will further discuss the findings related to Research Question 2: Which moral disengagement mechanisms are most frequently used to justify negative behaviour. 


\subsection{USe OF Moral Disengagement MeChanisMs}

The findings discussed in the previous section found support for Research Question 1, which confirms that some screen tourists used moral disengagement mechanisms to justify negative on-site behaviour in certain situations. The second research question examines the frequency of use of moral disengagement mechanisms. To answer this research question, participants' use of disengagement mechanisms in scenarios and their Moral Disengagement scale responses were examined. This section will discuss the findings with concepts from the literature, and previous research identified in the literature review.

\subsubsection{Application of Moral Disengagement Mechanisms}

Previous research discussed in the literature review, in particular the study on dark tourism and moral disengagement in liminal spaces by Sharma (2020), found that some moral disengagement mechanisms were more frequently used than others. This is suggested to be explained in light of Bandura's Moral Disengagement theory. The eight (here expanded to ten) moral disengagement mechanisms are divided into four categories based on their cognitive facilitation (Table 5.3.1). Furthermore, the Selective Exercise of Moral Agency proposed by Bandura (1986) (Section 2.3.2) suggests that mechanisms are cognitively activated as a process (Table 5.3.1, Figure 2.3.1).

Table 5.3.1 Cognitive facilitation of moral disengagement mechanisms (based on Bandura, 1999; Barriga \& Gibbs, 1996; Sykes \& Matza, 1957)

\begin{tabular}{lll}
\multicolumn{1}{c}{ Process Activation stage } & \multicolumn{1}{c}{ Cognitive Facilitation } & \multicolumn{1}{c}{ Moral Justification Mechanism } \\
\hline 1 & Cognitive restructuring & $\begin{array}{l}\text { Moral Justification } \\
\text { Advantageous comparison } \\
\text { Euphemistic labelling }\end{array}$ \\
\hline $1 / 2$ & Obscuring moral agency & $\begin{array}{l}\text { Diffusion of responsibility } \\
\text { Displacement of responsibility } \\
\text { Appeal to higher loyalties (Neutralization } \\
\text { techniques theory) }\end{array}$ \\
& & $\begin{array}{l}\text { Dehumanization of victim } \\
\text { Distortion of consequences } \\
\text { Attribution of blame }\end{array}$ \\
\hline 3 & Removing/reducing perceived & Primary self-serving cognitive distortions \\
& harm inflicted on victims & \\
\hline $\mathrm{n} / \mathrm{a}$ & Self-serving cognitive & \\
& distortions & \\
\hline
\end{tabular}

The analysis of participants' responses to the scenarios found that some moral disengagement mechanisms were more frequently used than others to justify engaging in 
the negative on-site behaviour participants were presented with. Two of the three mechanisms from the category Reducing/removing perceived harm inflicted on victims (Attribution of Blame and Distortion of consequences) were the two most frequently selected by both fandom groups and overall, followed by one mechanism from the category Cognitive restructuring (Euphemistic Language). These findings do not clearly align with findings from previous research. Sharma (2020) found that Euphemistic Language and Moral justification were the two most frequently used moral disengagement mechanisms in a dark tourism context. These two are mechanisms centred on the reprehensible conduct itself, and reframing the behaviour to make it morally legitimate (Bandura, 1986; Sharma, 2020). These mechanisms are activated early in the cognitive process (Table 5.3.1). However, two of the most frequently used mechanisms in the present study centre on the victim and detrimental effects, and are activated later in the cognitive process (Bandura, 1986). Together with Dehumanisation of victim, which is also one of the more frequently used mechanisms, these three mechanisms facilitate negative behaviour through the individual minimising or reducing the perceived harmful effects on the victim (Bandura, 1999, Table 5.3.1). Mechanisms that facilitate moral disengagement through Cognitive Restructuring and Obscuring moral agency were less frequently selected, and their patterns of application are less clear.

By activating the mechanisms that cognitively facilitate moral disengagement by minimising or reducing the harm inflicted on the victim(s), engaging in the behaviour (whether it is trespassing private property or souveniring) is justified as morally acceptable by and to the individual. The victims themselves are now perceived as responsible for any harm that might arise from the consequences of their own actions (e.g. moving to a house where a popular TV-series was filmed, or allowing filming episodes in nature). These mechanisms further cognitively facilitate moral disengagement by changing how the victim is perceived, through dehumanisation. The screen tourists justifies engaging in the negative behaviour as they "do not know who lives there" or because their behaviour will not cause harm to humans.

The use of mechanisms also differs between trespassing and souveniring (across both fandom groups), indicating that the type of behaviour itself might impact the selection of moral disengagement mechanisms. Both trespassing and souveniring are first justified by using mechanisms that remove/reduce perceived harm or distort blame. Trespassing is 
next justified using mechanisms that focus on Cognitive restructuring and then Obscuring moral agency. Participants continued to use mechanisms centred on the victim to justify engaging in souveniring, followed by mechanisms obscuring moral agency. Mechanisms centred on Cognitive restructuring are the least selected for souveniring. By cognitively restructuring the behaviour, trespassing is considered acceptable as it "could have been worse" (e.g. they are not breaking in, or it is "only a photo"). Souveniring, however, is deemed acceptable as the blame is attributed to the victim, and the potential harmful consequences are distorted or disregarded completely. Primary self-serving cognitive distortions is the third most selected mechanism for Souveniring but the least selected for Trespassing. This mechanism justifies engaging in the behaviour as it will bring back good memories, suggesting the importance of tangible objects to fans. The findings for souveniring do not align with Bandura's process of activation, where the activation process is the opposite of what Bandura proposes. This is different for trespassing however, as although one mechanism centred on the victim is activated first, the next selected mechanisms follow Bandura's proposed model.

\subsubsection{Impact of the Screen Tourism Context on Moral Disengagement}

Findings from the analysis of the Moral Disengagement scale scores indicate that, while there is a positive correlation between having a high mean score (less agreement with justifying the behaviour using a moral disengagement mechanism) and choosing "It is not ok to do this" in the scenarios, the selection of mechanisms differs between the general context (Moral Disengagement scale) and the tourism specific context (scenarios). Participants with a low mean score on the Moral Disengagement scale were more agreeable to justify negative behaviour using moral disengagement mechanisms, whereas participants with a high mean score were less agreeable to justify engaging in the behaviour. The most agreed with mechanism for the Moral Disengagement scale is centred on cognitive restructuring (Moral Justification), whereas a mechanism centred on removing the perceived harm on the victim (Dehumanisation of victim) is the least agreed with. These findings confirm Bandura's (1986) cognitive facilitation process model, as cognitive restructuring mechanisms are first activated, and mechanisms that aim to remove/reduce the perceived harm on the victim are the last to be activated. The second and third most agreed with mechanisms in the Moral Disengagement scale (centred on obscuring moral agency) are mechanisms that are activated second according to 
Bandura's (1986) model. Thus, these findings mostly follow the selective exercise of moral agency and activation of moral disengagement mechanisms process as proposed by Bandura (1986). Comparing these findings to the use of mechanisms to justify behaviour in scenarios, however, shows that activation of mechanisms in the screentourist context does not follow the process proposed by Bandura (1986). As noted above, participants would most frequently select mechanisms that are activated last to justify negative on-site tourist behaviour, and most mechanisms from the three other categories were less frequently used. However, it is unclear what causes this difference. Bandura (1990) notes that mechanisms that focus on cognitive restructuring are the most effective, as "what was once morally condemnable becomes a source of self-valuation." (p. 33). It is possible that these mechanisms are bypassed or not sufficient enough if engaging in the negative behaviour is not perceived to impact on their self-valuation, although engaging in the behaviour might increase their social value in the fandom community.

Furthermore, Bandura (1990) states that mechanisms that obscure personal agency are most effective when "a legitimate authority accepts responsibility for the consequences" (p. 34). However, this Displacement of Responsibility is less explicit in everyday life situations (Bandura, 1990, p. 34). The situations presented in the scenarios do not include explicit authoritative figures, and it is possible that friends and family members are not perceived as authoritative enough to obscure the participants' agency. Thus, mechanisms that centre on obscuring personal agency might not be as strongly or easily activated. Mechanisms centred on reducing or removing harmful consequences as well as shifting blame, however, are activated through "a series of reciprocally escalating actions" (Bandura, 1990, p. 41), and the victim is not perceived as faultless. The scenarios centred on situations where the participant did not know the victims of their behaviour, a factor which could make it easier for the participant to minimise or disregard the harmful consequences of their behaviour (Bandura, 1990). In turn, these mechanisms might be likely to be activated more readily than the other mechanisms. Bandura (1990) further notes that activation and use of moral disengagement is gradual, and dependent on the situation, context, previous experience with moral disengagement, personality, and other factors. 


\subsubsection{Summary and Answer to Research Question 2}

This section has discussed the findings related to Research Question 2, which asked whether some moral disengagement mechanisms are more frequently used than others, and the findings confirmed this. Instead of focusing on the individual mechanisms, the discussion focused on the category of cognitive facilitation the mechanisms belong to, and findings have been discussed and interpreted in the context of both previous research, and the process of Selective Exercise of Moral Agency proposed by Bandura (1986). While the findings from this research project somewhat align with previous research (e.g. Sharma, 2020), they also suggest that the most frequently used categories in the screen tourism context of this study differ from what has been found in other tourism contexts. Participants most frequently selected mechanisms that centred on removing or reducing the perceived harm on victims, and/or redirect blame onto the victims. This pattern was found across all scenarios. The findings from the Moral Disengagement scale scores were compared to participants' use of moral disengagement in the scenarios and indicate that, while the activation of moral disengagement mechanisms mostly follows Bandura's (1986) process of activation in a general context, the activation of mechanisms in a specific (screen tourism) context does not always follow this process.

Thus, the answer to Research Question 2 is that some of the moral disengagement mechanisms (in particular Attribution of Blame, Distortion of consequences) are more frequently selected than others.

The next section will discuss the findings related to Research Question 3, which is whether different groups of screen tourists differ in their use of moral disengagement mechanisms. 


\subsection{FAndoms, InVOLVEMENT ANd Moral Disengagement}

The third and final research question examines whether different groups differ in their use of moral disengagement mechanisms. This was examined through both scenarios and the Moral Disengagement scale. Data was analysed by level of fandom involvement, fandom identification, and demographic variables.

This section will first discuss the findings related to fandom and fandom involvement, then discuss the impact of fandom identification, before discussing the impact of level of involvement and fandom identification.

\subsubsection{Fandom and Fandom Involvement}

The findings suggest there is, at times, a significant difference between the two fandom groups in terms of behaviour and use of moral disengagement mechanisms as well as their level of fandom involvement. This section will discuss these findings, drawing on existing literature and research.

The data analysis found that Breaking Bad fans were significantly more likely to be highly involved in their fandom compared to the Game of Thrones group. Similarly, the majority of the Breaking Bad group falls within the moderately to highly involved groups, whereas the majority of the Game of Thrones respondents falls within the moderately to less involved groups. Furthermore, the highly involved participants also participated more frequently in fandom activities compared to the two less involved groups, confirming findings from previous research (see e.g. Cheng \& Tsaur, 2012). The overall trends in use of mechanisms mainly follow the same patterns as for previous findings, i.e. mechanisms that facilitate justification of negative behaviour through harm removal/reduction and shifting blame are the most frequently selected. The frequency of participants selecting "It is not ok do to this" increases as level of involvement decreases, with the less involved groups being the least willing to engage in the behaviour. The impact of level of involvement on using moral disengagement mechanisms might be explained in part by how level of involvement influences fan behaviour in general. The literature discussed in Chapter 2 suggests that level of involvement influences fan tourists' behaviours, how much time and energy they invest in fandom activities, and how important fandom is to them (Thorne \& Bruner, 2006). Highly involved fans invest more time and energy in fandom related activities (Thorne, 2011). 
Furthermore, Zubernis and Larsen (2018) suggested that fan tourists often wish to acquire tangible objects from their travel. Taking tangible objects (souveniring) during travel has been identified as one of the negative behaviours (screen) tourists engage in (BBC, 2020), and is the hypothetical behaviour participants were presented with in scenario 3 .

The data analysis found trespassing to be the behaviour participants in both fandom groups were most likely to justify engaging in. This finding aligns with the literature and further indicates that acquiring tangible objects is important to fan tourists, in particular to the highly involved groups. Similar to the overall patterns in use of moral disengagement mechanisms, the participants most frequently used mechanisms that remove or distort the perceived harm on victims. However, mechanisms that obscure moral agency were also more frequently used, in particular by the highly involved Breaking Bad group. Similar patterns are found for the other scenarios as well. This suggests that obscuring moral agency through justifying it as a fandom trend (Appeal to higher loyalties) or displacing or diffusing responsibility ("someone else asked me to do it"/“other people are doing it as well”), enables deactivation of self-regulatory mechanisms in the highly involved Breaking Bad fans. Thus they are able to engage in this negative on-site behaviour without a sense of self-reproach. This highlights the importance of the fandom ("It is a fandom trend"), and the role of social or peer pressure when it comes to both engaging in, and justifying, negative behaviour. It is also likely that the social and experiential aspects of fandom involvement/engagement influence use of moral disengagement and willingness to engage in negative behaviour. The use of mechanisms that involve a social/experiential component is relatively high and the social component is an important component of fandom involvement (Gyimóthy et al., 2015). Justifying negative behaviour based on the positive social or experiential outcome aligns with the literature, which suggests that immoral behaviour is likely to be morally justified when there is a perceived positive outcome.

Furthermore, according to Krakowiak and Tsay-Vogel (2013), while an individual is likely to condemn immoral behaviours by others, people are willing to excuse or justify the immoral behaviour engaged in by characters who are well-liked, using moral disengagement mechanisms. While this research project did not examine participants' character liking, it is reasonable to assume that especially highly involved fans like the character that is (wholly or part of) their fan object. According to Sanders and Tsay-Vogel (2016), an individual's moral disengagement and justifications of characters' immoral 
behaviour may be influenced by the individual's knowledge of the narrative and its characters through "long-term, repeated, and/or multimodal consumption" (p. 233). It can thus be assumed that highly involved fans have more experience with their fandom compared to moderately and especially less involved fans. Not only do they agree more strongly with the three constructs (attraction, centrality and self-expression) proposed by McIntyre and Pigram (1992), but they also engage more frequently in fandom related activities, subsequently increasing their fandom experience. It can therefore be assumed that their fandom (narrative) knowledge influences their moral disengagement and justification of Walter White's (and other Breaking Bad characters') immoral behaviour. This could also be assumed to be due to the higher level of fandom involvement. These factors, in turn, influence their own willingness to justify engaging in negative tourist behaviour themselves. Thus, interpreting the findings presented in the previous chapter in the light of this and the literature discussed in Chapter 2, provides potential explanation as to why highly involved Breaking Bad fans in particular have a higher propensity to justify engaging in not only negative (screen) tourist behaviour, but also agree more strongly with the general behaviours they were presented with in the Moral Disengagement scale.

\subsubsection{The Impact of Fandom Identification}

As discussed previously, the two fandoms were selected as there is evidence that fans of these two TV-series engage in negative tourist behaviour when visiting destinations and sites related to their fandom object. Throughout the data analysis, the Breaking Bad fandom group was found to have lower Moral Disengagement scale mean scores (i.e. being more agreeable to justify engaging in general negative behaviour using moral disengagement mechanisms), as well as using more moral disengagement mechanisms to justify engaging in the tourism-specific behaviour they were presented with in scenarios. As discussed in the literature review, the two TV-shows differ in moral values and moral alignment. This has been suggested to impact not only fans' character identification, character liking and moral justification of the character's immoral behaviour, but also fans' justification of their own immoral behaviour, which is influenced by the fandom object. This section will discuss and interpret the findings from the data analysis in order to better understand how and why the two fandom groups differ in their use of moral disengagement, and if there are similarities or patterns. 
The data analysis found that the two fandom groups differed in their use of moral disengagement mechanisms in scenarios. Whereas between $54 \%$ and $66.67 \%$ of the Breaking Bad fans selected at least one or more disengagement mechanism for each scenario, only $28 \%-46 \%$ the Game of Thrones fans selected one or more mechanism for each scenario, indicating they were less willing to engage in the behaviours they were presented with. Furthermore, the use of moral disengagement mechanisms differs between the two groups for comparable behaviours. Whereas just over half of the participants who identified as Breaking Bad Fans selected one or more mechanism to justify engaging in trespassing, over $70 \%$ of the Game of Thrones fans selected "It is not ok to do this", indicating they were not willing to engage in this behaviour. Similarly, for the second comparable behaviour (souveniring), just over 30\% of the Breaking Bad fans indicated they were not willing to engage in the behaviour, compared to over half of the Game of Thrones fans. However, the overall patterns of use of mechanisms across all scenarios are fairly similar between the two fandom groups (Figure 4.5.1). Both groups' most frequently used mechanisms centred on removing/reducing perceived harm and shifting blame onto the victim. However, the Breaking Bad group more frequently used mechanisms that obscure moral agency, after removing and reducing harm and blame, whereas the Game of Thrones group continued to use mechanisms from the "remove/reduce harm" category, and mechanisms that facilitate moral disengagement by cognitive restructuring.

It is possible that these differences are, at least in part, explained by the differences between the two TV-series. Participants identifying themselves as part of the Breaking Bad fandom may be more inclined to justify engaging in negative on-site tourist behaviour due the moral alignment of Breaking Bad. Krakowiak and Tsay-Vogel (2011) found that there is a connection between a person's propensity to morally disengage in their own lives and their use of moral disengagement to justify characters' negative and immoral actions (p. 98). While the three Breaking Bad scenarios in this research project are not centred on Walter White's criminal behaviour (the only behaviour directly from the TV-series is the pizza thrown on the roof), it is possible that the participants consciously or subconsciously model their behavioural justification on the use of moral disengagement in the TV-series. As the premise of Breaking Bad is to morally disengage in order to justify engaging in increasingly criminal behaviour it can be assumed that this influences fans' use and choice of moral disengagement mechanisms. This in turn 
contributes to participants' use of mechanisms to justify their own negative on-site tourist behaviour. Furthermore, the authors argue that individuals who are more willing to morally disengage are more willing to accept immoral behaviour and action by others, "regardless of whether the actions are performed by a fictional character or a real individual" (Krakowiak \& Tsay-Vogel, 2011, p. 98). This might help explain why Breaking Bad fans are more likely to justify engaging in negative behaviour.

This section has discussed the differences between the two fandom groups' use of moral disengagement mechanisms and affirms that participants who identify as Breaking Bad fans are more willing to justify negative behaviour using moral disengagement mechanisms. The upcoming section will discuss the impact of both fandom identification and level of fandom involvement.

\subsubsection{Summary and Answer to Research Question 3}

This research question asked whether groups differed in use of moral disengagement mechanisms. Both fandom identification and level of involvement were found to impact on screen tourists' use of moral disengagement mechanisms, and this section has drawn on relevant literature and previous research that can contribute to a better understanding of the differences between the groups. Therefore, the answer to Research Question 3 is that groups differ in their use of moral disengagement mechanisms, based both on fandom identification and level of involvement. First, the Breaking Bad group were found to be more willing to justify engaging in negative behaviour compared to the Game of Thrones fans. The two groups showed similar patterns in use and selection of mechanisms, as both groups' most selected mechanisms cognitively facilitate negative behaviour by removing and reducing perceived harm on victims. However, the Breaking Bad fans also used mechanisms that obscure moral agency more often than the Game of Thrones group. Furthermore, the level of fandom involvement clearly has an impact on the propensity to use moral disengagement. The highly involved groups from both fandoms were more willing to use moral disengagement, as the frequency "It is not ok to do this" increased as the level of fandom involvement decreased. The difference between the Breaking Bad group might be explained by the differences in moral alignment and characteristics of the two TV-series, whereas the differences between the level of involvement groups might be explained by some of the characteristics of fandom and the fandom community. For example, highly involved fans might be more willing to justify negative behaviour if it 
increases their fandom belonging or allows them to acquire tangible fandom objects. Furthermore, high involvement is suggested to increase fan object knowledge, which has been suggested in the literature to enable fans to not only morally disengage to justify the fan object's transgressive behaviour, but also their own.

\subsection{General Discussion, ConClusion AND Summary}

This chapter has discussed and interpreted the findings presented in Chapter 4, drawing on the literature review, as well as additional literature, in order to answer the research questions presented in Chapter 1.

First, the answer to Research Question 1 was discussed in Section 5.2. This asked whether screen tourists use moral disengagement mechanisms to justify engaging in negative behaviour. Based on the findings and previous discussion, the answer is that many screen tourists use moral disengagement to justify negative on-site behaviour in most situations. This confirms previous research which has found that moral disengagement is used in other tourism and non-tourism contexts. Next, Research Question 2 asked whether some moral disengagement mechanisms are more frequently used than others. The discussion in 5.3 answer this, and this research has found that in particular the category of mechanisms that facilitates moral disengagement through reducing/removing the perceived harm or shifting blame onto victims are most frequently used.

Section 5.4 discussed the findings that answer Research Question 3, which asked whether groups differ in their use of moral disengagement mechanisms. Both level of fandom involvement and fandom identification was found to impact on participants' use of moral disengagement, thus confirming Research Question 3. The data analysis found a difference between Breaking Bad fans' and Game of Thrones fans' use of moral disengagement, which might, at least in part, be explained by the differences in morality between Breaking Bad and Game of Thrones. Moral disengagement mechanisms are used throughout Breaking Bad to justify the criminal and immoral behaviour of what has been termed an anti-hero (Echart \& García, 2013). Fans have been found in previous research to model their behaviour and moral judgements on likeable characters, regardless of the character's morality (Krakowiak \& Tsay-Vogel, 2013). Furthermore, screen tourism creates a liminal space where the tourist is no longer constrained by their daily social expectations, norms, and constraints. Instead it creates a space where it is possible for the tourist to morally disengage and engage in behaviours the social structure would 
otherwise deem immoral or wrong, or behaviours that are outside what they would engaging in at home. This can be further influenced by the norms and values created by the fandom community. Thus, as discussed in Section 5.3, screen tourists use moral disengagement mechanisms to justify engaging in negative on-site tourist behaviour, in part due to the liminal aspects of tourism, combined with the specific characteristics of belonging to a fandom community.

Throughout the chapter, in particular Sections 5.3 and 5.4, it became clear that there are patterns in the use of moral disengagement mechanisms. Overall, the most frequently used mechanisms are centred on removing or reducing the perceived harm to the victim, or shifting blame onto the victim. This pattern in found for most behaviours and for both fandom groups. While there are some overlap with previous research, the findings about use of mechanisms from this research do not strongly confirm previous research, such as the research by Sharma (2020). Neither do the findings from the analysis of the scenarios confirm the process suggested by Bandura (1986), as the more frequently selected mechanisms in this research are the mechanisms that are activated second or last in Bandura's model from 1986. However, findings suggest that this might be context specific, as the data analysis found that participants' agreement with statements in the Moral Disengagement scale followed the process proposed by Bandura (1986). This suggests the contextual impact on activation of moral disengagement mechanisms. Lastly, findings confirm that groups differ in their use of moral disengagement mechanisms, where highly involved participants, and in particular highly involved Breaking Bad fans, are more likely to justify engaging in negative on-site behaviour. Previous research has found that highly involved fans are more invested in and willing to go to further lengths to engage in fandom activities, which might explain why they are more likely to justify engaging in negative on-site behaviour. Lastly, the conceptual framework in Section 2.5 proposes interrelations between screen tourists' level of involvement and their negative behaviour, as well as level of involvement's impact on use of moral disengagement mechanisms. These interrelations have been confirmed through this research.

The next chapter will discuss implications, present suggestions for future research, summarise and conclude. 


\section{Conclusion}

\subsection{INTRODUCTION}

Screen tourism is an as increasingly popular special interest tourism market that has many positive benefits for the stakeholders involved. However, negative screen tourist behaviour has also been found to be a problem that can negatively impact the destination and local stakeholders, as well as other tourists. This thesis examined screen tourists' moral disengagement in relation to negative on-site tourist behaviour, as there is little knowledge about how screen tourists justify engaging in transgressive behaviour. To do so, this study drew upon Bandura's Moral Disengagement theory, which has previously been applied to both tourism and non-tourism contexts to examine justifications of immoral behaviour. Furthermore, fandom identification and level of involvement are assumed to impact on screen tourists' moral disengagement. The research aim has guided and influenced all stages of the research process, including the literature review, methodological choices, data analysis, interpretation, and discussion. A quantitative online survey measuring Level of fandom involvement, use of moral disengagement in three hypothetical screen tourism related scenarios and agreement with justification of negative behaviour presented in Bandura's Moral Disengagement scale was used to examine screen tourists use of moral disengagement. Individuals who self-identified as part of either the Breaking Bad or the Game of Thrones fandom were invited to participate, and the survey received 243 eligible responses which were statistically analysed. This chapter will first conclude the research questions, then discuss strengths and weaknesses, implications of this research and theoretical and practical contributions, and directions and ideas for future research.

\subsection{Concluding The Research Questions AND Research Aim}

Three research questions were asked in order to address screen tourists' use of moral disengagement in a screen tourism context:

RQ1: "Do screen tourists use moral disengagement mechanisms to justify their negative on-site behaviour?", RQ2: “Which moral disengagement mechanisms are most frequently used by screen tourists to justify their negative behaviour?", and RQ3: "Do different groups of screen tourists differ in their use of moral disengagement mechanisms?"

The upcoming sections will summarise and conclude each research question. 


\subsubsection{Concluding Research Question 1}

The literature review identified that Moral Disengagement theory has been used in previous research to explain how people justify engaging in negative behaviour. The first research question asked if screen tourists use moral disengagement mechanisms to justify their negative behaviour. The answer to Research Question 1 is that many screen tourists often apply moral disengagement mechanisms to justify negative on-site behaviour, which aligns with findings from previous research. The literature suggests that this might be explained by characteristics of tourism (liminality) and fandom characteristics (fandom specific norms, values and rules). These factors create a space where moral disengagement can be more readily activated, and where some screen tourists do not experience the same moral constraints they would in their "normal" life. Thus the selfregulation that would normally generate self-reproach (and prohibit negative behaviour) is not activated.

\subsubsection{Concluding Research Question 2}

The second research question asked whether some mechanisms are more frequently used than others. The data analysis of participants' responses to the scenarios found that mechanisms do vary in frequency of application, confirming findings from previous tourism research. Mechanisms centred on removing and reducing the perceived harm on victims, as well as shifting blame onto the victim are the most frequently used. These findings however, do not clearly align with previous research, where other mechanisms have been found to be used more frequently. Furthermore, Bandura (1986) proposes that mechanisms facilitating moral disengagement through cognitive restructuring of the reprehensible conduct is activated first, whereas mechanisms focused on the detrimental effects and the victim are activated second and third, respectively. The selection of mechanisms in the scenarios in this research do not clearly follow Bandura's proposed process of activation, as the most frequently selected mechanisms are activated last. However, participants' responses to the Moral Disengagement scale aligned with Bandura's process, and participants who are less likely to use moral disengagement in a tourism context are also less likely to use moral disengagement in a non-tourism context. Differences in the activation of mechanisms could be explained by context specific characteristics of this research. Other factors might influence the activation as well, such as participants' personality, knowledge, experience, and other external factors and further research is required to identify the underlying reasons. 


\subsubsection{Concluding Research Question 3}

Research question 3 asked whether there are differences between different groups in their use of moral disengagement mechanisms. This was examined for impact of fandom identification and level of involvement, as well as age groups and gender identification. Findings established that different groups did differ in their use of moral justification, and both fandom identification and level of fandom involvement were found to, at times, impact on participants' use of moral disengagement mechanisms. No significant differences were found for age groups, and only very minor differences were found for gender identification.

Overall, participants who identified as part of the Breaking Bad fandom were more likely to morally justify engaging in negative behaviour, compared to Game of Thrones fans. Furthermore, Breaking Bad fans were found to be significantly more likely to be highly involved when measuring level of involvement. Examining fandom involvement's impact on use of moral disengagement found that highly involved participants were more willing to justify negative behaviour in both a tourism specific context (scenarios) and a general context (Moral Disengagement scale). Breaking Bad participants, in particular those highly involved, were the most willing to use moral disengagement mechanisms while highly involved Game of Thrones fans were less willing to use moral disengagement. Thus, both fandom identification and level of involvement impact on use of moral disengagement. The differences between both fandom groups and level of involvement groups can have multiple explanations. For example, research suggests that the characteristics and moral alignment of the TV-series, characteristics of fandom and fandom involvement, and the individual's own knowledge and experience might impact on behaviour and thus use of moral disengagement mechanisms.

\subsection{STRENGTHS AND WEAKNESSES}

\subsubsection{Strengths}

This research has begun to fill the research gap identified in the Introduction and contributes to a better understanding of how screen tourists justify negative on-site behaviour. Further, the thesis draws upon existing and well-tested scales and theories to strengthen the methodology, and the theoretical framework is expanded by incorporating mechanisms from two additional moral justification theories to account for the unique characteristics of the fandom-specific context. The data collection is further strengthened 
by the development of hypothetical scenarios which focus on negative fandom specific behaviour identified in both the literature and media. Lastly, data is analysed using advanced statistics in an attempt to identify the interrelationships between tourist behaviour and fandoms.

\subsubsection{Weaknesses}

The quantitative approach does not allow for an in-depth exploration to understand why exactly moral disengagement mechanisms are applied to allow tourists to engage in negative behaviour. As such, underlying psychological factors or other influencing factors are not yet considered. The studies' small sample size and the difference in sample size between the two fandom groups may also negatively impact the reliability of results where a larger sample size and more even distribution between groups could provide better insights. Furthermore, social desirability bias might have influenced participants' responses to questions about morally questionable behaviour, perhaps resulting in untruthful responses. Lastly, this thesis does not consider actual tourist behaviour, only responses to behaviour in hypothetical scenarios. It is possible that justification of actual tourist behaviour differs from justification of hypothetical behaviour. Thus, Section 6.5 presents several opportunities for further research to deepen our understanding.

\subsection{CONTRIBUTIONS AND IMPLICATIONS}

\subsubsection{Theoretical Contributions}

This research contributes to a better understanding of how Moral Disengagement theory can be applied to a tourism context, and hitherto non-existent insight into screen tourists' use of moral disengagement to justify negative on-site tourist behaviour. Level of fandom involvement and fandom identification have been identified as two factors that can influence both screen tourists' negative behaviour and their use of moral disengagement, both of which were likely found to be influenced by the fan object itself and its moral alignment. This research also adds new knowledge of how the liminality of tourism spaces can contribute to behaviour. A fandom context can shift the perception of what is or is not appropriate tourist behaviour, as findings suggest that the specific context of screen tourism can activate moral disengagement differently to how it is applied in a general context. These insights hold value for research on responsible and environmentally sustainable tourist behaviour, receiving increased attention as the 
tourism industry prepares for the development of regenerative tourism post-COVID-19. Further, this research has implications for the tourism industry and other related stakeholders.

\subsubsection{Industry Contributions}

As noted above, this research has contributed to a better understanding of screen tourists and how they might justify engaging in negative behaviour. This increased knowledge is helpful for screen tourism stakeholders in the development, planning, and management of screen tourism, and when developing measures that will reduce or mitigate screen tourists' negative behaviour. This research has identified specific behaviours and factors that can increase the likelihood of moral disengagement, in turn providing the opportunity to inform and guide initiatives to manage negative tourist behaviour.

First, high levels of fandom involvement increased participants' tendency to justify negative behaviour. Interventions aiming to mitigate both activation of moral disengagement and the negative tourist behaviour itself should account for screen tourists' level of fandom involvement. For example, highly involved screen tourists were more likely to engage in negative behaviours while distorting consequences or shifting blame. Interventions increasing the tourist's sense of connection with the relevant stakeholder (e.g. the house owner in the context of Breaking Bad), as well as informing the tourists about potential consequences of their behaviour might mitigate the activation of mechanisms, or reduce the negative impact on the stakeholders. Less involved fans however often justified engaging in negative behaviours using Primary Self-serving cognitive distortions or Euphemistic Language.

Reducing the likelihood of a mechanism being activated by explicitly acknowledging the behaviour (i.e. mitigating Euphemistic labelling by calling the behaviour what it is) and developing products that enable the tourist to legally and morally create positive memorable experiences can be successful for this group. For example, both the literature and findings suggest that acquiring tangible objects is important to screen tourists. Aside from providing screen tourists with a legal and moral option to the behaviour (e.g. souveniring), insights into the most frequently used moral disengagement mechanisms, and potential causes, can further inform the development of measures. By doing this, the individual's moral agency is also addressed. Second, the use of moral disengagement 
might be influenced by fandom identification, and the moral alignment of the fan object. Related to this is the role of fandom communities' own social structures that might influence the screen tourist. It can therefore be assumed that fandom specific measures or interventions will be more successful.

\subsection{FUtURE RESEARCH}

As discussed above, further in-depth research is necessary to achieve a better and deeper understanding of why screen tourists use moral disengagement mechanisms, e.g. by conducting qualitative interviews with screen tourists. Questions such as screen tourists' motivation for engaging in negative behaviour and their use of moral disengagement, the reasons behind deviations in mechanism selection processes, and the specific dynamic influence of fandom and community remain unanswered. Future research would thus benefit from taking other factors into consideration, such as identity, motivation, culture, personality, and context. Research that examines actual screen tourist behaviour and experiences instead of only hypothetical scenarios would also add further insight. Other sample characteristics (place of residence, fandom identification/object, specific screen tourism related destinations, and so forth) could be examined in future research, in particular exploring the impact of the moral alignment of the fan object on use of moral disengagement. While findings from this research suggest that the two fandom groups vary in their use of moral disengagement, this research does not examine the reasons behind this in-depth. Research that examines differences between fandoms and why these differ, at times significantly, is needed, in particular since this research focuses on two distinct TV-series. However, there are multiple screen locations experiencing negative tourist behaviour (e.g. Notting Hill, The Beach in Thailand) that could provide further valuable insight. Lastly, future research should explore measures and interventions that will be successful in mitigating moral disengagement and reducing impacts of negative on-site tourist behaviour in screen tourism destinations. 


\subsection{Conclusion}

This thesis has filled a research gap by examining screen tourists' use of moral disengagement to justify negative on-site tourist behaviour. The introduction identified common negative behaviours of screen tourists in screen related locations, including examples of disruptive and destructive behaviours. Drawing on these examples, the research examined moral justification of common on-site behaviours engaged in by Breaking Bad and Game of Thrones fans. Thus, it contributes to broadening current theoretical knowledge on the topic, in addition to its practical contributions. Screen tourism stakeholders can benefit from greater understanding of screen tourists' justification of negative behaviour when developing strategies, products, and services, and in developing interventions that aim to mitigate or reduce activation of moral disengagement as well as negative impacts while encouraging more positive behaviour. Further, understanding how fandom identification and level of involvement influence moral justification and negative behaviour is beneficial when tailoring both products and interventions to particular segments. 


\section{APPENDICES}

\section{APPENDiX A: SURVEY INVITATION}

Hi!

Are you a Breaking Bad or Game of Thrones fan living in either the UK, Ireland, Canada, the US, Australia, or New Zealand? Are you interested in participating in a research project about tourist behaviour and visiting locations famous from Breaking Bad/Game of Thrones, with the possibility of winning a \$100 NZD Amazon gift card? The survey is completely anonymous, and takes about 10-20 minutes to complete. Link to more information and survey: https://vuw.qualtrics.com/jfe/form/SV_cIueX2Qpoy1Febb

It would also be very much appreciated it if you would share this post with anyone you think might be interested!

I am a student at Victoria University of Wellington, New Zealand, and am currently doing a research project for my Master thesis in Tourism Management. This research has been approved by the Victoria University of Wellington Human Ethics Committee, \#0000028770.

Thank you so much in advance!

Feel free to contact me with any questions.

Best wishes,

Taran Jorgensen 


\section{APPENDIX B: INFORMATION SHEET}

\section{Research about Screen Tourist Behaviour}

Thank you so much for considering participating in this research project! Your time and participation are both very much appreciated.

This is a survey about understanding why some tourists behave the way they do in different contexts, how they justify their behaviour, and if being part of a fandom has an influence on this.

At the end of the survey, you will have the option to click a link to a separate form where you can enter a price draw for one of three $\$ 100$ NZD Amazon gift vouchers. Your participation in this survey is anonymous, and if you decide to enter the prize draw, your contact details will not be linked to your survey participation.

Below you will find more information about me, the research project, the survey (including more about the topics and questions), contact information, and information about Ethics approval.

Thank you again so much for participating!

\section{INFORMATION FOR PARTICIPANTS}

You are invited to take part in this research. Please read this information before deciding whether or not to take part. If you decide to participate, thank you. If you decide not to participate, thank you for considering this request.

\section{Who am I?}

My name is Taran Jorgensen and I am a Master student in Tourism management at Victoria University of Wellington. This research project is work towards my thesis.

\section{What is the aim of the project?}

This project examines how tourists might behave in hypothetical settings when visiting a site, attraction or place famous from a tv-series or movie, such as Breaking Bad or Game of Thrones. Having a better understanding of why and how tourists behave in certain settings is important for tourism planning, development and management. Your participation will support this research by contributing important insights to this topic. This information will contribute to a better understanding of tourist behaviour in certain contexts, and will also help improve tourism development, planning and management. This research has been approved by the Victoria University of Wellington Human Ethics Committee, \#0000028770

\section{How can you help?}

You have been invited to participate because you are part of the Breaking Bad or Game of Thrones fandom, living in either the UK, Ireland, Canada, the US, Australia or New Zealand. If you agree to take part, you will complete a survey. The survey will ask you questions about behaviour in hypothetical scenarios, and fandom involvement. The questions include questions about behaviour in hypothetical scenarios related to your fandom, and multiple choice and scaled questions. In one part of the survey you will have to indicate the extent you agree or disagree with different statements about different behaviours. Examples of statements you will be asked are "It is okay to tell small lies because they don't really do any harm" and "If people are careless where they leave their things, it is their own fault if they get stolen". 
The hypothetical scenarios will present situations where you are visiting a location famous from your fandom, and might want to engage in a certain behaviour, such as taking a selfie or picture. You will then be provided with a list of statements about this behaviour, and you are asked to select the statements you agree with.

The fandom questions will ask you about behaviours related to your fandom, for example how much time you spend on fandom related activities, how being part of a fandom makes you feel, etc. You will also be asked demographic questions, about age, gender identification, where you live, and so forth.

The survey will take you 15-20 minutes to complete. You can any time pause or exit the survey. If you decide to exit the survey, any responses will be deleted.

If you at any time feel uncomfortable or experience emotional distress, you are advised to stop and exit the survey, and seek support if necessary. A list of free mental health support services is provided throughout the survey and in the debriefing sheet at the end of the survey. The information can also be found by clicking here.

You can also choose to enter in a prize draw for one of three $\$ 100$ NZD Amazon gift vouchers. The winners of the prize draw will be selected using a random number generator once the survey has closed, and will be contacted via email by August 2021.

\section{What will happen to the information you give?}

This research is anonymous. This means that nobody, including the researchers will be aware of your identity. By answering it, you are giving consent for us to use your responses in this research. Your answers will remain completely anonymous and unidentifiable. Once you submit the survey, it will be impossible to retract your answer. Please do not include any personal identifiable information in your responses.

Personal details will be collected only for those who wish to enter the prize draw/request a copy of the final report. All personal details will be received separately from the survey data and will be held in confidence. This ensures that your answers to the survey questions will not be linked to your identity.

\section{What will the project produce?}

The information from my research will be used in my Masters thesis and potentially in academic publications and conferences.

If you have any questions or problems, who can you contact?

If you have any questions, either now or in the future, please feel free to contact either:

\begin{tabular}{|c|c|}
\hline \multirow{2}{*}{ Student: } & Supervisor: \\
Taran Jorgensen & Dr. Ina Reichenberger \\
jorgentara@myvuw.ac.nz & Role: Senior Lecturer in Tourism Management \\
& School: School of Management \\
& Phone: +64 04 4635375 \\
& Ina.reichenberger@vuw.ac.nz \\
\hline
\end{tabular}

Human Ethics Committee information

If you have any concerns about the ethical conduct of the research you may contact the Victoria University of Wellington HEC Convenor: Associate Professor Judith Loveridge.

Email hec@vuw.ac.nz or telephone+64-4-463 6028. 


\section{APPENDIX C: QuestionNAIRE}

\section{VICTORIA UNIVERSITY OF}

WELLINGTON

TE HERENGA WAKA

By selecting yes below and continuing the survey, you are consenting to participation in the research project. However, you are at any time able to change your mind and quit the survey. If you decide to quit the survey, all your collected data will be deleted. All data collected is anonymous.

If you select no, you will automatically exit the survey.

Do you consent to participate in this research project?

Yes

No

$0 \%$

Thank you so much for deciding to participate!

In this section you will be asked questions about where you live, your gender, age group, and level of completed education.

What is your current country of residence?

Onited Kingdom

O Ireland

Canada

United States of America

O Australia

New Zealand

Prefer not to say

None of the above 
What is your age group? (Please select one)

Under 18

O $18-19$

O 20-24

O $25-29$

O $30-34$

O $35-39$

O $40-44$

O $45-49$

O $50-54$

O $55-59$

O 60-69

O 70 and older

Prefer not to answer

$0 \%$

Which gender do you identify as? (Please select one)

O Male

O Female

Another gender

Prefer not to say

What is your highest level of completed education? (Please select one)

O No completed education

High school graduate

$\mathrm{O}$ Undergraduate degree

O Postgraduate degree

O Doctorate

Prefer not to say

$0 \%$ 


\section{Fandom Identification and Level of Involvement scale}

In this section you will be asked about which fandom you identify as part of.

Please select the most appropriate option. If you consider yourself part of both fandoms, please choose the fandom you are most active in.

Do you identify as a Breaking Bad fan, or a Game of Thrones Fan?

Breaking Bad

Game of Thrones

None of the above

$0 \%$

This section will ask you about your involvement and engagement with [fandom] in general, and how the fandom is important to you. This information will help us better understand if fans' behaviour is likely to differ based on their involvement in the series and fandom.

For please statement please indicate the extent to which you agree or disagree.

Strongly
agree Agree $\begin{gathered}\begin{array}{c}\text { Somewhat } \\ \text { agree }\end{array} \\ \begin{array}{l}\text { [fandom] is very } \\ \text { important to me }\end{array}\end{gathered}$




\begin{tabular}{|c|c|c|c|c|c|c|c|}
\hline & $\begin{array}{l}\text { Strongly } \\
\text { agree }\end{array}$ & Agree & $\begin{array}{c}\text { Somewhat } \\
\text { agree }\end{array}$ & $\begin{array}{l}\text { Neither } \\
\text { agree } \\
\text { nor } \\
\text { disagree }\end{array}$ & $\begin{array}{c}\text { Somewhat } \\
\text { disagree }\end{array}$ & Disagree & $\begin{array}{l}\text { Strongly } \\
\text { disagree }\end{array}$ \\
\hline $\begin{array}{l}\text { I find a lot of my } \\
\text { life is organized } \\
\text { around activities } \\
\text { that involve } \\
\text { [fandom] }\end{array}$ & 0 & 0 & 0 & 0 & 0 & 0 & 0 \\
\hline $\begin{array}{l}\text { Activities that } \\
\text { involve [fandom] } \\
\text { have a central } \\
\text { role in my life }\end{array}$ & 0 & 0 & 0 & 0 & 0 & 0 & 0 \\
\hline $\begin{array}{l}\text { I enjoy } \\
\text { discussing } \\
\text { [fandom] with } \\
\text { my friends }\end{array}$ & 0 & 0 & 0 & 0 & 0 & 0 & 0 \\
\hline \multirow{2}{*}{$\begin{array}{l}\text { Most of my } \\
\text { friends are in } \\
\text { some ways } \\
\text { connected in } \\
\text { activities related } \\
\text { to [fandom] }\end{array}$} & 0 & 0 & 0 & 0 & $\mathrm{O}$ & 0 & 0 \\
\hline & $\begin{array}{l}\text { Strongly } \\
\text { agree }\end{array}$ & Agree & $\begin{array}{c}\text { Somewhat } \\
\text { agree }\end{array}$ & $\begin{array}{l}\text { Neither } \\
\text { agree } \\
\text { nor } \\
\text { disagree }\end{array}$ & $\begin{array}{l}\text { Somewhat } \\
\text { disagree }\end{array}$ & Disagree & $\begin{array}{l}\text { Strongly } \\
\text { disagree }\end{array}$ \\
\hline $\begin{array}{l}\text { Participating in } \\
\text { activities that } \\
\text { involve [fandom] } \\
\text { says a lot about } \\
\text { who I am }\end{array}$ & 0 & 0 & 0 & $\mathrm{O}$ & $\mathrm{O}$ & 0 & $\mathrm{O}$ \\
\hline $\begin{array}{l}\text { You can tell a lot } \\
\text { about people by } \\
\text { seeing them } \\
\text { participating in } \\
\text { activities that } \\
\text { involve [fandom] }\end{array}$ & 0 & 0 & 0 & 0 & 0 & 0 & 0 \\
\hline $\begin{array}{l}\text { When I } \\
\text { participate in } \\
\text { activities that } \\
\text { involve [fandom] } \\
\text { I can really be } \\
\text { myself }\end{array}$ & 0 & 0 & 0 & 0 & 0 & 0 & 0 \\
\hline $\begin{array}{l}\text { When I } \\
\text { participate in } \\
\text { activities that } \\
\text { involve [fandom] } \\
\text { others see me } \\
\text { the way I want } \\
\text { them to see me }\end{array}$ & 0 & 0 & 0 & 0 & 0 & 0 & 0 \\
\hline $0 \%$ & & & & & & & $100 \%$ \\
\hline$\leftarrow$ & & & & & & & $\rightarrow$ \\
\hline
\end{tabular}


Here we are interested in your behaviours related to [fandom].

For each statement, please select the option that best reflect your behaviour.

Over the last 12 months how often have you...

\begin{tabular}{|c|c|c|c|c|c|c|c|}
\hline ... watched [fandom]? & $\begin{array}{c}\text { Daily or } \\
\text { nearly } \\
\text { every } \\
\text { day }\end{array}$ & $\begin{array}{c}2-3 \\
\text { times a } \\
\text { week } \\
\end{array}$ & $\begin{array}{c}\text { At least } \\
\text { once a } \\
\text { week } \\
\bigcirc\end{array}$ & $\begin{array}{c}\text { At least } \\
\text { once a } \\
\text { month } \\
\mathrm{O}\end{array}$ & $\begin{array}{l}\text { Less } \\
\text { than } \\
\text { once a } \\
\text { month } \\
\text { O }\end{array}$ & $\begin{array}{l}\text { Once or } \\
\text { twice } \\
\mathrm{O}\end{array}$ & $\begin{array}{c}\text { Never } \\
\bigcirc\end{array}$ \\
\hline $\begin{array}{l}\text {... participated in fan } \\
\text { meetings/activities } \\
\text { (online or in person) } \\
\text { related to [fandom]? }\end{array}$ & & & & & & & \\
\hline $\begin{array}{l}\text {... obtained } \\
\text { information about } \\
\text { [fandom] through the } \\
\text { internet (including } \\
\text { blogs, forums, wikis, } \\
\text { etc.), news articles, } \\
\text { and magazines? }\end{array}$ & & & & & & & \\
\hline $\begin{array}{l}\text {... talked about } \\
\text { [fandom] with other } \\
\text { people? }\end{array}$ & & & & & & & \\
\hline $\begin{array}{l}\text {... purchased items } \\
\text { associated with } \\
\text { [fandom]? }\end{array}$ & & & & & & & \\
\hline
\end{tabular}

In the next 12 months, how likely do you think it is that you will participate in activities related to [fandom] (e.g. watch movies/TV programs, participate in fan meetings (online and/or in person), and/or purchase items associated with [fandom])?

Extremely likely

Moderately likely

O Slightly likely

Neither likely nor unlikely

S Slightly unlikely

Moderately unlikely

$\mathrm{O}$ Extremely unlikely

$0 \%$ 


\section{Scenarios related to the Breaking Bad fandom}

The following section will show you three hypothetical scenarios related to Breaking Bad. Each scenario will present a hypothetical behaviour (for example behaviour related to taking a selfie), and ten statements that people might use to justify engaging in that behaviour (for example it is ok if someone asked you to do it).

Please select all the statements that best reflect your justifications in each scenario.

$0 \%$

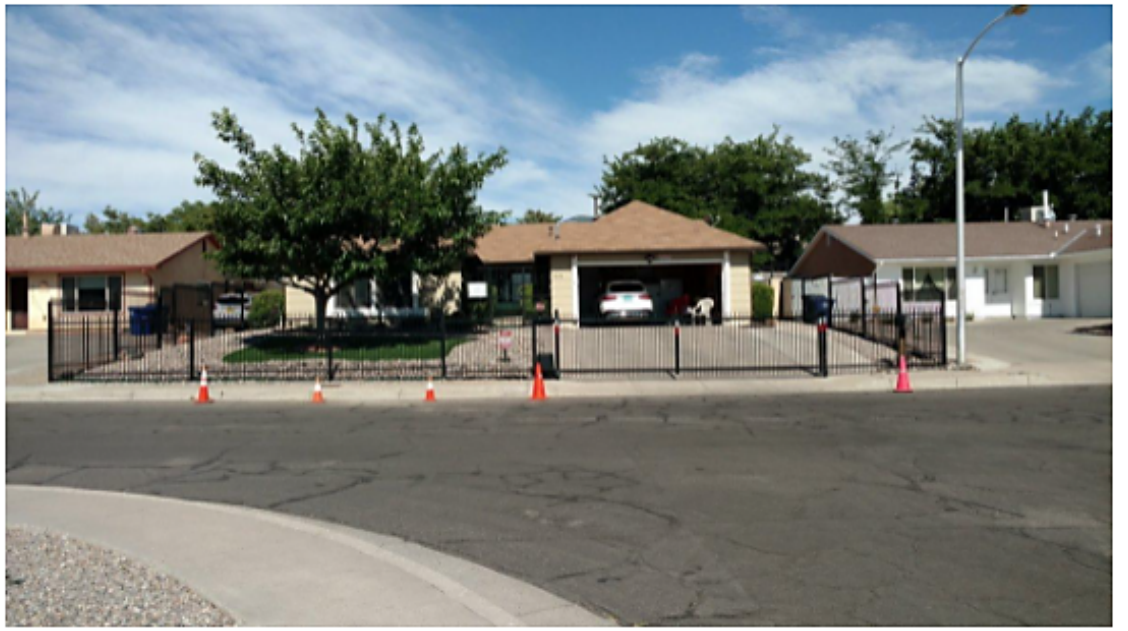

You want to take a really good selfie/picture for Instagram/social media, but you have to enter through a locked gate to get up close and take it. (Please select all that apply)

$\square$ It is ok to do this because it is not like you are breaking in or anything

$\square$ It is ok to do this because it is a Breaking Bad fandom trend

$\square$ It is ok to do this because the people who live there knew what they signed up for when they decided to live there

$\square$ It is ok to do this because I don't know the people living here

$\square$ It is ok to do this if other people are doing it as well

$\square$ It is ok to do this if someone else asks/tells you to do it

$\square$ It is ok to do this as it does not really cause any harm

$\square$ It is ok to do this because it's not trespassing, just a quick photo

$\square$ It is ok to do this because sometimes you have to do things like this to have a good experience

$\square$ It is ok to do this because you know it will bring back good memories

$\square$ It is not ok to do this 


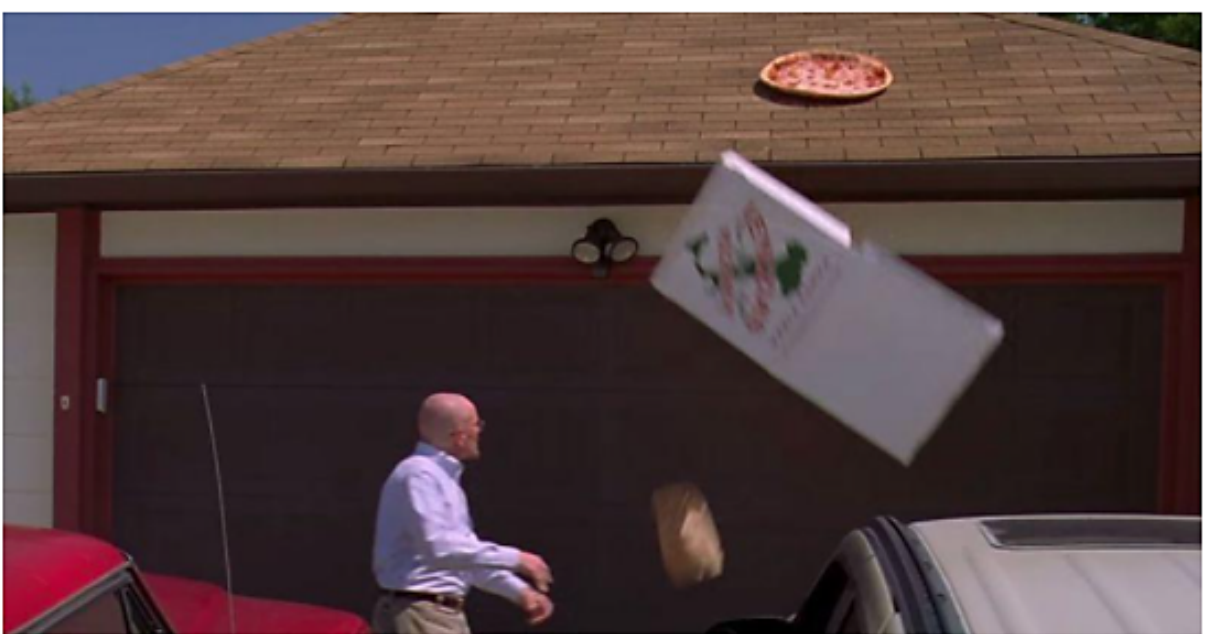

You have read about other fans visiting and re-creating the "pizza scene", and think this would be fun do to. (Please select all that apply)

$\square$ It is ok to do this because it is not like you are breaking in or anything

$\square$ It is ok to do this because it is a Breaking Bad fandom trend

$\square$ It is ok to do this because the people who live there knew what they signed up for when they decided to live there

$\square$ It is ok to do this because I don't know the people living here

$\square$ It is ok to do this if other people are doing it as well

$\square$ It is ok to do this if someone else asks/tells you to do it

$\square$ It is ok to do this as it does not really cause any harm

$\square$ It is ok to do this because it is just a prank

$\square$ It is ok to do this because sometimes you have to do things like this to have a good experience

$\square$ It is ok to do this because you know it will bring back good memories

$\square$ It is not ok to do this 
Scenario 3

You want to take a rock or flower you find in front of the house home as a souvenir. (Please select all that apply)

It is ok to do this because there are worse things you could do (like stealing their personal belongings)

$\square$ It is ok to do this because it is a Breaking Bad fandom trend

$\square$ It is ok to do this because the people who live there knew what they signed up for when they decided to live there

$\square$ It is ok to do this because I don't know the people living here

$\square$ It is ok to do this if other people are doing it as well

$\square$ It is ok to do this if someone else asks/tells you to do it

$\square$ It is ok to do this because taking just one rock or flower will not do any harm

$\square$ It is ok to do this because you are just "borrowing it"

$\square$ It is ok to do this because sometimes you have to do things like this to have a good experience

$\square$ It is ok to do this because you know it will bring back good memories

$\square$ It is not ok to do this

$0 \%$ 


\section{Scenarios related to the Game of Thrones fandom}

The following section will show you three hypothetical scenarios related to Game of Thrones. Each scenario will present a hypothetical behaviour (for example behaviour related to taking a selfie), and ten statements that people might use to justify engaging in that behaviour (for example it is ok if someone asked you to do it).

Please select all the statements that best reflect your justifications in each scenario.

$0 \%$

You are travelling to visit destinations famous from Game of Thrones.

\section{Scenario 1}

You are visiting Dubrovnik, Croatia, where parts of Game of Thrones were filmed.

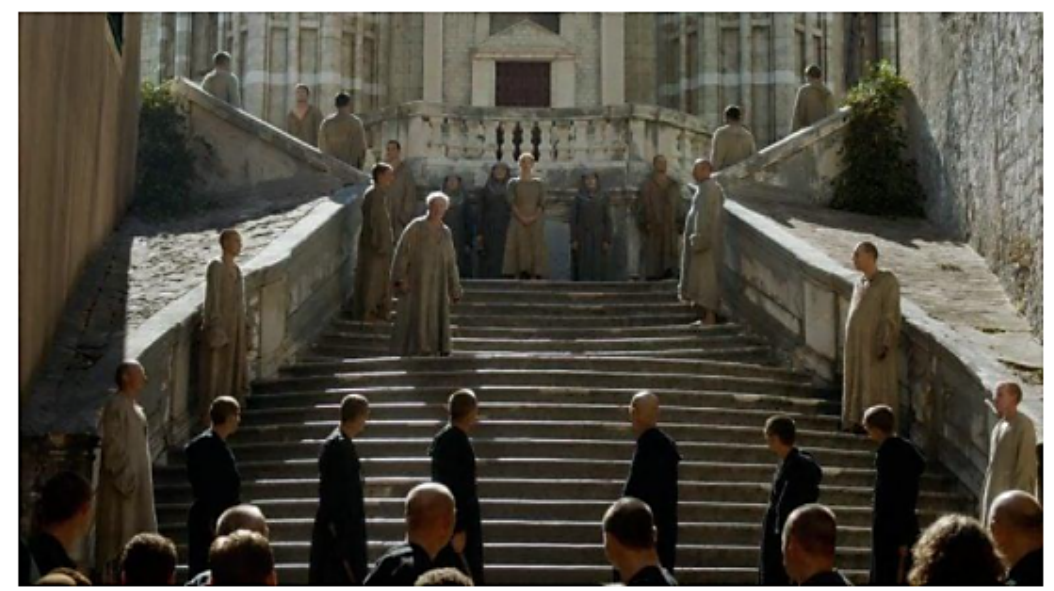

You want to re-create a famous scene from the show, however this means you have to block the location, and it is a busy time of the day. (Please select all that apply)

It is ok to do this because people are or could be doing worse things (like trespassing on someone's property)

$\square$ It is ok to do this because it is a GoT fandom trend

$\square$ It is ok to do this because they allowed the scenes from the tv-series to be filmed here and should have known these things would happen

$\square$ It is ok to do this because I don't know the people living here

$\square$ It is ok to do this if other people are doing it as well

$\square$ It is ok to do this if someone else asks/tells you to do it

$\square$ It is ok to do this as it does not really cause any harm

$\square$ It is ok to do this because it is just a quick photo

$\square$ It is ok to do this because sometimes you have to do things like this to have a good experience

$\square$ It is ok to do this because you know it will bring back good memories

$\square$ It is not ok to do this 
You are visiting Iceland's Fjaס́rárgljúfur Canyon, where parts of Game of Thrones were filmed.

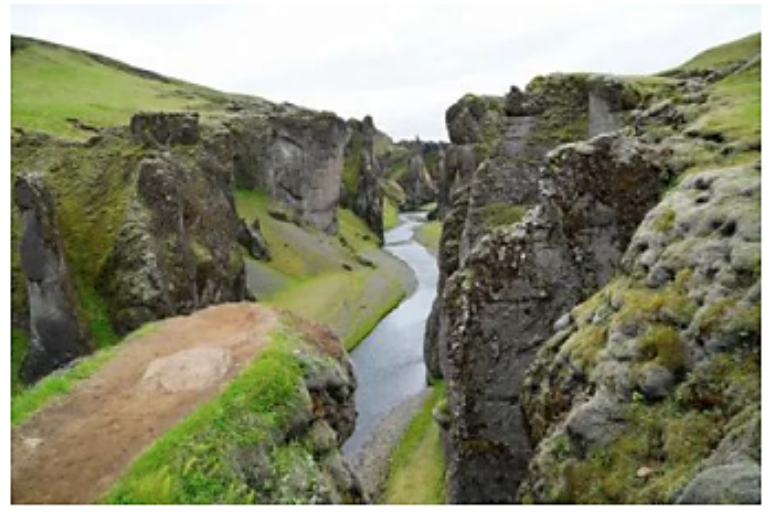

You want to take a selfie in an especially important location from the series, however, it is closed off by rope fence structure and a sign that says it is closed to tourists due to environmental damage. (Please select all that apply)

$\square$ It is ok to climb over the rope because they probably did more damage when they filmed here

$\square$ It is ok to do this because it is a GoT fandom trend

$\square$ It is ok to climb over the rope, since it is only a rope, and not a fence. If they wanted to make sure people stayed away, they would have put up a real fence

$\square$ It is ok to do this because doing this because nature is not human, and doing this will not harm anyone

$\square$ It is ok to do this if other people are doing it as well

$\square$ It is ok to do this if someone else asks/tells you to do it

$\square$ It is ok to climb over the rope because the damage has already been done and one more tourist does not have an impact really

$\square$ It is ok to do this because it's not trespassing, just a quick photo

$\square$ It is ok to do this because sometimes you have to do things like this to have a good experience

$\square$ It is ok to do this because you know it will bring back good memories

$\square$ It is not ok to do this 
Scenario 3

You are still visiting Iceland's Fjaס̋rárgljúfur Canyon, and you want to take a rock to bring home as a souvenir. (Please select all that apply)

$\square$ It is ok to do this because there are worse things you could do (like causing permanent damage)

$\square$ It is ok to do this because it is a GoT fandom trend

$\square$ It is ok to do this because they allowed the tv-series to be filmed in nature, and should have known that this could happen

$\square$ It is ok to do this because doing this because nature is not human, and doing this will not harm anyone

$\square$ It is ok to do this if other people are doing it as well

$\square$ It is ok to do this if someone else asks/tells you to do it

$\square$ It is ok to do this because taking just one rock will not do any harm

$\square$ It is ok to do this because you are just "borrowing it"

$\square$ It is ok to do this because sometimes you have to do things like this to have a good experience

$\square$ It is ok to do this because you know it will bring back good memories

$\square$ It is not ok to do this

$0 \%$ 


\section{Moral Disengagement Scale}

In the previous section, you were asked questions about how you might justify engaging in certain behaviours in a tourism setting specific to your fandom. The following section explores different ways in which people think about immoral behaviour in general. This allows us to compare the two different contexts, and explore if being a fan of a tv-show influence how people think about engaging in different immoral behaviours.

This scale uses questions that refer to different behaviours that include a few violent behaviours. If you are uncomfortable answering these questions, you can skip this part and continue to the next section of the survey.

Do you want to continue or skip this section?

$$
\begin{aligned}
& \text { I want to continue } \\
& \text { I want to skip this section }
\end{aligned}
$$

$0 \%$

\begin{tabular}{|c|c|c|c|c|c|c|c|}
\hline & $\begin{array}{c}\text { Strongly } \\
\text { agree }\end{array}$ & Agree & $\begin{array}{c}\text { Somewhat } \\
\text { agree }\end{array}$ & $\begin{array}{l}\text { Neither } \\
\text { agree } \\
\text { nor } \\
\text { disagree }\end{array}$ & $\begin{array}{c}\text { Somewhat } \\
\text { disagree }\end{array}$ & Disagree & $\begin{array}{l}\text { Strongly } \\
\text { disagree }\end{array}$ \\
\hline $\begin{array}{l}\text { 1. It is alright to } \\
\text { do what it takes } \\
\text { to protect your } \\
\text { friends }\end{array}$ & $\bigcirc$ & $\mathrm{O}$ & $\bigcirc$ & 0 & $\mathrm{O}$ & $\bigcirc$ & $\bigcirc$ \\
\hline $\begin{array}{l}\text { 2. Being } \\
\text { physical with } \\
\text { someone is just } \\
\text { a way of joking }\end{array}$ & 0 & 0 & 0 & 0 & 0 & 0 & 0 \\
\hline $\begin{array}{l}\text { 3. Damaging } \\
\text { some property } \\
\text { is no big deal } \\
\text { when you } \\
\text { consider that } \\
\text { others are } \\
\text { fighting other } \\
\text { people }\end{array}$ & $\bigcirc$ & $\mathrm{O}$ & $\bigcirc$ & $\bigcirc$ & $\mathrm{O}$ & $\mathrm{O}$ & $\mathrm{O}$ \\
\hline $\begin{array}{l}\text { 4. A person in a } \\
\text { group should } \\
\text { not be blamed } \\
\text { for the trouble } \\
\text { the group } \\
\text { causes }\end{array}$ & 0 & 0 & 0 & 0 & 0 & 0 & 0 \\
\hline $\begin{array}{l}\text { 5. If people are } \\
\text { living under bad } \\
\text { conditions they } \\
\text { cannot be } \\
\text { blamed for } \\
\text { behaving } \\
\text { aggressively }\end{array}$ & 0 & 0 & $\mathrm{O}$ & $\mathrm{O}$ & 0 & 0 & 0 \\
\hline $\begin{array}{l}6 \text {. It is okay to } \\
\text { tell small lies } \\
\text { because they } \\
\text { don't really do } \\
\text { any harm }\end{array}$ & 0 & 0 & 0 & 0 & 0 & 0 & 0 \\
\hline $\begin{array}{l}\text { 7. Some people } \\
\text { deserve to be } \\
\text { treated like } \\
\text { animals }\end{array}$ & 0 & 0 & $\bigcirc$ & 0 & $\mathrm{O}$ & $\bigcirc$ & 0 \\
\hline
\end{tabular}

For please statement please indicate the extent to which you agree or disagree. 


\begin{tabular}{|c|c|c|c|c|c|c|c|}
\hline & $\begin{array}{l}\text { Strongly } \\
\text { agree }\end{array}$ & Agree & $\begin{array}{c}\text { Somewhat } \\
\text { agree }\end{array}$ & $\begin{array}{l}\text { Neither } \\
\text { agree } \\
\text { nor } \\
\text { disagree }\end{array}$ & $\begin{array}{l}\text { Somewhat } \\
\text { disagree }\end{array}$ & Disagree & $\begin{array}{l}\text { Strongly } \\
\text { disagree }\end{array}$ \\
\hline $\begin{array}{l}\text { 8. If people } \\
\text { misbehave } \\
\text { during a tour it } \\
\text { is their guide's } \\
\text { fault }\end{array}$ & O & 0 & 0 & 0 & 0 & 0 & 0 \\
\hline $\begin{array}{l}\text { 9. It is alright to } \\
\text { fight someone } \\
\text { who bad } \\
\text { mouths your } \\
\text { family or loved } \\
\text { ones }\end{array}$ & 0 & 0 & 0 & 0 & 0 & 0 & 0 \\
\hline $\begin{array}{l}\text { 10. To hit } \\
\text { obnoxious } \\
\text { people is just } \\
\text { giving them "a } \\
\text { lesson" }\end{array}$ & O & O & O & O & O & $\bigcirc$ & 0 \\
\hline $\begin{array}{l}\text { 11. Stealing } \\
\text { some money is } \\
\text { not too serious } \\
\text { compared to } \\
\text { those who steal } \\
\text { a lot of money }\end{array}$ & 0 & 0 & 0 & 0 & O & 0 & 0 \\
\hline $\begin{array}{l}\text { 12. A person } \\
\text { who only } \\
\text { suggests } \\
\text { breaking rules } \\
\text { should not be } \\
\text { blamed if other } \\
\text { people go } \\
\text { ahead and do it }\end{array}$ & ○ & 0 & ○ & O & 0 & 0 & 0 \\
\hline $\begin{array}{l}\text { 13. If people } \\
\text { are not } \\
\text { disciplined they } \\
\text { should not be } \\
\text { blamed for } \\
\text { misbehaving }\end{array}$ & 0 & 0 & 0 & 0 & 0 & 0 & 0 \\
\hline \multirow{2}{*}{$\begin{array}{l}\text { 14. People do } \\
\text { not mind being } \\
\text { teased because } \\
\text { it shows } \\
\text { interest in them }\end{array}$} & O & 0 & 0 & 0 & 0 & 0 & 0 \\
\hline & $\begin{array}{l}\text { Strongly } \\
\text { agree }\end{array}$ & Agree & $\begin{array}{c}\text { Somewhat } \\
\text { agree }\end{array}$ & $\begin{array}{l}\text { Neither } \\
\text { agree } \\
\text { nor } \\
\text { disagree }\end{array}$ & $\begin{array}{l}\text { Somewhat } \\
\text { disagree }\end{array}$ & Disagree & $\begin{array}{l}\text { Strongly } \\
\text { disagree }\end{array}$ \\
\hline $\begin{array}{l}\text { 15. It is okay to } \\
\text { treat badly } \\
\text { somebody who } \\
\text { behaved like a } \\
\text { "worm" }\end{array}$ & 0 & 0 & 0 & 0 & 0 & 0 & 0 \\
\hline $\begin{array}{l}\text { 16. If people } \\
\text { are careless } \\
\text { where they } \\
\text { leave their } \\
\text { things it is their } \\
\text { own fault if they } \\
\text { get stolen }\end{array}$ & 0 & 0 & 0 & 0 & 0 & 0 & 0 \\
\hline $\begin{array}{l}\text { 17. It is alright } \\
\text { to fight when } \\
\text { your group's } \\
\text { honour is } \\
\text { threatened }\end{array}$ & 0 & 0 & 0 & 0 & 0 & 0 & 0 \\
\hline $\begin{array}{l}\text { 18. Taking } \\
\text { someone's } \\
\text { property } \\
\text { without their } \\
\text { permission is } \\
\text { just "borrowing } \\
\text { it" }\end{array}$ & 0 & 0 & 0 & 0 & 0 & 0 & 0 \\
\hline $\begin{array}{l}\text { 19. It is okay to } \\
\text { insult someone } \\
\text { because } \\
\text { fighting them is } \\
\text { worse }\end{array}$ & 0 & 0 & 0 & 0 & 0 & 0 & 0 \\
\hline $\begin{array}{l}\text { 20. If a group } \\
\text { decides } \\
\text { together to do } \\
\text { something } \\
\text { harmful it is } \\
\text { unfair to blame } \\
\text { any one person } \\
\text { in the group for } \\
\text { it }\end{array}$ & 0 & 0 & 0 & 0 & 0 & 0 & 0 \\
\hline $\begin{array}{l}\text { 21. People } \\
\text { cannot be } \\
\text { blamed for } \\
\text { using bad } \\
\text { words when all } \\
\text { their friends do } \\
\text { it }\end{array}$ & 0 & 0 & O & O & 0 & 0 & 0 \\
\hline
\end{tabular}




\begin{tabular}{|c|c|c|c|c|c|c|c|}
\hline & $\begin{array}{l}\text { Strongly } \\
\text { agree }\end{array}$ & Agree & $\begin{array}{l}\text { Somewhat } \\
\text { agree }\end{array}$ & $\begin{array}{l}\text { Neither } \\
\text { agree } \\
\text { nor } \\
\text { disagree }\end{array}$ & $\begin{array}{l}\text { Somewhat } \\
\text { disagree }\end{array}$ & Disagree & $\begin{array}{l}\text { Strongly } \\
\text { disagree }\end{array}$ \\
\hline $\begin{array}{l}\text { 22. Teasing } \\
\text { someone does } \\
\text { not really hurt } \\
\text { them }\end{array}$ & 0 & 0 & 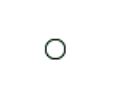 & 0 & 0 & 0 & 0 \\
\hline $\begin{array}{l}23 \text {. Someone } \\
\text { who is } \\
\text { obnoxious does } \\
\text { not deserve to } \\
\text { be treated like } \\
\text { a human being }\end{array}$ & 0 & 0 & 0 & 0 & 0 & 0 & 0 \\
\hline $\begin{array}{l}\text { 24. People who } \\
\text { get mistreated } \\
\text { usually do } \\
\text { things that } \\
\text { deserve it }\end{array}$ & O & O & $\mathrm{O}$ & $\mathrm{O}$ & 0 & $\mathrm{O}$ & 0 \\
\hline $\begin{array}{l}\text { 25. It is alright } \\
\text { to lie to keep } \\
\text { your friends } \\
\text { and family out } \\
\text { of trouble }\end{array}$ & 0 & 0 & 0 & 0 & 0 & 0 & 0 \\
\hline $\begin{array}{l}\text { 26. It is not a } \\
\text { bad thing to } \\
\text { "get high" once } \\
\text { in a while }\end{array}$ & O & 0 & $\mathrm{O}$ & $\mathrm{O}$ & O & 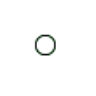 & 0 \\
\hline $\begin{array}{l}\text { 27. Compared } \\
\text { to the illegal } \\
\text { things people } \\
\text { do, taking some } \\
\text { things from a } \\
\text { store without } \\
\text { paying for them } \\
\text { is not very } \\
\text { serious }\end{array}$ & 0 & 0 & 0 & 0 & 0 & 0 & 0 \\
\hline \multirow{2}{*}{$\begin{array}{l}\text { 28. It is unfair } \\
\text { to blame a } \\
\text { person who } \\
\text { had only a } \\
\text { small part in the } \\
\text { harm caused } \\
\text { by a group }\end{array}$} & 0 & O & 0 & 0 & $\bigcirc$ & 0 & O \\
\hline & $\begin{array}{l}\text { Strongly } \\
\text { agree }\end{array}$ & Agree & $\begin{array}{l}\text { Somewhat } \\
\text { agree }\end{array}$ & $\begin{array}{l}\text { Neither } \\
\text { agree } \\
\text { nor } \\
\text { disagree }\end{array}$ & $\begin{array}{l}\text { Somewhat } \\
\text { disagree }\end{array}$ & Disagree & $\begin{array}{l}\text { Strongly } \\
\text { disagree }\end{array}$ \\
\hline $\begin{array}{l}\text { 29. A person } \\
\text { cannot be } \\
\text { blamed for } \\
\text { misbehaving if } \\
\text { their friends } \\
\text { pressured them } \\
\text { to do it }\end{array}$ & 0 & 0 & 0 & 0 & 0 & 0 & 0 \\
\hline $\begin{array}{l}\text { 30. Insults } \\
\text { among adults } \\
\text { do not hurt } \\
\text { anyone }\end{array}$ & $\mathrm{O}$ & 0 & 0 & 0 & 0 & 0 & 0 \\
\hline $\begin{array}{l}\text { 31. Some } \\
\text { people have to } \\
\text { be treated } \\
\text { roughly } \\
\text { because they } \\
\text { lack feelings } \\
\text { that can be hurt }\end{array}$ & 0 & $\mathrm{O}$ & 0 & 0 & $\mathrm{O}$ & 0 & 0 \\
\hline $\begin{array}{l}\text { 32. A person is } \\
\text { not at fault for } \\
\text { misbehaving if } \\
\text { someone } \\
\text { "higher up" } \\
\text { force them too } \\
\text { much }\end{array}$ & 0 & 0 & 0 & 0 & 0 & 0 & 0 \\
\hline \multicolumn{8}{|c|}{$\begin{array}{l}\text { If you feel uncomfortable or experience emotional distress, you are advised to end the survey and seek support if necessary. } \\
\text { Fiease click here to acoess an overview of free mental health support services. }\end{array}$} \\
\hline $0 \%$ & & & & & & & $100 \%$ \\
\hline$\leftarrow$ & & & & & & & $\rightarrow$ \\
\hline
\end{tabular}


Appendix D: Debrief Sheet and Invitation To Prize DraW

Thank you again so much for participating in this research project. Your participation and time are very much appreciated!

This aim of this survey is to better understand how screen tourists might justify engaging in negative behaviour in different settings, and if being part of a fandom influence this. Below you will find more information about where to find mental health support services information if needed, and more information about the research project, such as the theory and information about the scales used. When you continue, you can click the link to an external page (not linked to your participation), where you can enter your contact information if you are interested in entering the prize draw and/or receiving a summary report when the project is completed. Please remember to still submit your response to this survey as well.

This section will provide you with some more information about the purpose of the research project, the questions you were asked, and a link to information about free mental health support services you can access if necessary.

If you feel uncomfortable or experience emotional distress, you are advised to seek support if necessary. A list of free mental health support services can be found by clicking here.

This survey has asked you about different behaviours related to your fandom, and behaviours in general. The purpose of this study is to better understand how tourists might justify their behaviour in different scenarios, both in general, and in a fandom-tourism setting (when tourists visit a location famous from the movie or tv-series they are a fan of). We are interested in this because research and experience show that some tourists and people engage in some behaviour they otherwise would not engage in. By better understanding why and how tourists justify this behaviour, the tourism industry can develop strategies, plans, products and services to better manage tourist behaviour, and make tourism a more positive experience for everyone involved. 
One of the theories used to better understand how people justify their behaviours is called Moral Disengagement Theory by Albert Bandura. According to this theory, people might engage in behaviours they otherwise would not do, because of something called moral disengagement mechanisms. These mechanisms allow the person do justify the behaviour to themselves by for example re-naming them ("Taking someone's property without their permission is just "borrowing it""), shifting responsibility ("If a group decides together to do something harmful it is unfair to blame any one person in the group for it"). These are things that all people do at some point.

This theory is used in this research project, and the "moral disengagement scale" with statements about different general behaviours is adapted from Albert Bandura's work. This scale allows us to better understand how people justify engaging in behaviours they might otherwise not engage in, but do in some circumstances, by asking different questions related to the different moral disengagement mechanisms identified by Albert Bandura. Examples of statements from this scale include "People do not mind being teased because it shows interest in them", "If a group decides together to do something harmful it is unfair to blame any one person in the group for it", and "It is alright to lie to keep your friends and family out of trouble".

You were also asked questions about hypothetical behaviour in hypothetical scenarios specific to your fandom. The statements and questions are based Albert Bandura's scale, and allow us to better understand how tourists might justify their behaviour in different context specific scenarios, such as when you are a fan visiting a place that is important to you.

Related to this is the questions about your fandom involvement. These questions were asked to explore your level of fandom involvement, and to examine if level of fandom involvement impact on justification of behaviours, and behaviours tourists engage in.

A reminder, when you click to continue, you can click the link to an external page (not linked to your participation in this survey), where you can enter your contact information if you are interested in entering the prize draw and/or receiving a summary report when the project is completed. Please remember to still submit your response to this survey as well.

Thank you again so much participating in this research project!

Best wishes,

Taran Jorgensen

Remember, if you feel uncomfortable or experience emotional distress, you are advised to seek support if necessary. A list of free mental health support services can be found by clicking $\underline{\text { here. }}$.

$0 \%$ $100 \%$ 
Appendix E: Prize DraW Survey

Thank you so much for participating in this research project!

If you wish to enter the prize draw and/or receive a summary report when the research project is completed, please enter your email address below and answer the two questions. Winners of the prize draw will be drawn using a random number generator, and will be contacted on or before August 1st 2021.

Your email address will not in any way be connected to your submitted survey response, and will only be used for the purpose of sending the summary report and/or the prize draw.

Thank you again for participating in this research project!

Please enter your email address below

I want a summary report when the research project is complete

$\bigcirc$ Yes

No

I want to enter the prize draw

Yes

No 


\section{APPENDIX F: SCENARIO STATEMENTS AND CORRESPONDING MECHANISMS}

\section{Breaking Bad Scenarios}

Scenario 1 - Trespassing (Entering through locked gate)

\begin{tabular}{ll} 
Mechanism & Scenario Statement \\
\hline Advantageous comparison (MDE) & $\begin{array}{l}\text { It is ok to do this because it is not like you are breaking } \\
\text { in or anything }\end{array}$ \\
\hline Appeal to higher loyalties (NT) & $\begin{array}{l}\text { It is ok to do this because it is a Breaking Bad fandom } \\
\text { trend }\end{array}$ \\
\hline Attribution of blame (MDE) & $\begin{array}{l}\text { It is ok to do this because the people who live there } \\
\text { knew what they signed up for when they decided to live } \\
\text { there }\end{array}$ \\
\hline Dehumanisation of victim (MDE) & $\begin{array}{l}\text { It is ok to do this because I don't know the people } \\
\text { living here }\end{array}$ \\
\hline Diffusion of responsibility (MDE) & It is ok to do this if other people are doing it as well \\
\hline Displacement of responsibility (MDE) & It is ok to do this if someone else asks/tells you to do it \\
\hline Distortion of consequences (MDE) & It is ok to do this as it does not really cause any harm \\
\hline Euphemistic language (MDE) & $\begin{array}{l}\text { It is ok to do this because it's not trespassing, just a } \\
\text { quick photo }\end{array}$ \\
\hline Moral justification (MDE) & $\begin{array}{l}\text { It is ok to do this because sometimes you have to do } \\
\text { things like this to have a good experience }\end{array}$ \\
\hline Primary Self-serving cognitive distortions & $\begin{array}{l}\text { It is ok to do this because you know it will bring back } \\
\text { good memories }\end{array}$ \\
\hline
\end{tabular}

Scenario 2 - Throwing pizzas on roof

\begin{tabular}{ll} 
Mechanism & Scenario Statement \\
\hline Advantageous comparison (MDE) & $\begin{array}{l}\text { It is ok to do this because it is not like you are } \\
\text { breaking in or anything }\end{array}$ \\
\hline Appeal to higher loyalties (NT) & $\begin{array}{l}\text { It is ok to do this because it is a Breaking Bad } \\
\text { fandom trend }\end{array}$ \\
\hline Attribution of blame (MDE) & $\begin{array}{l}\text { It is ok to do this because the people who live } \\
\text { there knew what they signed up for when they } \\
\text { decided to live there }\end{array}$ \\
\hline Dehumanisation of victim (MDE) & $\begin{array}{l}\text { It is ok to do this because I don't know the people } \\
\text { living here }\end{array}$ \\
\hline Diffusion of responsibility (MDE) & $\begin{array}{l}\text { It is ok to do this if other people are doing it as } \\
\text { well }\end{array}$ \\
\hline Displacement of responsibility (MDE) & $\begin{array}{l}\text { It is ok to do this if someone else asks/tells you to } \\
\text { do it }\end{array}$ \\
\hline Distortion of consequences (MDE) & $\begin{array}{l}\text { It is ok to do this as it does not really cause any } \\
\text { harm }\end{array}$ \\
\hline Euphemistic language (MDE) & It is ok to do this because it is just a prank \\
\hline Moral justification (MDE) & $\begin{array}{l}\text { It is ok to do this because sometimes you have to } \\
\text { do things like this to have a good experience }\end{array}$ \\
\hline Primary Self-serving cognitive distortions & $\begin{array}{l}\text { It is ok to do this because you know it will bring } \\
\text { back good memories }\end{array}$ \\
\hline
\end{tabular}


Scenario 3 - Souveniring (Taking a rock/other object from the garden/yard)

\begin{tabular}{ll} 
Mechanism & Scenario Statement \\
\hline Advantageous comparison (MDE) & $\begin{array}{l}\text { It is ok to do this because there are worse things } \\
\text { you could do (like stealing their personal } \\
\text { belongings) }\end{array}$ \\
\hline Appeal to higher loyalties (NT) & $\begin{array}{l}\text { It is ok to do this because it is a Breaking Bad } \\
\text { fandom trend }\end{array}$ \\
\hline Attribution of blame (MDE) & $\begin{array}{l}\text { It is ok to do this because the people who live } \\
\text { there knew what they signed up for when they } \\
\text { decided to live there }\end{array}$ \\
\hline Dehumanisation of victim (MDE) & $\begin{array}{l}\text { It is ok to do this because I don't know the people } \\
\text { living here }\end{array}$ \\
\hline Diffusion of responsibility (MDE) & $\begin{array}{l}\text { It is ok to do this if other people are doing it as } \\
\text { well }\end{array}$ \\
\hline Displacement of responsibility (MDE) & $\begin{array}{l}\text { It is ok to do this if someone else asks/tells you to } \\
\text { do it }\end{array}$ \\
\hline Distortion of consequences (MDE) & $\begin{array}{l}\text { It is ok to do this because taking just one rock or } \\
\text { flower will not do any harm }\end{array}$ \\
\hline Euphemistic language (MDE) & $\begin{array}{l}\text { It is ok to do this because you are just "borrowing } \\
\text { it" }\end{array}$ \\
\hline Moral justification (MDE) & $\begin{array}{l}\text { It is ok to do this because sometimes you have to } \\
\text { do things like this to have a good experience }\end{array}$ \\
\hline Primary Self-serving cognitive distortions & $\begin{array}{l}\text { It is ok to do this because you know it will bring } \\
\text { back good memories }\end{array}$ \\
\hline
\end{tabular}




\section{Game of Thrones Scenarios}

Scenario 1 - Block access

\begin{tabular}{ll} 
Mechanism & Scenario Statement \\
\hline Advantageous comparison (MDE) & $\begin{array}{l}\text { It is ok to do this because people are or could be } \\
\text { doing worse things (like trespassing on } \\
\text { someone's property) }\end{array}$ \\
\hline Appeal to higher loyalties (NT) & $\begin{array}{l}\text { It is ok to do this because it is a GoT fandom } \\
\text { trend }\end{array}$ \\
\hline Attribution of blame (MDE) & $\begin{array}{l}\text { It is ok to do this because they allowed the scenes } \\
\text { from the TV-series to be filmed here and should } \\
\text { have known these things would happen }\end{array}$ \\
\hline Dehumanisation of victim (MDE) & $\begin{array}{l}\text { It is ok to do this because I don't know the people } \\
\text { living here }\end{array}$ \\
\hline Diffusion of responsibility (MDE) & $\begin{array}{l}\text { It is ok to do this if other people are doing it as } \\
\text { well }\end{array}$ \\
\hline Displacement of responsibility (MDE) & $\begin{array}{l}\text { It is ok to do this if someone else asks/tells you to } \\
\text { do it }\end{array}$ \\
\hline Distortion of consequences (MDE) & $\begin{array}{l}\text { It is ok to do this as it does not really cause any } \\
\text { harm }\end{array}$ \\
\hline Euphemistic language (MDE) & It is ok to do this because it is just a quick photo \\
\hline Moral justification (MDE) & $\begin{array}{l}\text { It is ok to do this because sometimes you have to } \\
\text { do things like this to have a good experience }\end{array}$ \\
\hline Primary Self-serving cognitive distortions & $\begin{array}{l}\text { It is ok to do this because you know it will bring } \\
\text { back good memories }\end{array}$ \\
\hline
\end{tabular}

Scenario 2 - Trespassing (Climb over rope)

\begin{tabular}{ll} 
Mechanism & Scenario Statement \\
\hline Advantageous comparison (MDE) & $\begin{array}{l}\text { It is ok to climb over the rope because they } \\
\text { probably did more damage when they filmed here }\end{array}$ \\
\hline Appeal to higher loyalties (NT) & $\begin{array}{l}\text { It is ok to do this because it is a GoT fandom } \\
\text { trend }\end{array}$ \\
\hline Attribution of blame (MDE) & $\begin{array}{l}\text { It is ok to climb over the rope, since it is only a } \\
\text { rope, and not a fence. If they wanted to make sure } \\
\text { people stayed away, they would have put up a } \\
\text { real fence }\end{array}$ \\
\hline Dehumanisation of victim (MDE) & $\begin{array}{l}\text { It is ok to do this because doing this because } \\
\text { nature is not human, and doing this will not harm } \\
\text { anyone }\end{array}$ \\
\hline Diffusion of responsibility (MDE) & $\begin{array}{l}\text { It is ok to do this if other people are doing it as } \\
\text { well }\end{array}$ \\
\hline Displacement of responsibility (MDE) & $\begin{array}{l}\text { It is ok to do this if someone else asks/tells you to } \\
\text { do it }\end{array}$ \\
\hline Distortion of consequences (MDE) & $\begin{array}{l}\text { It is ok to climb over the rope because the } \\
\text { damage has already been done and one more } \\
\text { tourist does not have an impact really }\end{array}$ \\
\hline Euphemistic language (MDE) & $\begin{array}{l}\text { It is ok to do this because it's not trespassing, just } \\
\text { a quick photo }\end{array}$ \\
\hline Moral justification (MDE) & $\begin{array}{l}\text { It is ok to do this because sometimes you have to } \\
\text { do things like this to have a good experience }\end{array}$ \\
\hline Primary Self-serving cognitive distortions & $\begin{array}{l}\text { It is ok to do this because you know it will bring } \\
\text { back good memories }\end{array}$ \\
\hline
\end{tabular}


Scenario 3 - Souveniring (Taking a rock/other object)

\begin{tabular}{ll} 
Mechanism & Scenario Statement \\
\hline Advantageous comparison (MDE) & $\begin{array}{l}\text { It is ok to do this because there are worse things } \\
\text { you could do (like causing permanent damage) }\end{array}$ \\
\hline Appeal to higher loyalties (NT) & $\begin{array}{l}\text { It is ok to do this because it is a GoT fandom } \\
\text { trend }\end{array}$ \\
\hline Attribution of blame (MDE) & $\begin{array}{l}\text { It is ok to do this because they allowed the TV- } \\
\text { series to be filmed in nature, and should have } \\
\text { known that this could happen }\end{array}$ \\
\hline Dehumanisation of victim (MDE) & $\begin{array}{l}\text { It is ok to do this because doing this because } \\
\text { nature is not human, and doing this will not harm } \\
\text { anyone }\end{array}$ \\
\hline Diffusion of responsibility (MDE) & $\begin{array}{l}\text { It is ok to do this if other people are doing it as } \\
\text { well }\end{array}$ \\
\hline Displacement of responsibility (MDE) & $\begin{array}{l}\text { It is ok to do this if someone else asks/tells you to } \\
\text { do it }\end{array}$ \\
\hline Distortion of consequences (MDE) & $\begin{array}{l}\text { It is ok to do this because taking just one rock } \\
\text { will not do any harm }\end{array}$ \\
\hline Euphemistic language (MDE) & $\begin{array}{l}\text { It is ok to do this because you are just "borrowing } \\
\text { it" }\end{array}$ \\
\hline Moral justification (MDE) & $\begin{array}{l}\text { It is ok to do this because sometimes you have to } \\
\text { do things like this to have a good experience }\end{array}$ \\
\hline Primary Self-serving cognitive distortions & $\begin{array}{l}\text { It is ok to do this because you know it will bring } \\
\text { back good memories }\end{array}$ \\
\hline
\end{tabular}




\section{REFERENCES}

Adam, F. (2014). Methodological and Epistemic Framework: From Positivism to Postpositivism. In Measuring National Innovation Performance: The Innovation Union Scoreboard Revisited (pp. 5-7). Berlin, Heidelberg: Springer Berlin Heidelberg. https://doi.org/10.1007/978-3-642-39464-5_2

Alreck, P. L., \& Settle, R. B. (2004). The survey research handbook (3rd ed.). Boston, MA: McGraw-Hill/Irwin.

Bandura, A. (1986). Social foundations of thought and action: A social cognitive theory. NJ, US: Prentice-Hall, Inc.

Bandura, A. (1990). Selective activation and disengagement of moral control. Journal of Social Issues, 46(1), 27-46.

Bandura, A. (1999). Moral disengagement in the perpetration of inhumanities. Personality and Social Psychology Review: An Official Journal of the Society for Personality and Social Psychology, Inc, 3(3), 193-209. https://doi.org/10.1207/s15327957pspr0303_3

Bandura, A. (2001a). Social Cognitive Theory: An agentic perspective. Annual Review of Psychology, 52(1), 1-26. https://doi.org/10.1146/annurev.psych.52.1.1

Bandura, A. (2001b). Social Cognitive Theory of mass communication. Media Psychology, 3(3), 265-299. https://doi.org/10.1207/S1532785XMEP0303_03

Bandura, A. (2002). Selective moral disengagement in the exercise of moral agency. Journal of Moral Education, 31(2), 101-119. https://doi.org/10.1080/0305724022014322

Bandura, A. (2004). Selective Exercise of Moral Agency. In T. A. Thorkildsen \& H. J. 
Walberg (Eds.), Nurturing Morality. Issues in Children's and Families' Lives, vol 5 (pp. 37-57). Boston, MA: Springer. https://doi.org/10.1007/978-1-4757-4163$6 \_3$

Bandura, A. (2016). Moral Disengagement: How people do harm and live with themselves. New York, N.Y.: Worth Publishers.

Bandura, A., Barbaranelli, C., Caprara, G. V., \& Pastorelli, C. (1996). Mechanisms of moral disengagement in the exercise of moral agency. Journal of Personality and Social Psychology, 71(2), 364.

Barriga, A. Q., \& Gibbs, J. C. (1996). Measuring cognitive distortion in antisocial youth: Development and preliminary validation of the "how I think" questionnaire. Aggressive Behavior, 22(5), 333-343.

BBC. (2020). Outlander tourism effect a "double edged sword". Retrieved from https://www.bbc.com/news/uk-scotland-highlands-islands-51488784

Beeton, S. (2016). Film-induced tourism. Bristol: Channel View Publications.

Black, J. E., Helmy, Y., Robson, O., \& Barnes, J. L. (2019). Who can resist a villain? Morality, Machiavellianism, imaginative resistance and liking for dark fictional characters. Poetics, 74. https://doi.org/https://doi.org/10.1016/j.poetic.2018.12.005

Blanco, A., Davies-Rubio, A., De la Corte, L., \& Mirón, L. (2020). Violent extremism and Moral Disengagement: A Study of Colombian armed groups. Journal of Interpersonal Violence. https://doi.org/10.1177/0886260520913643

Boardley, I. D., \& Kavussanu, M. (2007). Development and validation of the moral disengagement in sport scale. Journal of Sport \& Exercise Psychology, 29(5), 608628. https://doi.org/10.1123/jsep.29.5.608 
Brady, S. (2019). This colourful London neighbourhood doesn't want to be on your Instagram. Retrieved from https://www.lonelyplanet.com/articles/notting-hilldoesnt-want-to-be-on-your-instagram

Briggs, D., \& Turner, T. (2012). Understanding British youth behaviors on holiday in Ibiza. International Journal of Culture, Tourism and Hospitality Research, 6(1), 81-90. https://doi.org/10.1108/17506181211206270

Brown, T. A. (2015). Confirmatory factor analysis for applied research. In Confirmatory factor analysis for applied research (2nd ed.). New York: The Guilford Press.

Budeanu, A. (2007). Sustainable tourist behaviour - A discussion of opportunities for change. International Journal of Consumer Studies, 31(5), 499-508. https://doi.org/10.1111/j.1470-6431.2007.00606.x

Cardoso, L., Estevão, C., Fernandes, C., \& Alves, H. (2017). Film induced tourism: A systematic literature review. Tourism \& Management Studies, 13(3), 23-30. https://doi.org/10.18089/tms.2017.13303

Cardwell, S. M., Piquero, A. R., Jennings, W. G., Copes, H., Schubert, C. A., \& Mulvey, E. P. (2015). Variability in Moral Disengagement and its relation to offending in a sample of serious youthful offenders. Criminal Justice and Behavior, 42(8), 819-839. https://doi.org/10.1177/0093854814567472

Caton, K. (2012). Taking the moral turn in tourism studies. Annals of Tourism Research, 39(4), 1906-1928. https://doi.org/10.1016/j.annals.2012.05.021

Caton, K. (2015). Growing on the go? Moral development and tourism. Annals of Leisure Research, 18(1), 1-8. https://doi.org/10.1080/11745398.2015.1004253

Chang, S., \& Gibson, H. J. (1996). Physically active leisure and tourism connection: 
Leisure involvement and choice of tourism activities among paddlers. Leisure Sciences, 33(2), 162-181. Retrieved from

https://doi.org/10.1080/01490400.2011.550233

Cheng, T.-M. M., \& Tsaur, S.-H. H. (2012). The relationship between serious leisure characteristics and recreation involvement: A case study of Taiwan's surfing activities. Leisure Studies, 31(1), 53-68.

https://doi.org/10.1080/02614367.2011.568066

Clark, A. M. (1998). The qualitative-quantitative debate: Moving from Positivism and confrontation to Post-Positivism and reconciliation. Journal of Advanced Nursing, 27(6), 1242-1249. https://doi.org/https://doi.org/10.1046/j.1365-

2648.1998.00651.x

Connell, J. (2012). Film tourism - Evolution, progress and prospects. Tourism Management, 33(5), 1007-1029. https://doi.org/10.1016/j.tourman.2012.02.008

Daniel, J. (2015). Public health research methods. London, UK: SAGE Publications, Inc. https://doi.org/10.4135/9781483398839

de Graaff, M. C., Giebels, E., \& Verweij, D. E. M. (2020). On moral grounds: Moral identity and moral disengagement in relation to military deployment. Military Psychology, 32(4), 363-375. https://doi.org/10.1080/08995605.2020.1774321

De Vaus, D. (2002). Surveys in Social Research (5th ed.). London, UK: Routledge. https://doi.org/https://doi.org/10.4324/9780203501054

Detert, J. R., Treviño, L. K., \& Sweitzer, V. L. (2008). Moral Disengagement in ethical decision making: A study of antecedents and outcomes. Journal of Applied Psychology, 93(2), 374-391. https://doi.org/10.1037/0021-9010.93.2.374

Di-Clemente, E., Hernández-Mogollón, J. M., \& Campón-Cerro, A. M. (2020). 
Tourists' involvement and memorable food-based experiences as new determinants of behavioural intentions towards typical products. Current Issues in Tourism, 23(18), 2319-2332. https://doi.org/10.1080/13683500.2019.1631265

Dimitriou, C. K. (2017). The quest for a practical approach to morality and the tourism industry. Journal of Hospitality and Tourism Management, 31, 45-51. https://doi.org/https://doi.org/10.1016/j.jhtm.2016.08.001

Du, Y., Li, J., Pan, B., \& Zhang, Y. (2020). Lost in Thailand: A case study on the impact of a film on tourist behavior. Journal of Vacation Marketing, 26(3), 365377. https://doi.org/10.1177/1356766719886902

Duffett, M. (2013). Understanding fandom: An introduction to the study of media fan culture. Bloomsbury Publishing USA.

Echart, P., \& García, A. N. (2013). Crime and punishment: Greed, pride and guilt in Breaking Bad. In H. Yeandle \& A. Simón-López (Eds.), A Critical Approach to the Apocalypse (pp. 205-217). Leiden, The Netherlands: Brill. https://doi.org/https://doi.org/10.1163/9781848882706_018

Everett, J. A. C., \& Crockett, M. J. (2019). What Game of Thrones reveals about moral decision-making. Retrieved from https://blogs.scientificamerican.com/observations/what-game-of-thrones-revealsabout-moral-decision-making/

Farmaki, A., Stergiou, D., \& Kaniadakis, A. (2019). Self-perceptions of Airbnb hosts' responsibility: A moral identity perspective. Journal of Sustainable Tourism. https://doi.org/10.1080/09669582.2019.1707216

Field, A. P. (2018). Discovering statistics using IBM SPSS statistics (5th Ed). London; SAGE Publications. 
Fowler Jr, F. J. (1995). Improving survey questions: Design and evaluation. Thousand Oaks, California: SAGE Publications Inc.

Fox, N. J. (2008). Postpositivism. The SAGE Encyclopedia of Qualitative Research Methods, 2, 659-664.

Fuschillo, G. (2020). Fans, fandoms, or fanaticism? Journal of Consumer Culture, 20(3), 347-365. https://doi.org/10.1177/1469540518773822

Grimwood, B. S. R. R., \& Caton, K. (2017). Pausing at the intersections of tourism moralities and mobilities: Some neighborhood history and a traffic report. Tourist Studies, 17(1), 3-16. https://doi.org/10.1177/1468797616685640

Gyimóthy, S., Lundberg, C., Lindström, K. N., Lexhagen, M., \& Larson, M. (2015). Popculture tourism: A research manifesto. Tourism Social Science Series, 20, 1326. Emerald Group Publishing Ltd. https://doi.org/10.1108/S1571504320150000020006

Havitz, M., \& Dimanche, F. (1997). Leisure involvement revisited: Conceptual conundrums and measurement advances. Journal of Leisure Research, 29(3), 245278. https://doi.org/10.1080/00222216.1997.11949796

He, H., \& Harris, L. (2014). Moral disengagement of hotel guest negative WOM: Moral identity centrality, moral awareness, and anger. Annals of Tourism Research, 45, 132-151. https://doi.org/10.1016/j.annals.2013.10.002

Heitmann, S. (2010). Film tourism planning and development-Questioning the role of stakeholders and sustainability. Tourism and Hospitality Planning \& Development, 7(1), 31-46. https://doi.org/10.1080/14790530903522606

Henderson, K. A. (2011). Post-Positivism and the Pragmatics of Leisure Research. Leisure Sciences, 33(4), 341-346. https://doi.org/10.1080/01490400.2011.583166 
Human Ethics Committee. (2018). Human Ethics Guidelines. Retrieved from https://www.wgtn.ac.nz/documents/policy/research-policy/appendix-a-humanethics-committee-guidelines.pdf

Jennings, G. (2010). Tourism research (2nd ed.). Milton, Qld: John Wiley \& Sons.

Juvan, E., \& Dolnicar, S. (2014). The attitude-behaviour gap in sustainable tourism. Annals of Tourism Research, 48, 76-95. https://doi.org/https://doi.org/10.1016/j.annals.2014.05.012

Juvan, E., Ring, A., Leisch, F., \& Dolnicar, S. (2016). Tourist segments' justifications for behaving in an environmentally unsustainable way. Journal of Sustainable Tourism, 24(11), 1506-1522. https://doi.org/10.1080/09669582.2015.1136635

Krakowiak, M., \& Tsay-Vogel, M. (2011). The role of moral disengagement in the enjoyment of real and fictional characters. International Journal of Arts and Technology, 4(1), 90-101. Retrieved from https://doi.org/10.1504/IJART.2011.037772

Krakowiak, M., \& Tsay-Vogel, M. (2013). What makes characters' bad behaviors acceptable? The effects of character motivation and Omtcome on perceptions, character liking, and moral disengagement. Mass Communication and Society, 16(2), 179-199. https://doi.org/10.1080/15205436.2012.690926

Krebs, D. L. (2011). What is morality? In The Origins of Morality: An Evolutionary Account. Oxford University Press. https://doi.org/10.1093/acprof:oso/9780199778232.003.0010

Krumpal, I. (2013). Determinants of social desirability bias in sensitive surveys: A literature review. Quality \& Quantity, 47(4), 2025-2047. https://doi.org/10.1007/s11135-011-9640-9 
Kyle, G., Absher, J., Norman, W., Hammitt, W., \& Jodice, L. (2007). A modified Involvement Scale. Leisure Studies, 26(4), 399-427. https://doi.org/10.1080/02614360600896668

Lai, K., \& Green, S. B. (2016). The problem with having two watches: Assessment of fit when RMSEA and CFI disagree. Multivariate Behavioral Research, 51(2-3), 220-239. https://doi.org/10.1080/00273171.2015.1134306

Laurent, G., \& Kapferer, J.-N. (1985). Measuring consumer involvement profiles. Journal of Marketing Research, 22(1), 41-53.

LeBlanc, V., \& Cox, M. (2017). Interpretation of the point-biserial correlation coefficient in the context of a school examination. The Quantitative Methods for Psychology, 13, 46-56. https://doi.org/10.20982/tqmp.13.1.p046

Lee, S. (2007). Celebrity fandom and its relationship to tourism and leisure behaviors: The case of Korean wave (Texas A\&M University). Texas A\&M University. Retrieved from https://oaktrust.library.tamu.edu/bitstream/handle/1969.1/ETDTAMU-1376/LEE-DISSERTATION.pdf?sequence=1

Lee, S. (2012). From fandom to tourism: An examination of self-expansion theory (University of Nevada, Las Vegas). University of Nevada, Las Vegas. https://doi.org/http://dx.doi.org/10.34917/4332570 This

Lee, S., \& Yoo, M. (2015). Examining celebrity fandom levels and its impact on destination loyalty. Journal of Quality Assurance in Hospitality \& Tourism, 16(4), 369-388. https://doi.org/10.1080/1528008X.2015.1063354

Lee, T. H. (2011). How recreation involvement, place attachment and conservation commitment affect environmentally responsible behavior. Journal of Sustainable Tourism, 19(7), 895-915. https://doi.org/10.1080/09669582.2011.570345 
Li, S. N., Li, H., Song, H., Lundberg, C., \& Shen, S. (2017). The economic impact of on-screen tourism: The case of The Lord of the Rings and the Hobbit. Tourism Management, 60, 177-187. https://doi.org/10.1016/j.tourman.2016.11.023

Lovelock, B. (2014). The moralization of flying: Cocktails in seat 33G, famine and pestilence below. In M. Mostafanezhad \& K. Hannam (Eds.), Moral encounters in tourism (pp. 153-168). N.Y.: Routledge.

Lund Research Ltd. (2018). Point-Biserial Correlation using SPSS Statistics. Retrieved from https://statistics.laerd.com/spss-tutorials/point-biserial-correlation-using-spssstatistics.php

Macionis, N. (2004). Understanding the film-induced tourist. In W. Frost, G. Croy, \& S. Beeton (Eds.), International Tourism and Media Conference Proceedings (pp. 8697). Melbourne: Tourism Research Unit, Monash University.

Mackenzie, N., \& Knipe, S. (2006). Research dilemmas: Paradigms, methods and methodology. Issues in Educational Research, 16, 193-205.

Marsh, H. W., \& Hocevar, D. (1985). Application of confirmatory factor analysis to the study of self-concept: First- and higher order factor models and their invariance across groups. Psychological Bulletin, 97(3), 562-582.

https://doi.org/10.1037/0033-2909.97.3.562

Mason, P. (2014). Researching Tourism, Leisure and Hospitality for Your Dissertation. Oxford, UK: Goodfellow Publishers, Limited. Retrieved from http://ebookcentral.proquest.com/lib/vuw/detail.action?docID=1726106

Matosic, D., Ntoumanis, N., Boardley, I. D., \& Sedikides, C. (2020). Narcissism, beliefs about controlling interpersonal style, and moral disengagement in sport coaches. International Journal of Sport and Exercise Psychology, 18(5), 592-606. 
https://doi.org/10.1080/1612197X.2018.1549580

McIntyre, N., \& Pigram, J. J. (1992). Recreation specialization reexamined: The case of vehicle-based campers. Leisure Sciences, 14(1), 3-15.

https://doi.org/10.1080/01490409209513153

Mertler, C. A. (2018). Introduction to educational research. Thousand Oaks, California: SAGE Publications, Inc.

Miller, Z. (2020, February 14). 10 famous movie and TV locations that locals say have been ruined by tourists. Insider.Com. Retrieved from https://www.insider.com/famous-movie-and-tv-locations-ruined-by-tourism-20202

Mkono, M., \& Holder, A. (2019). The future of animals in tourism recreation: Social media as spaces of collective moral reflexivity. Tourism Management Perspectives, 29, 1-8. https://doi.org/https://doi.org/10.1016/j.tmp.2018.10.002

Moore, C. (2015). Moral disengagement. Current Opinion in Psychology, 6, 199-204. https://doi.org/https://doi.org/10.1016/j.copsyc.2015.07.018

Moore, C., Detert, J. R., Treviño, L. K., Baker, V. L., \& Mayer, D. M. (2012). Why employees do bad things: Moral disengagement and unethical organizational behavior. Personnel Psychology, 65(1), 1-48. https://doi.org/https://doi.org/10.1111/j.1744-6570.2011.01237.x

Moss, S. (2016). Fit indices for structural equation modelling. Retrieved from https://www.sicotests.com/psyarticle.asp?id=277

Muijs, D. (2011). Doing quantitative research in education with SPSS (2nd Ed.). London: SAGE Publications Ltd. https://doi.org/10.4135/9781849203241 
Munar, A. M., \& Jamal, T. (2016). Tourism research paradigms critical and emergent knowledges . Bingley, U.K: Emerald.

Mura, P. (2010). 'Scary ... but I like it!' Young tourists' perceptions of fear on holiday. Journal of Tourism and Cultural Change, 8(1-2), 30-49.

https://doi.org/10.1080/14766825.2010.482209

Nardi, P. M. (2018). Doing Survey Research: A Guide to Quantitative Methods (4th ed.). Milton: Routledge. https://doi.org/10.4324/9781315172231

Obermann, M.-L. (2011). Moral disengagement in self-reported and peer-nominated school bullying. Aggressive Behavior, 37(2), 133-144. https://doi.org/https://doi.org/10.1002/ab.20378

Patel, B. (2020). Please stop visiting, actually: Council tells tourists to STOP visiting Love Actually house where Andrew Lincoln declared his love for Keira Knightley after owner tires of Instagrammers posing outside for photos. Retrieved from https://www.dailymail.co.uk/news/article-7848097/Council-tells-tourists-STOPvisiting-Love-Actually-house.html

Pearce, P. L. (2019). Behaving badly. In Tourist Behaviour (pp. 283-303). Cheltenham, UK: Edward Elgar Publishing. https://doi.org/https://doi.org/10.4337/9781786438577.00021

Penguin Random House. (2021). A Song of Ice and Fire Series. Retrieved from https://www.penguinrandomhouse.com/series/SOO/a-song-of-ice-and-fire

Preston, C. C., \& Colman, A. M. (2000). Optimal number of response categories in rating scales: Reliability, validity, discriminating power, and respondent preferences. Acta Psychologica, 104(1), 1-15. https://doi.org/https://doi.org/10.1016/S0001-6918(99)00050-5 
QualtricsXM. (2021). Survey Software. Retrieved from https://www.qualtrics.com/corexm/survey-software/

Ribeaud, D., \& Eisner, M. (2010). Are Moral Disengagement, Neutralization Techniques, and Self-Serving Cognitive Distortions the same? Developing a unified scale of Moral Neutralization of aggression. International Journal of Conflict and Violence, 4(2), 298-315. https://doi.org/10.4119/UNIBI/ijcv.92

Ryan, A. B. (2006). Methodology: Analysing qualitative data and writing up your findings. In Researching and Writing your thesis: a guide for postgraduate students. Mace: Maynooth Adult and Community Education.

Ryan, C., \& Kinder, R. (1996). Sex, tourism and sex tourism: Fulfilling similar needs? Tourism Management, 17(7), 507-518.

https://doi.org/https://doi.org/10.1016/S0261-5177(96)00068-4

Sanders, M. S., \& Tsay-Vogel, M. (2016). Beyond heroes and villains: Examining explanatory mechanisms underlying moral disengagement. Mass Communication and Society, 19(3), 230-252. https://doi.org/10.1080/15205436.2015.1096944

Sawant, P. (2019). How the moral ambiguity in A Song of Ice and Fire reflects the real world. Retrieved from https://www.thecuriousreader.in/features/a-song-of-ice-andfire/

Scott, N., \& Gao, L. (2018). Tourism products and experiences. In C. Cooper, S. Volo, W. C. Gartner, \& N. Scott (Eds.), The SAGE Handbook of Tourism Management (pp. 191-206). SAGE Publications. Retrieved from https://ebookcentral-proquestcom.helicon.vuw.ac.nz/lib/VUW/detail.action?docID=5504160\#

Sharma, N. (2020). Dark tourism and moral disengagement in liminal spaces. Tourism Geographies, 22(2), 273-297. https://doi.org/10.1080/14616688.2020.1713877 
Singer, E., \& Bossarte, R. M. (2006). Incentives for survey participation: When are they “coercive"? American Journal of Preventive Medicine, 31(5), 411-418. https://doi.org/https://doi.org/10.1016/j.amepre.2006.07.013

Solstrand, M.-V., \& Gressnes, T. (2014). Marine angling tourist behavior, noncompliance, and implications for natural resource management. Tourism Management (1982), 45, 59-70. https://doi.org/10.1016/j.tourman.2014.03.014

Stevens, Z. M., Grimwood, B. S. R., \& Caton, K. (2019). Story and moral development in tourism education. Journal of Teaching in Travel \& Tourism, 19(1), 22-38. https://doi.org/10.1080/15313220.2018.1560529

Su, X., Wang, H., \& Wen, T. (2013). Profit, Responsibility, and the moral economy of tourism. Annals of Tourism Research, 43, 231-250. https://doi.org/https://doi.org/10.1016/j.annals.2013.07.008

Sykes, G. M., \& Matza, D. (1957). Techniques of Neutralization: A theory of delinquency. American Sociological Review, 22(6), 664-670. https://doi.org/10.2307/2089195

Taber, K. S. (2018). The use of Cronbach's Alpha when developing and reporting research instruments in science education. Research in Science Education, 48(6), 1273-1296. https://doi.org/10.1007/s11165-016-9602-2

Tavakol, M., \& Dennick, R. (2011). Making sense of Cronbach's alpha. International Journal of Medical Education, 2, 53-55. https://doi.org/10.5116/ijme.4dfb.8dfd

Taylor, F. (2018). The Beach goes full circle: The case of Koh Phi Phi, Thailand. In S. Kim \& S. Reijnders (Eds.), Film Tourism in Asia: Evolution, Transformation, and Trajectory (pp. 87-106). Singapore: Springer Singapore.

https://doi.org/10.1007/978-981-10-5909-4_6 
Thorne, S. (2011). An exploratory investigation of the theorized levels of consumer fanaticism. Qualitative Market Research, 14(2), 160-173. https://doi.org/10.1108/13522751111120675

Thorne, S., \& Bruner, G. C. (2006). An exploratory investigation of the characteristics of consumer fanaticism. Qualitative Market Research, 9(1), 51-72. https://doi.org/10.1108/13522750610640558

Tickle, L., \& von Essen, E. (2020). The seven sins of hunting tourism. Annals of Tourism Research, 84. https://doi.org/https://doi.org/10.1016/j.annals.2020.102996

Tkalec, M., Zilic, I., \& Recher, V. (2017). The effect of film industry on tourism: Game of Thrones and Dubrovnik. International Journal of Tourism Research, 19(6), 705-714. https://doi.org/10.1002/jtr.2142

Tsai, J.-J., Wang, C.-H., \& Lo, H.-J. (2014). Locus of control, moral disengagement in sport, and rule transgression of athletes. Social Behavior and Personality: An International Journal, 42(1), 59-68.

Tsaur, S.-H., Cheng, T.-M., \& Hong, C.-Y. (2019). Exploring tour member misbehavior in group package tours. Tourism Management, 71, 34-43. https://doi.org/https://doi.org/10.1016/j.tourman.2018.09.018

Tucker, H. (2014). Mind the gap: Opening up spaces of multiple moralities in tourism encounters. In M. Mostafanezhad \& K. Hannam (Eds.), Moral Encounters in Tourism (pp. 199-208). London: Routledge. Retrieved from https://www.taylorfrancis.com/books/e/9781315596068/chapters/10.4324/9781315 $596068-22$

Turner, V. (2017). The ritual process: Structure and anti-structure. Routledge.

Tutenges, S. (2012). Nightlife tourism: A mixed methods study of young tourists at an 
international nightlife resort. Tourist Studies, 12(2), 131-150.

https://doi.org/10.1177/1468797612454250

Uriely, N., Ram, Y., \& Malach-Pines, A. (2011). Psychoanalytic sociology of deviant tourist behavior. Annals of Tourism Research, 38(3), 1051-1069.

https://doi.org/https://doi.org/10.1016/j.annals.2011.01.014

Van Gennep, A. (1960). The rites of passage. University of Chicago Press.

Wakita, T., Ueshima, N., \& Noguchi, H. (2012). Psychological distance between categories in the Likert Scale: Comparing different numbers of options.

Educational and Psychological Measurement, 72(4), 533-546.

https://doi.org/10.1177/0013164411431162

Waysdorf, A. S. (2017). Placing fandom - Film tourism in contemporary fan culture.

ERMeCC - Erasmus Research Centre by Media, Communication and Culture.

Wray, M., \& Croy, W. G. (2015). Film tourism: Integrated strategic tourism and regional economic development planning. Tourism Analysis, Vol. 20, pp. 313-326. Retrieved from https://doi.org/10.3727/108354215X14356694891898

Wu, J., Font, X., \& Liu, J. (2020). Tourists' pro-environmental behaviors: Moral obligation or disengagement? Journal of Travel Research. https://doi.org/10.1177/0047287520910787

Zhang, H., \& Xu, H. (2019). A structural model of liminal experience in tourism. Tourism Management, 71(October 2018), 84-98.

https://doi.org/10.1016/j.tourman.2018.09.015

Zubernis, L., \& Larsen, K. (2018). Make space for us! Fandom in the real world. $A$ Companion to Media Fandom and Fan Studies, 145-159. 